BIANCA DE CÁSSIA ROMERO

\title{
Análise da Localização de Plataformas Logísticas: aplicação ao caso do ETSP - Entreposto Terminal São Paulo - da CEAGESP.
}

Dissertação apresentada à Escola Politécnica da Universidade de São Paulo, para obtenção do Título de Mestre em Engenharia de Sistemas Logísticos.

SÃO PAULO

2006 


\section{Análise da Localização de Plataformas Logísticas: aplicação ao caso do ETSP - Entreposto Terminal São Paulo - da CEAGESP.}

Dissertação apresentada à Escola Politécnica da Universidade de São Paulo, para obtenção do Título de Mestre em Engenharia de Sistemas Logísticos.

Área de concentração: Engenharia de Sistemas Logísticos.

Orientador: Prof. Dr. Nicolau Dionísio Fares Gualda. 
"Most of the fundamental ideas of science are essentially simple and may, as a rule, be expressed in a language comprehensive to anyone"

- Albert Einstein 


\section{AGRADECIMENTOS}

Ao Professor Nicolau Dionísio Fares Gualda pela orientação, dedicação e permanente incentivo.

Ao Programa de Mestrado em Engenharia de Sistemas Logísticos da Universidade de São Paulo e à Coordenadoria de Aperfeiçoamento de Pessoal e de Nível Superior (CAPES) pela bolsa de estudos concedida.

A minha família, em especial aos meus pais e meu irmão, pelo estímulo e incansável apoio.

A todos que, direta ou indiretamente, colaboraram na execução deste trabalho. E em especial aos amigos Daniel Abdo Brohem Ventri, Luciele Wu, Mariana Bergmann, Luigi Pigliacelli, Celso Sakuraba, Tatiana de Campos, Paulo Gimenez, Magaly Piñero e Mariana Carmona.

E especialmente a todos aqueles que contribuíram nas entrevistas e aplicação dos questionários, dedicando sua atenção e precioso tempo.

A realização deste trabalho conta com o apoio e infra-estrutura do Laboratório de Planejamento e Operação de Transportes (LPT/EPUSP), contando ainda com o interesse da CEAGESP e com o material do Projeto "Estudos Básicos para Elaboração do Plano Diretor do ETSP da CEAGESP”, realizado pelo LPT/EPUSP em 2003/2004 e coordenado pelo Prof. Dr. Nicolau D. F. Gualda. 


\section{RESUMO}

O presente trabalho aborda o problema de localização de plataformas logísticas. Buscaram-se métodos de auxílio à tomada de decisão com enfoque multicritério. A essência da tomada de decisão multicritério é a escolha da melhor alternativa, a partir de um conjunto de alternativas competitivas que são avaliadas sob critérios conflitantes.

Entre os métodos estudados, o Método de Análise Hierárquica (AHP), proposto inicialmente por Saaty (1971), foi selecionado como ferramenta de apoio à tomada de decisão. Ele permite considerar simultaneamente atributos quantitativos e qualitativos e, também, incorporar a experiência e a preferência dos tomadores de decisão.

Foram ainda levantados os fatores determinantes para escolha de alternativas de localização para plataformas logísticas. O caso do ETSP (Entreposto Terminal São Paulo) da CEAGESP (Companhia de Entrepostos e Armazéns Gerais de São Paulo) foi objeto da aplicação do método selecionado. A análise do problema de localização do Entreposto da CEAGESP está restrita à Região Metropolitana de São Paulo.

O software Expert Choice foi utilizado para a aplicação do AHP ao caso do CEAGESP. Após a discussão dos resultados, conclusões e recomendações são apresentadas.

Palavras-chave: Localização de plataformas logísticas; Critérios de localização; Métodos de decisão multicritério; Método da Análise Hierárquica. 


\begin{abstract}
This work deals with the facility location problems of logistics platforms, considering multi-criteria approaches for decision making. The essence of multicriteria decision making is the choice of the best alternative, from a set of competitive alternatives, which are evaluated under conflicting criteria.
\end{abstract}

Among the multi-criteria methods researched in the bibliography, the Analytic Hierarchy Process (AHP), initially proposed by Saaty (1971), has been chosen and successfully applied to the case in consideration. This method allows to consider quantitative and qualitative measurable criteria and, also, to incorporate the experience and preference of the decision makers.

Determinant factors for the choice of location alternatives for logistic platforms have been considered. The case of the ETSP (Entreposto Terminal São Paulo) of the CEAGESP (Companhia de Entrepostos e Armazéns Gerais de São Paulo) was object of application of the selected method.

The Expert Choice software was used for the AHP application to the CEAGESP case. After discussion of the results, conclusions and recommendations from the application are presented.

Keywords: Location of logistics platforms; Location criteria; Multi-criteria decision making, Analytic Hierarchy Process (AHP). 


\section{SUMÁRIO}

\section{LISTA DE FIGURAS}

LISTA DE TABELAS

LISTA DE ABREVIATURAS E SIGLAS

1 .

$$
\text { INTRODUÇÃO }
$$

1.1. Objetivo

1.2. Apresentação do Problema.................................................................... 1

1.3. Justificativa e Relevância do Problema....................................................... 3

1.4. Seqüência dos Capítulos ......................................................................... 3

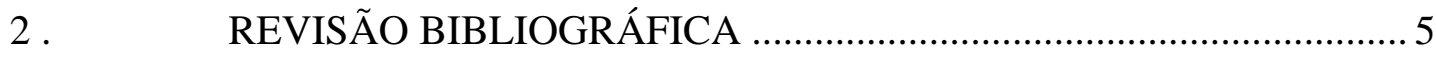

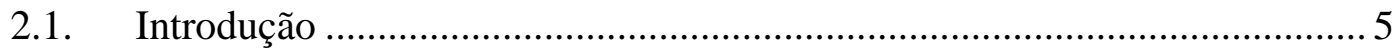

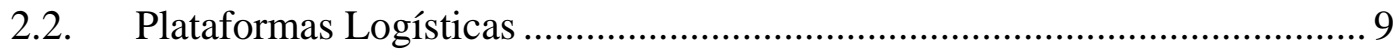

2.3. Localização das Instalações ..................................................................... 12

2.4. Métodos ou Modelos para solução de problemas de localização das

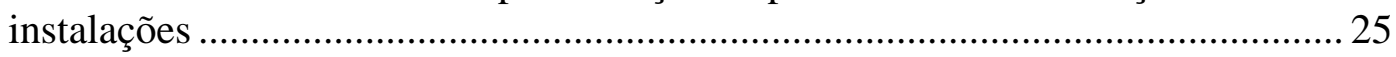

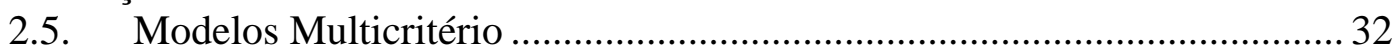

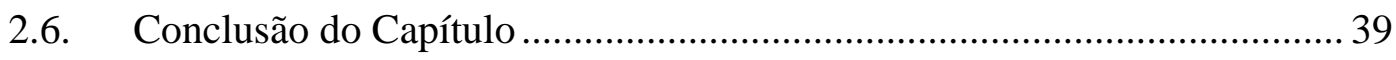

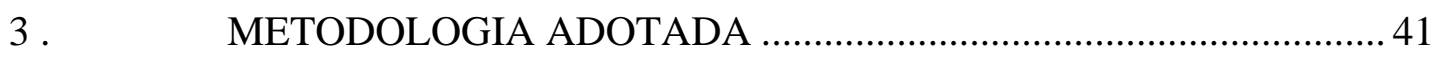

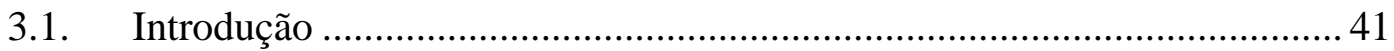

3.2. Caracterização do Problema de Localização de Plataformas Logísticas ... 41

3.3. Justificativa do Método Selecionado ..................................................... 43

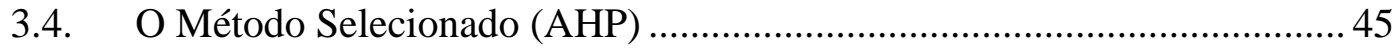

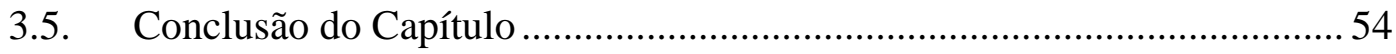

4. CARACTERIZAÇÃO DO PROBLEMA PROPOSTO - O ETSP DA

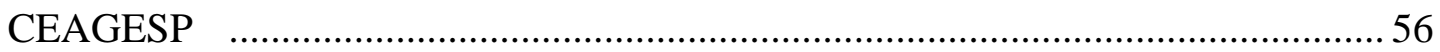

4.1. Histórico do ETSP da CEAGESP …........................................................ 57

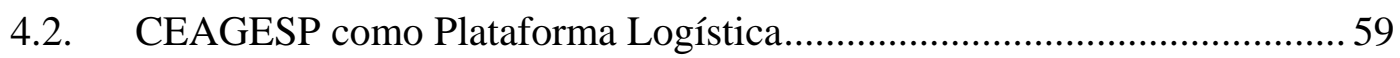

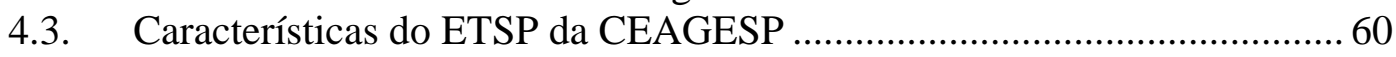

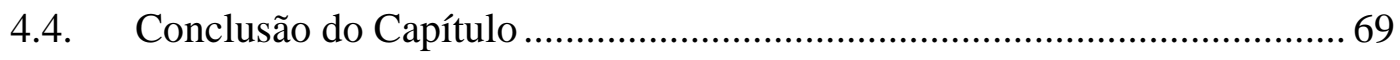

5. APLICAÇÃO AO PROBLEMA PROPOSTO - O ETSP DA CEAGESP .70

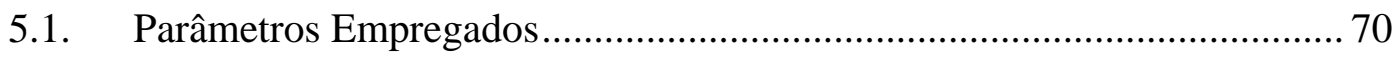

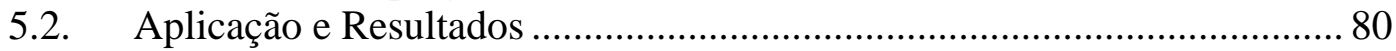

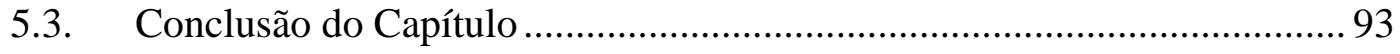

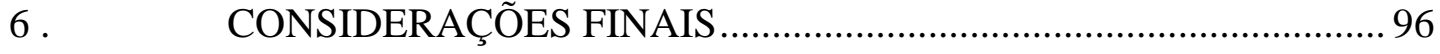

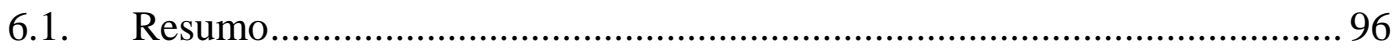




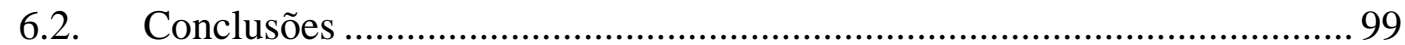

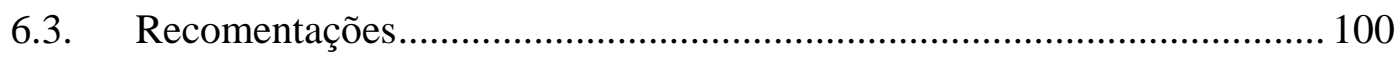

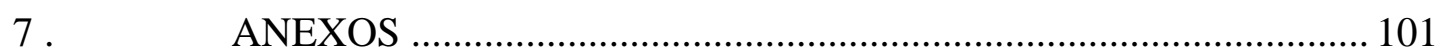

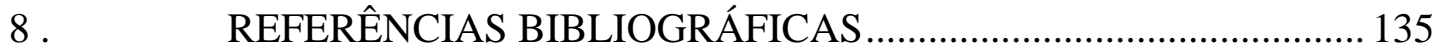




\section{LISTA DE FIGURAS}

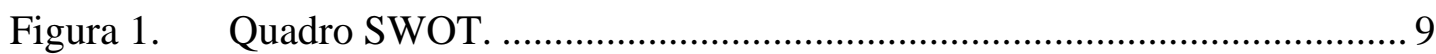

Figura 2. Estrutura de Análise de Decisão Multicritério...................................... 36

Figura 3. Fluxograma de Apresentação da resolução do problema...................... 42

Figura 4. Representação de uma Hierarquia....................................................... 47

Figura 5. Exemplo de preenchimento de uma matriz de comparação.................. 52

Figura 6. Ilustração dos fluxos de origem das mercadorias comercializadas pelo

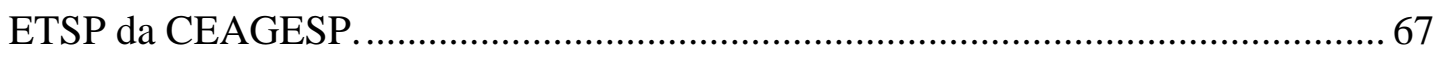

Figura 7. Análise SWOT para ETSP na Vila Leopoldina.................................... 73

Figura 8. Análise SWOT para ETSP no Rodoanel............................................. 74

Figura 9. Análise SWOT para descentralização do ETSP.................................... 75

Figura 10. Representação da Hierarquia do Problema do ETSP da CEAGESP. ... 79

Figura 11. Administração - Gráfico de desempenho dos critérios, para cada uma das alternativas.

Figura 12. Permissionários - Gráfico de desempenho dos critérios, para cada uma das alternativas.

Figura 13. Clientes - Gráfico de desempenho dos critérios, para cada uma das alternativas. 90

Figura 14. Administração - Gráfico de sensibilidade dos critérios e alternativas. . 91

Figura 15. Permissionários - Gráfico de sensibilidade dos critérios e alternativas.92

Figura 16. Clientes - Gráfico de sensibilidade dos critérios e alternativas. 93

Figura 1A. Representação da Hierarquia do Problema do ETSP da CEAGESP. . 109

Figura 2A. Comparação paritária dos critérios em relação ao objetivo final. 110

Figura 3A. Comparação paritária dos critérios em relação à área.

Figura 4A. Comparação paritária dos critérios em relação ao acesso. 
Figura 5A. Comparação paritária dos critérios em relação ao mercado

Figura 6A. Comparação paritária dos critérios em relação ao meio ambiente....... 113

Figura 7A. Comparação paritária dos critérios em relação à ocupação urbana. ... 114

Figura 8A. Comparação paritária dos critérios em relação ao fator humano......... 114

Figura 9A. Resultado da Avaliação das alternativas............................................ 122

Figura 10A. Gráfico de desempenho dos critérios, para cada uma das alternativas.....

Figura 11A. Gráfico de sensibilidade dos critérios e alternativas.

Figura 12A. Comparação dos pesos entre as alternativas: Vila Leopoldina $\mathrm{x}$ Rodoanel 124

Figura 13A. Comparação dos pesos entre as alternativas: Rodoanel $\mathrm{x}$ Descentralização 125

Figura 14A. Comparação dos pesos entre as alternativas: Vila Leopoldina $\mathrm{x}$ Descentralização. 


\section{LISTA DE TABELAS}

Tabela 1- Exemplo de hierarquia de decisões em logística.................................... 2

Tabela 2- Lista de Critérios para a Localização de Instalações. ............................ 22

Tabela 3- Lista de Critérios para a Localização de Instalações. ............................. 26

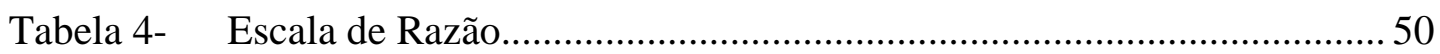

Tabela 5- Valores de IR em função da Ordem da Matriz. ..................................... 53

Tabela 6- Valores de IC máximo em função da ordem da matriz.......................... 53

Tabela 7- $\quad$ Regiões, Brasil e Mercosul, de Destino das Mercadorias....................... 61

Tabela 8- Estados, da Região Sudeste, de Destino das Mercadorias. ..................... 62

Tabela 9- Regiões e Municípios, do Estado de São Paulo, de Destino das Mercadorias.

Tabela 10- Destino das Mercadorias por Zonas e Municípios da Região Metropolitana de São Paulo.

Tabela 11- Destino das Mercadorias Comercializadas, segundo a Natureza do Destinatário.

Tabela 12- Destino das Mercadorias Comercializadas, segundo o Tipo de Carga. 64

Tabela 13- Origem das Mercadorias Comercializadas, segundo o Tipo de Carga. 65

Tabela 14- Veículos de Transporte Utilizados pelos Usuários. .65

Tabela 15- Resumo das Quantidades, em kg e em notas, por Via de Acesso a São Paulo. 66

Tabela 16- Resumo da lista inicial de Critérios para a Localização de Instalações, relevantes para o estudo de caso da CEAGESP. 76

Tabela 17- Lista de Critérios para a Localização de Instalações, relevantes para o estudo de caso da CEAGESP.

Tabela 18- Resultado final da avaliação das alternativas para as respostas individuais. 
Tabela 19- Resultado final da avaliação das alternativas para os grupos.

85 
LISTA DE ABREVIATURAS E SIGLAS

AHP - Analytic Hierarchy Process

CEAGESP - Companhia de Entrepostos e Armazéns Gerais de São Paulo

EPUSP - Escola Politécnica da Universidade de São Paulo

ETSP - Entreposto Terminal São Paulo

IC - Índice de Consistência

IR - Índice Randômico

LPT / EPUSP - Laboratório de Planejamento e Operação de Transportes da Escola Politécnica da Universidade de São Paulo

MCP - Matriz de Comparação Paritária

MAH - Método da Análise Hierárquica

RC - Razão de Consistência

RMSP - Região Metropolitana de São Paulo

SWOT - Strengths, Weaknesses, Opportunities and Threats

$\lambda_{\text {máx }}-$ Autovalor Máximo 


\section{INTRODUÇÃO}

\subsection{Objetivo}

Em linhas gerais, este trabalho apresenta os seguintes objetivos:

1. Tratar problemas de localização de instalações de plataformas logísticas;

2. Estudar ferramentas analíticas de apoio à tomada de decisão sobre múltiplos critérios;

3. Mapear os critérios que deverão ser considerados na análise de problemas de localização;

4. Avaliar os impactos, dos critérios escolhidos, no objetivo geral do problema;

5. Aplicar a metodologia no caso do problema de localização do ETSP da CEAGESP.

No capítulo de revisão bibliográfica será apresentado o conjunto dos autores e trabalhos que forneceu sustentação teórica para toda esta pesquisa.

A contribuição que este trabalho pretende oferecer consiste na apresentação e validação de um método de seleção de locais para instalações de plataformas logísticas.

\subsection{Apresentação do Problema}

Os problemas inseridos em logística podem ser divididos nos diferentes níveis de decisão:

- $\quad$ Nível Estratégico: podem envolver tanto ações imediatas quanto ações tomadas em longo prazo. Porém, estas ações resultam necessariamente em efeitos de longo prazo. Exemplos de ações inseridas no contexto de planejamento estratégico: definição de produtos, criação de novas instalações, alocação de investimentos em infra-estrutura e transporte; 
- Nível tático: ações com conseqüências de médio prazo como, por exemplo, determinação de política de gestão de estoques e programação de entregas. $\mathrm{O}$ nível tático faz integração com os níveis estratégico e operacional;

- Nível operacional: ações do dia-a-dia como, por exemplo, programação da produção, seleção de fornecedores e transportadores, entre outros.

A Tabela 1 apresenta diversos exemplos inseridos nos três níveis de decisão para as diversas atividades da logística.

Tabela 1- Exemplo de hierarquia de decisões em logística.

\begin{tabular}{|c|c|c|c|c|c|c|}
\hline $\begin{array}{c}\text { nível de } \\
\text { decisão }\end{array}$ & localização & transportes & estoques & proc. do pedido & armazenagem & compras \\
\hline \hline estratégico & $\begin{array}{c}\mathrm{n}^{\circ} \text {, tamanho e } \\
\text { localização das } \\
\text { instalações }\end{array}$ & $\begin{array}{c}\text { seleção do } \\
\text { modal }\end{array}$ & $\begin{array}{c}\text { politicas de } \\
\text { estoque, } \\
\text { rotatividade }\end{array}$ & $\begin{array}{c}\text { projeto do } \\
\text { sistema de } \\
\text { processamento } \\
\text { do pedido }\end{array}$ & $\begin{array}{c}\text { layout; seleção } \\
\text { de equipamento } \\
\text { de manuseio }\end{array}$ & $\begin{array}{c}\text { políticas de } \\
\text { relacionamento }\end{array}$ \\
\hline tático & $\begin{array}{c}\text { posicionamento } \\
\text { do estoque }\end{array}$ & $\begin{array}{c}\text { aluguel } \\
\text { sazonal de } \\
\text { equipamento }\end{array}$ & $\begin{array}{c}\text { estoques de } \\
\text { segurança, } \\
\text { regras de } \\
\text { controle }\end{array}$ & $\begin{array}{c}\text { regras de } \\
\text { prioridade }\end{array}$ & $\begin{array}{c}\text { utilização do } \\
\text { espaço; escolhas } \\
\text { sazonais }\end{array}$ & $\begin{array}{c}\text { contratação e } \\
\text { seleção de } \\
\text { fornecedores }\end{array}$ \\
\hline operacional & $\begin{array}{c}\text { determinação de } \\
\text { carga }\end{array}$ & $\begin{array}{c}\text { roteirização, } \\
\text { agendamento } \\
\text { e despacho }\end{array}$ & $\begin{array}{c}\text { reposição } \\
\text { (quantidades } \\
\text { e prazos) }\end{array}$ & atendimento & $\begin{array}{c}\text { coleta e } \\
\text { arrumação }\end{array}$ & $\begin{array}{c}\text { liberação de } \\
\text { pedidos }\end{array}$ \\
\hline
\end{tabular}

Fonte: Yoshizaki(2002).

Para Mintzberg (1996), decisões estratégicas são aquelas que determinam o curso geral de um empreendimento e são responsáveis pelas mudanças que ocorrem nos principais ambientes de uma organização. As decisões estratégicas talham os objetivos da organização. Ajudam a delinear a abrangência de operação do empreendimento. Elas definem fontes de recursos, assim como sua alocação, e conferem efetividade ao empreendimento.

A presente dissertação apresenta o estudo de um problema em nível estratégico, mais precisamente a localização geográfica de instalações. Com a finalidade de tratar a seleção do local mais adequado, buscaram-se métodos de apoio à tomada de decisão. 
Mais precisamente, as instalações tratadas no presente estudo podem ser definidas como Plataformas Logísticas. Esse tipo de instalação oferece uma estrutura apropriada para operação dos processos de uma organização, integrando as diversas atividades do sistema. Essas plataformas podem reunir atividades como transporte, armazenagem e comercialização, encerrando a oferta de bens e serviços à população.

\subsection{Justificativa e Relevância do Problema}

O problema estudado nesta pesquisa envolve a questão de localização das instalações, que constitui uma questão bastante abrangente e de grande importância estratégica. A localização das instalações impõe certas restrições à rede logística e, muitas vezes, determina o modo como acontecem as operações de determinada organização.

As alterações ocorridas recentemente no mercado mundial e a crescente expansão das operações das empresas impulsionaram a importância do estudo de localização.

A importância da análise de localização teve um crescimento rápido na década de 80 (Love, 1988). A localização das instalações e o uso do solo costumam ser decisões que são altamente valorizadas e requerem grandes investimentos (Chan, 2001).

As plataformas logísticas representam a integração das diversas atividades da organização e sua localização é extremamente importante, pois envolve diversas características do sistema como, por exemplo, tráfego urbano, indicadores ambientais, fatores sociais e econômicos, além dos custos das operações logísticas.

\subsection{Seqüência dos Capítulos}

No capítulo 2, apresentar-se-á toda a revisão bibliográfica, incluindo a conceituação do termo plataforma logística, a caracterização do problema de localização de instalações e os métodos ou modelos para solução destes problemas. 
O capítulo 3 apresentará a metodologia de resolução do problema proposto, caracterizando o problema e justificando a escolha do método selecionado. Após a justificativa de escolha, o método selecionado será apresentado mais detalhadamente.

No capítulo 4, o estudo de caso do ETSP da CEAGESP será apresentado. Neste capítulo, buscar-se-á caracterizar o problema proposto para o estudo de caso. Além de um breve histórico do Entreposto, serão apontadas características relevantes para o estudo.

Posteriormente, ao longo do capítulo 5, será realizada a aplicação do método selecionado, descrevendo os parâmetros empregados e relatando os resultados obtidos.

As considerações finais, contendo resumo, conclusões e recomendações pertinentes para a realização de estudos futuros, serão apresentadas no capítulo 6.

Por fim, o capítulo 7 encerrará os anexos pertinentes ao assunto tratado. 


\section{REVISÃO BIBLIOGRÁFICA}

\subsection{Introdução}

O problema de localização é um dos mais importantes a considerar na área de logística (BALLOU, 2001; DASKIN, 1995).

As decisões de localização são, na sua essência, estratégicas e de longo prazo. Esse tipo de decisão apresenta alto grau de irreversibilidade, considerando-se a dificuldade na execução de correções e ajustes. E freqüentemente envolve múltiplos objetivos conflitantes.

A localização das instalações é um problema que relaciona várias questões, as quais se encontram, direta ou indiretamente, associadas à eficácia e eficiência das operações do sistema logístico como um todo.

Bowersox; Closs (2001) afirmam que a importância da análise de localização é reconhecida desde meados do século XIX, quando foi publicado o trabalho The isolate state, onde o economista alemão Joachim von Thünem estabelecia que os principais fatores que determinavam o crescimento econômico eram o preço da terra e o custo do transporte entre os locais de produção. Entretanto, esse tipo de problema é bastante antigo, proposto inicialmente por Fermat, no século XVII, que enunciou o seguinte problema: “[...] dados três pontos em um plano, encontrar o quarto ponto cuja soma das distâncias até os primeiros três pontos seja mínima”. Torricelli solucionou o problema em 1940, demonstrando que os círculos circunscritos aos triângulos eqüiláteros, construídos a partir dos lados do triângulo formado pelos três pontos originais, se cruzam no ponto onde a somatória da distância é mínima. (LOVE, 1988).

Todavia, em termos de introdução formal da teoria da localização na literatura, considera-se que de fato ocorreu através de Alfred Weber, em 1909, que analisou como posicionar um depósito de forma a minimizar a soma das distâncias de um 
conjunto de clientes para esta instalação. O modelo de Weber estabelecia as seguintes hipóteses:

- As localizações dos mercados consumidores e das fontes de abastecimento são conhecidas a priori;

- Os volumes de transporte entre o centro de distribuição e os pontos de abastecimento e consumo não dependem da posição final que o centro venha a ocupar;

- O trajeto dos transportes é realizado em linha reta;

- $\quad$ O custo de transporte é proporcional à distância a ser percorrida e o peso a ser transportado.

Weber ainda tratou da questão da mão-de-obra como fator locacional e do fator aglomerativo, que considerou como sendo a redução de custo que uma indústria obtém ao se localizar nas proximidades de outras empresas do mesmo ramo de atividade (VALLIM, 2004).

Em meados da década de 60, a questão da localização ganhou interesse, e apenas nesta época o problema pôde ser considerado resolvido, através do trabalho de Kuhn, publicado em 1962. Desde então, uma série de trabalhos começou a ser desenvolvida e o problema continua a merecer a atenção de pesquisadores e empresas até os dias atuais.

Segundo Bowersox; Closs (2001), por mais simples que pareçam, os problemas da análise da localização caracterizam-se por sua complexidade e por serem altamente dependentes de grandes quantidades de dados. De forma geral, os dados necessários em análises dessa natureza são os seguintes:

- $\quad$ Definição de mercados;

- $\quad$ Definição de produtos;

- Definição de redes;

- $\quad$ Definição da demanda dos clientes;

- $\quad$ Taxas de fretes;

- Custos fixos e variáveis. 
A dificuldade de obtenção dos dados é uma realidade na resolução de problemas reais e, muitas vezes, constitui um fator limitante na pesquisa e implantação de melhorias em determinado sistema.

Para a resolução de problemas mais complexos, o enfoque sistêmico surge como auxílio no entendimento do problema e planejamento das ações. Na análise da localização, o enfoque sistêmico facilita a compreensão do problema e a busca de soluções ótimas. O enfoque sistêmico tem como propósito (GOMES; GOMES; ALMEIDA, 2002):

- Identificar a definição, missão e/ou finalidade do sistema;

- Entender como os elementos do sistema interagem e influenciam-se para a realização dos objetivos do sistema;

- Utilizar modelos para auxiliar a identificação do problema correto.

A respeito da estrutura apresentada pelo enfoque sistêmico, Churchman (1971) faz as seguintes considerações básicas:

1. Objetivos totais do sistema, e mais especificamente, as medidas de rendimento do sistema inteiro;

2. O ambiente do sistema, representando as coações fixas;

3. Os recursos do sistema, que se encontram inseridos no sistema e representam os meios que o sistema usa para desempenhar suas tarefas;

4. Os componentes do sistema, suas atividades, finalidades e medidas de rendimento;

5. A administração do sistema, que trata da criação de planos para o sistema. A administração determina as finalidades dos componentes, procede a alocação de recursos e controla o rendimento do sistema.

É importante ressaltar que o ambiente representa os aspectos externos à organização e afeta o processo decisório através da influência sobre o decisor e a organização. 
A razão para a divisão de um sistema em componentes é oferecer ao analista o tipo de informação que este necessita para avaliar a operação do sistema e planejar as ações.

Gualda (1995) considera que ao empregar o enfoque sistêmico devem-se seguir as seguintes etapas básicas:

1. Identificação do sistema, seus componentes, seus objetivos, recursos disponíveis, aspectos inerentes à sua administração e seu ambiente (restrições);

2. Formulação do problema e das medidas de rendimento a considerar;

3. Geração de alternativas para a solução do problema;

4. Avaliação das alternativas geradas a partir das medidas de rendimento formuladas;

5. Seleção da alternativa que melhor atende às premissas consideradas.

De maneira geral, o enfoque sistêmico significa observar cada parte do componente em função do papel que desempenha no sistema mais amplo (Churchman, 1971).

Como alternativa de auxílio no detalhamento dos componentes do sistema, pode ser empregada a análise SWOT (Strengths, Weaknesses, Opportunities e Threats), para a identificação dos fatores internos e externos relacionados ao problema em questão. Como o próprio nome já diz, a idéia central da análise SWOT é avaliar os pontos fortes, os pontos fracos, as oportunidades e as ameaças da organização e do mercado onde ela atua.

A análise SWOT surgiu de uma pesquisa conduzida pelo Instituto de Pesquisa de Stanford, entre 1960 e 1970, e é largamente utilizada nas áreas de planejamento estratégico, avaliação de competidores, marketing, negócios e pesquisa e desenvolvimento de produtos.

Segundo Wiig (1995), o objetivo da análise SWOT é conduzir ao processo de solução do problema através: (a) do entendimento das condições presentes e da direção futura da organização, baseado em fatores relevantes - internos e externos; 
(b) do desenvolvimento de uma técnica para alcançar o objetivo com o delineamento de passos táticos levando em consideração tempo e recursos disponíveis.

De acordo com Goldschmidt (2003), a análise é dividida em duas partes: o ambiente externo à organização (oportunidades e ameaças) e o ambiente interno à organização (pontos fortes e pontos fracos). A Figura 1, a seguir, mostra o quadro representativo desta análise.

\begin{tabular}{|c|c|c|}
\hline SWOT & Forças & Riscos \\
\hline $\begin{array}{c}\text { Questão } \\
\text { interna }\end{array}$ & Pontos Fortes & Pontos Fracos \\
\hline $\begin{array}{c}\text { Questão } \\
\text { externa }\end{array}$ & Oportunidades & Ameaças \\
\hline
\end{tabular}

Figura 1. Quadro SWOT.

O ambiente interno pode ser controlado pelos dirigentes da organização, já que constitui o resultado de estratégias de atuação definidas pelos mesmos. Desta forma, quando se percebe um ponto forte em nossa análise, deve-se ressaltá-lo ainda mais; quando se percebe um ponto fraco, deve-se agir para controlá-lo ou, pelo menos, minimizar seu efeito (GOLDSCHMIDT, 2003).

Já o ambiente externo está totalmente fora do controle da organização. Isso não significa que não seja útil conhecê-lo. Apesar de não poder controlá-lo, é possível monitorá-lo e procurar aproveitar as oportunidades da maneira mais ágil e eficiente e evitar as ameaças quando for possível (GOLDSCHMIDT, 2003).

O presente trabalho busca tratar, mais especificamente, o problema de localização de Plataformas Logísticas. A seguir, tratar-se-á da conceituação do termo plataforma logística e dos problemas da localização das instalações e métodos de solução empregados.

\subsection{Plataformas Logísticas}


O conceito de Plataforma Logística é ainda pouco explorado, e a bibliografia que faz referência ao termo é bastante escassa.

No artigo de Aldin; Stahre (2003), o termo plataforma logística é tratado como ”[...] a parte mais homogênea do sistema logístico [...] as plataformas logísticas constituem um recurso para alcançar novas posições no mercado”.

Ainda segundo Aldin; Stahre (2003), “numa plataforma logística, processos padronizados e medidas, como o índice de similaridade entre os processos utilizados, podem ser pré-requisitos que possibilitam o gerenciamento central e a coordenação da plataforma como um todo”.

Duarte (1999) compreende uma plataforma logística como um local de reunião de tudo o que diz respeito à eficiência logística. O texto de Duarte (1999) ainda afirma que uma plataforma logística acolhe zonas logísticas de empreendimentos e infraestruturas de transporte, importantes por sua dinamização na economia, melhorando a competitividade das empresas, criando empregos e viabilizando as atividades logísticas.

Duarte (1999) afirma que existem vários tipos de plataformas logísticas, voltadas a diferentes vocações como, por exemplo, aquelas visando a distribuição de produtos nas grandes metrópoles, com transbordo de carga para veículos menores, que podem circular pelos centros urbanos, ou mesmo portos com vocação para a multimodalidade.

Uma plataforma logística busca promover o uso eficaz e eficiente do espaço das instalações, oferecendo uma estrutura apropriada para operação dos processos pertinentes a determinada atividade. Ao buscar-se a eficácia no uso das instalações, significa que a utilização deve acontecer da melhor maneira possível, e quando se busca a eficiência, o foco é a redução de custos. 
A elaboração de um projeto de uma plataforma logística deve estar sempre voltada para o cliente, por ser esta relação de extrema importância. No caso do ETSP da CEAGESP, por exemplo, podem-se considerar os fornecedores, permissionários e consumidores (atacadistas e varejistas) pertencentes ao grupo de clientes.

Segundo um estudo desenvolvido pela Secretaria de Planejamento e Desenvolvimento de Goiás, as plataformas logísticas foram desenvolvidas inicialmente na França com a função de substituir os ineficientes terminais de cargas dispersos nas áreas periféricas das grandes cidades. E as plataformas se tornaram um elemento primordial para a redução dos custos logísticos e integração de Cargas na Europa. Uma característica importante das plataformas logísticas européias é a presença de integração multimodal.

O estudo da Secretaria de Planejamento e Desenvolvimento de Goiás aponta, como resultado da implantação de plataformas logísticas multimodais, os seguintes benefícios aos seus usuários:

- Competitividade: otimização do tráfego de cargas e redução dos custos operacionais;

- Flexibilidade: logística integrada para atender as exigências dos clientes finais;

- Confiabilidade: serviços diversificados e tecnologia da informação;

- Mão-de-obra especializada.

Ainda é possível utilizar o termo Pólo Gerador de Tráfego para caracterizar uma plataforma logística. Conforme o Decreto Municipal nº15.980/79, São Paulo, artigo 19, parágrafo $1^{\circ}$ (apud PORTUGAL; GOLDNER, 2003): “Consideram-se Pólos Geradores de Tráfego as edificações ou instalações que exercem grande atratividade sobre a população, mediante a oferta de bens e serviços, gerando elevado número de viagens, com substanciais interferências no tráfego do entorno e a necessidade de grandes espaços para estacionamento ou carga e descarga.” 
As definições para Pólos Geradores de Tráfego envolvem três variáveis básicas: o desenvolvimento de atividades, a produção de viagens e a geração de tráfego. (CUNHA, 2001 apud PORTUGAL; GOLDNER, 2003).

Retomando a conceituação de Plataformas Logísticas, é possível inserir neste termo as instalações que reúnam várias atividades logísticas, tais como transporte, armazenagem e comercialização, encerrando a oferta de bens e serviços à população.

Segundo Rosa (2004), considera-se Plataforma Logística a área de serviços logísticos localizada em um ponto nodal das cadeias de transporte e de logística, no qual se obtenham contribuições importantes na cadeia de valor, por meio de prestação de serviços de valor agregado, quer seja através de rede de transporte, da rede de telecomunicações ou apenas por intermédio de serviços pontuais à mercadoria, às pessoas (clientes, usuários, trabalhadores), aos veículos e equipamentos.

As plataformas logísticas geram impactos na região do seu entorno. Esses impactos podem ser de ordem social, econômica, ambiental, ou política. Portanto, no estudo da localização dessas plataformas fica evidente a necessidade de levantar e analisar, cuidadosamente, os vários fatores que influenciam o problema, que podem ser tanto objetivos quanto subjetivos.

Na seqüência, apresentar-se-ão alguns trabalhos que estudam os fatores locacionais importantes aplicadas a diferentes problemas.

\subsection{Localização das Instalações}

A importância estratégica da localização das instalações está relacionada com o valor de contribuição desta decisão para o sistema, a médio e longo prazo.

Randhawa; West (1995) salientam que a correta localização pode não só gerar significantes melhorias de produtividade, mas ainda possibilita novos mercados e novos negócios, enquanto localizações sub-ótimas podem gerar ineficiências em 
transporte, mão-de-obra inadequada, e gastos adicionais de capital investido em instalações e operações.

Belcorso (2001) conceitua instalação como uma unidade de negócios que, através da realização de operações (manufatura, armazenagem, manuseio, entre outros), agrega valor a um determinado produto ou serviço.

Na visão de Gualda (1995) o problema de localização pode ser definido como um problema de alocação espacial de recursos.

Korpela; Tuominen (1996) consideram que a decisão para a seleção de locais, para o estabelecimento de armazéns, possui um efeito significativo nos tipos de transporte, nos mercados a serem servidos e no nível de serviço oferecido aos clientes. A disponibilidade e confiabilidade dos serviços de transporte são fatores importantes, que devem ser considerados no processo de seleção de locais.

De acordo com Daskin (1995), no problema de localização no setor privado, os custos de investimento e benefícios são tipicamente medidos em unidades monetárias. Além disso, os custos e benefícios são gerados pelas ações dos diferentes atores: a empresa, sua administração, e seus investidores, que possuem os mesmos objetivos e metas. Esse contexto torna a análise, baseada em custos/benefícios, relativamente simples. Já nos problemas de localização inseridos no setor público, muitos custos e benefícios não monetários também devem ser considerados.

Segundo Ballou (2001) a localização das instalações é determinada freqüentemente por um fator que é mais crítico que os outros; esta característica pode ser denominada de força direcionadora. Por exemplo, na localização de fábricas e armazéns, os fatores econômicos geralmente são dominantes. O custo de transporte, por sua vez, também possui relevância significativa na determinação da localização. No caso de centros de varejo, a análise de localização deve ser altamente sensível às receitas e aos fatores de acessibilidade. 
Outro aspecto interessante apresentado em Ballou (2001) é a proposta de fatores locacionais que devem ser considerados em problemas envolvendo o varejo e o serviço:

- Demografia local, base populacional e renda potencial;

- $\quad$ Fluxo de tráfego e acessibilidade, número e tipos de veículos, número e tipos de pedestres, disponibilidade de transporte público, fácil acesso às vias principais, nível de congestionamento;

- Estrutura do varejo, disponibilidade, número e tipos de concorrentes e de lojas na área, lojas complementares vizinhas, proximidade de áreas comerciais e promoções conjuntas por comerciantes locais;

- Características do ponto, proximidade e qualidade do estacionamento, visibilidade, tamanho e forma do ponto, qualidade de entradas e saídas e boas condições dos edifícios existentes;

- $\quad$ Fatores legais e de custo, tipo de zoneamento, períodos e cláusulas restritivas de locação, impostos locais, serviços e manutenção.

Como citado anteriormente, os fatores locacionais se dividem em econômicos e extra-econômicos. Em relação aos fatores econômicos relevantes nos estudos de localização podemos citar:

- $\quad$ Custo de produção/compra;

- $\quad$ Custo de estocagem e manuseio;

- Custos fixos do armazém;

- Custos de manutenção do estoque;

- $\quad$ Custo de pedido e processamento;

- Custos de transporte de entrada e saída.

Segundo Wanke (2003), o objetivo deve ser o desenho ou a conFiguração da rede logística de modo a minimizar os custos totais, para um ano de operação, de produção, compras, manutenção de produtos em estoque, instalações (armazenagem, manuseio e demais custos fixos) e transporte, sujeitos a um determinado nível de serviço (tempo de entrega) ao cliente final. 
O objetivo da análise de custo total é minimizar os custos de transporte, armazenagem, estoques, processamento do pedido e sistemas de informação e custo do tamanho do lote. E ao mesmo tempo, alcançar o nível de serviço requerido pelo cliente.

Além do custo total do sistema, existe a necessidade de avaliar fatores locacionais que não possuem uma medida quantitativa bem definida e, ao mesmo tempo, possuem importante relevância no problema. Diversos autores apresentaram em seus estudos, critérios utilizados em problemas de localização. Neste texto são apresentados alguns destes estudos.

Conforme ReVelle et al. (1970) apud Tondo (1992), os fatores que influenciam a tomada de decisões na localização das instalações são os seguintes:

- Compromisso entre os custos de construção e operação da instalação, para satisfazer a demanda, e o custo de transporte;

- Fatores aleatórios, como variação de demanda por sazonalidade e condições climáticas e econômicas;

- Restrições no horário de funcionamento da instalação, principalmente em meio urbano;

- Direção de crescimento da demanda, competição, aceitação do produto e tecnologia;

- Restrições e influências criadas pela sociedade como, por exemplo, aquelas relacionadas ao meio ambiente;

- O fator transporte;

- Fatores quantitativos e não quantitativos.

Lopez; Henderson (1989) consideraram os seguintes fatores nas decisões de localização:

- $\quad$ Disponibilidade de matéria-prima;

- $\quad$ Proximidade com o mercado;

- Possível existência prévia de uma instalação;

- Estar localizado ou já fazer negócio no estado; 
- $\quad$ Disponibilidade de mão-de-obra;

- $\quad$ Disponibilidade e qualidade da água;

- $\quad$ Proximidade aos centros de distribuição;

- Disponibilidade de instalações de tratamento e depósito de lixo;

- $\quad$ Atratividade do local;

- $\quad$ Produtividade da mão-de-obra;

- $\quad$ Custo do terreno;

- Regulamentação em relação à poluição d’água;

- $\quad$ Existência de centros de capacitação profissional;

- $\quad$ Existência de instalações municipais para despejo e manuseio de lixo sólido;

- $\quad$ Custo de despejo de esgoto;

- $\quad$ Disponibilidade e custo de serviços de transporte;

- $\quad$ Custo das utilidades;

- $\quad$ Custo de construção;

- $\quad$ Custos anuais de conformidade com as regulamentações ambientais;

- $\quad$ Regulamentação de poluição do ar;

- $\quad$ Proximidade de instalações portuárias;

- Custo de vida na região;

- Dificuldade de identificação das leis ambientais;

- Imagem do estado;

- Impostos em geral.

Yang; Lee (1997) sugeriram que a adequação de um local específico para as operações de uma instalação depende dos fatores que serão selecionados e avaliados, bem como seus impactos potenciais nos objetivos e operações associadas. Os fatores de localização que têm sido largamente utilizados nas pesquisas podem ser genericamente agrupados nas seguintes categorias: mercado, transporte, mão-deobra, considerações do local, matéria-prima, serviços, utilidades, regras governamentais e meio ambiente.

Segundo Chan (2001), os primeiros fatores determinantes para a localização estão relacionados com os aspectos físicos tais como, rodovias, aeroportos, ferrovias, 
fornecimento de energia, canalização de água e esgoto e irrigação. Portanto, tudo aquilo que torna possível o funcionamento da instalação. Os fatores econômicos, geográficos, políticos e sociais também influenciam a determinação das instalações. Dentre os fatores políticos podemos citar as leis de zoneamento, os incentivos fiscais e a legislação ambiental. É válido destacar que disponibilidade de matéria-prima e acessibilidade aos mercados consumidores representam fatores de elevado grau de importância.

Chuang (2001) apresentou em seu trabalho alguns critérios e requisitos relevantes no problema de localização. Segundo ele, os critérios de localização que devem ser avaliados são os seguintes:

- Características do terreno;

- Custos de implantação e operação;

- Condições de transporte;

- $\quad$ Proximidade de fornecedores e clientes;

- Leis e regras políticas;

- Comunidade e ambiente de trabalho;

- Condições de trabalho;

- Energia e utilidades;

- Condições de tecnologia da informação.

Em relação aos requisitos referentes à localização, Chuang (2001) lista os seguintes itens:

- Distribuição rápida e precisa;

- Transporte conveniente;

- Espaço do terreno adequado;

- Localização apropriada;

- Baixo custo de transporte;

- Transporte regular;

- $\quad$ Disponibilidade de mão-de-obra;

- Disponibilidade de instalações públicas;

- Fornecimento regular dos serviços públicos; 
- Respostas rápidas às necessidades.

Ao longo da sua dissertação, Belcorso (2001) elaborou uma lista de critérios para localização industrial. Esta lista foi adaptada de Schmenner (1982) e encerra os seguintes critérios:

- Custo de transporte de produtos acabados;

- $\quad$ Custo de transporte de matéria-prima;

- $\quad$ Aspectos governamentais;

- $\quad$ Aspectos da comunidade;

- $\quad$ Qualidade de vida;

- Considerações sobre a concorrência;

- Considerações sobre o meio ambiente;

- Interação com outras plantas da empresa;

- $\quad$ Custo de mão-de-obra;

- Grau de sindicalização;

- Características intrínsecas ao local;

- Impostos e taxas;

- $\quad$ Condições de financiamento;

- Transportes;

- Utilidades e serviços.

Bhatnagar; Jayaram; Phua (2003) listaram os seguintes fatores relevantes na localização das instalações:

- Custo: terra, energia, infra-estrutura de transporte, serviços, telecomunicações e mão-de-obra;

- Infra-estrutura: disponibilidade e qualidade;

- Serviços: disponibilidade e qualidade de serviços de transporte, financeiros, jurídicos, e de tecnologia da informação;

- Mão-de-obra: disponibilidade e qualidade;

- Governo: presença de agências reguladoras, estabilidade das políticas de governo, estabilidade das políticas de impostos e taxas, proteção ao investimento estrangeiro e transparência e eficiência administrativa; 
- Cliente e Mercado: proximidade, dimensão e estabilidade das condições de mercado;

- $\quad$ Fornecedores e Recursos: disponibilidade e proximidade;

- Competição: reação dos competidores frente à localização.

O artigo apresentado por Kabir; Shiman (2003) trata da escolha de uma tecnologia de energia renovável. Este problema é caracterizado como uma tomada de decisão multicritério, e os critérios de decisão selecionados pelos autores foram os seguintes:

- Custo unitário;

- $\quad$ Impacto social (aceitabilidade da população e qualidade de vida);

- Técnico (design e complexidade do equipamento, design da instalação, disponibilidade de equipamento e peças, segurança da instalação, manutenção e treinamento necessário);

- Localização (flexibilidade e dimensão da instalação);

- $\quad$ Ambiente (impacto no ecossistema e ruído).

O artigo de Galvão, Cunha e Gualda (2003) estuda uma aplicação do Analytic Hierarchy Process (AHP) na localização de um centro de distribuição. Com o objetivo de auxiliar a tomada de decisão, foi proposto um checklist típico para seleção de um local. Abaixo, apresenta-se, resumidamente, este checklist:

- Área para implementação:

- Custo;

- Disponibilidade;

- Entradas:

- Água e efluentes;

- Gás natural;

- Energia elétrica;

- Transporte;

- Matéria-prima;

- Mercado;

- $\quad$ Aspectos ambientais;

- Vegetação, fauna e clima; 
- Ocupação urbana e habitação;

- Recursos humanos;

- $\quad$ Qualidade de vida;

- Taxas e impostos;

- Incentivos fiscais e tributários.

Randhawa; West (1995) sugerem que os seguintes atributos devem ser considerados na seleção de locais:

- $\quad$ Acesso a mercados;

- Acesso a matérias-primas e suprimentos;

- $\quad$ Disponibilidade de mão-de-obra, profissionais e executivos;

- Disponibilidade de infra-estrutura de transporte;

- $\quad$ Disponibilidade, qualidade e preço de utilidades e serviços;

- Consideração de aspectos de legislação e incentivos fiscais;

- Considerações ambientais e ecológicas;

- Custo, dimensão, zoneamento e topografia das áreas disponíveis;

- Aspectos comunitários, incluindo moradia, escolas e custo de vida.

No trabalho apresentado por Targa (2004), foram apontados os seguintes fatores determinantes para a escolha de um sítio aeroportuário:

- Fatores de relacionamento urbano: distância entre pólos geradores de demanda, facilidade nas vias de acesso (pavimentação e acessibilidade) e facilidades públicas (água, esgoto, energia elétrica, telecomunicações);

- $\quad$ Fatores físicos geográficos: ventos, visibilidade, altitude e temperatura;

- Fatores operacionais: obstáculos, impacto no tráfego aéreo, situação legal da área do sítio e tipos de operações previstas;

- Fatores ambientais: ruídos, fauna e flora, qualidade do ar e impacto no sistema hídrico;

- Fatores sócio-econômicos: valor da terra, custo de desapropriação, influência econômica e social do aeroporto na região, condição de uso do solo (existência de barreiras ao ruído aeronáutico), tempo de construção e renda per capita da região do entorno. 
Uma lista genérica dos fatores relevantes na seleção de locais é apresentada de forma resumida na Tabela 2. Esta lista busca tratar os critérios envolvidos nos problemas de localização tradicionais, e foi elaborada com base na bibliografia pesquisada e nas diversas listas dos trabalhos citados anteriormente.

Em estudos de localização aplicados para o cenário brasileiro, os fatores relacionados aos incentivos fiscais, na maioria das situações, apresentam-se como determinantes na escolha do local das instalações. Entretanto, no estudo de caso do ETSP da CEAGESP este critério pode ser ignorado, pois a análise será realizada nos limites da Região Metropolitana de São Paulo, que não apresenta variações significativas nos valores de incentivos fiscais e tributários.

Como citado anteriormente, a lista apresentada, Tabela 2, encerra um conjunto representativo dos fatores relevantes aos diversos problemas de localização encontrados na literatura pesquisada. Adiante, neste trabalho, será elaborada uma lista específica, que atenda as necessidades do estudo de caso do ETSP da CEAGESP.

Em relação à atribuição de valor para a área de implantação da instalação, há uma grande preocupação na estimativa deste número. A Associação Brasileira de Normas Técnicas (ABNT - 1989) propõe a NBR 5676, que contempla uma "Norma Brasileira para Avaliação de Imóveis Urbanos”. Segundo Brondino (1999), além do nível de rigor, a NBR 5676 também indica variáveis formadoras de valor para a avaliação dos terrenos, que incluem: caracterização física (relevo, solo, subsolo e ocupação), acessos, serviços e melhoramentos públicos, utilização atual e potencial, legal e econômica e classificação do imóvel. Para terrenos loteados ainda devem ser consideradas as seguintes influências: (1) área e profundidade e (2) frente.

Como é possível notar, o valor da área para a implantação da instalação já considera, ainda que indiretamente, alguns fatores caracterizados como relevantes para decisão da localização da instalação. 
Tabela 2- Lista de Critérios para a Localização de Instalações.

\begin{tabular}{|c|c|}
\hline CRITÉRIOS & SUB-CRITÉRIOS \\
\hline \multirow[t]{3}{*}{ 1. Área para implementação: } & Custo da área (considerar eventuais custos de desapropriação); \\
\hline & Disponibilidade de espaço necessário para o Projeto; \\
\hline & Custos associados à construção da instalação. \\
\hline \multirow[t]{13}{*}{ 2. Utilidades Públicas: } & Disponibilidade de fornecimento de água; \\
\hline & Disponibilidade de instalações de coleta de esgoto; \\
\hline & Custos de fornecimento de água; \\
\hline & Custo de coleta de esgoto; \\
\hline & Custo de tratamento de água; \\
\hline & Custo de tratamento de esgoto; \\
\hline & $\begin{array}{l}\text { Distância dos recursos de água e esgoto (este critério pode ser } \\
\text { considerado no item de custo); }\end{array}$ \\
\hline & Disponibilidade de sistema de coleta de resíduos (lixo); \\
\hline & $\begin{array}{l}\text { Disponibilidade e confiabilidade do sistema de energia elétrica (ou outros } \\
\text { tipos de fontes de energia, caso haja necessidade); }\end{array}$ \\
\hline & Custo do fornecimento de energia elétrica; \\
\hline & Custo de acessar as redes de energia; \\
\hline & $\begin{array}{l}\text { Distância às fontes ou redes de energia (este critério pode ser considerado } \\
\text { no item de custo); }\end{array}$ \\
\hline & Disponibilidade de instalações de telecomunicação. \\
\hline \multirow[t]{5}{*}{ 3. Acessibilidade: } & Disponibilidade e custo para a mão-de-obra chegar (acessar) ao local; \\
\hline & $\begin{array}{l}\text { Disponibilidade e custo de transporte dos produtos (tanto entrada, quanto } \\
\text { saída - no caso de indústrias tem que considerar matéria-prima e produtos } \\
\text { acabados, separadamente); }\end{array}$ \\
\hline & Distâncias entre o local e os fornecedores e clientes; \\
\hline & Rotas de acesso (rodovia, ferrovia, hidrovia); \\
\hline & Qualidade dos serviços de transporte que atendem a região. \\
\hline \multicolumn{2}{|c|}{ 4. Disponibilidade e custo da matéria-prima; } \\
\hline \multirow[t]{3}{*}{ 5. Mercado: } & $\begin{array}{l}\text { Identificação de consumidores (tamanho e proximidades aos mercados } \\
\text { consumidores); }\end{array}$ \\
\hline & Estabilidade das condições de mercado; \\
\hline & Análise de competitividade (considerações sobre a concorrência). \\
\hline \multirow[t]{5}{*}{ 6. Aspectos Ambientais: } & Conformidade com as legislações ambientais estaduais e municipais; \\
\hline & Obtenção de licenças ambientais; \\
\hline & Políticas de controle da Poluição (associado à qualidade do ar); \\
\hline & Impacto no sistema hídrico; \\
\hline & Preservação do meio ambiente da região. \\
\hline \multirow{4}{*}{\begin{tabular}{|l|} 
7. Aspectos físicos geográficos \\
\\
\\
\end{tabular}} & Características geográficas e topológicas do local; \\
\hline & Clima e temperatura; \\
\hline & Padrões de chuvas e enchentes; \\
\hline & Ventos. \\
\hline \multirow[t]{5}{*}{ 8. Ocupação Urbana: } & Cidades próximas; \\
\hline & $\begin{array}{l}\text { População (aceitação da população em relação à atividade da } \\
\text { empresa/indústria na região); }\end{array}$ \\
\hline & Desenvolvimento de projetos; \\
\hline & $\begin{array}{l}\text { Condições de uso do solo (possíveis restrições ou barreiras para a } \\
\text { implantação do projeto); }\end{array}$ \\
\hline & $\begin{array}{l}\text { Impactos sociais (considerar eventuais benefícios sócio-econômicos } \\
\text { gerados pela implantação da instalação). }\end{array}$ \\
\hline
\end{tabular}


Continuação

\begin{tabular}{|c|c|}
\hline CRITÉRIOS & SUB-CRITÉRIOS \\
\hline \multirow[t]{5}{*}{ 9. Recursos humanos: } & Legislação trabalhista; \\
\hline & Grau de sindicalização; \\
\hline & Disponibilidade de mão-de-obra qualificada; \\
\hline & Existência de centros de treinamento e educação; \\
\hline & $\begin{array}{l}\text { Custos de mão-de-obra na região (salários médios - média salarial da } \\
\text { região). }\end{array}$ \\
\hline \multirow[t]{4}{*}{ 10. Qualidade de vida: } & Habitação, segurança e infra-estrutura social; \\
\hline & Disponibilidade de lazer; \\
\hline & Disponibilidade de serviços médicos e odontológicos; \\
\hline & Custo de vida na região (habitação, transporte e infra-estrutura). \\
\hline \multicolumn{2}{|c|}{$\begin{array}{l}\text { 11. Impostos e taxas (além de valores, é necessário avaliar a estabilidade das políticas de impostos e } \\
\text { taxas). }\end{array}$} \\
\hline \multirow{2}{*}{$\begin{array}{l}\text { 12. Incentivos fiscais e } \\
\text { tributários: }\end{array}$} & Estadual; \\
\hline & Municipal. \\
\hline \multirow[t]{4}{*}{ 13. Governo: } & Presença de agências reguladoras; \\
\hline & Estabilidade das políticas de governo; \\
\hline & Proteção ao investimento estrangeiro; \\
\hline & Transparência e eficiência administrativa \\
\hline
\end{tabular}

Ainda a respeito da área para implementação, Borges (1975) apud Brondino (1999) fez um estudo a respeito da valorização de terrenos e levantou alguns fatores condicionantes para o diferencial de valor dos terrenos urbanos. Entre os principais fatores determinantes deste diferencial, ele destaca os seguintes: distribuição espacial dos centros de emprego, a organização e tecnologia dos sistemas de transporte, características sócio-econômicas da vizinhança, a complementaridade de uso do solo, a densidade demográfica, as características topográficas dos terrenos, as características dos lotes e a qualidade de infra-estrutura urbana.

Quanto aos custos associados à construção da instalação, é possível fazer um levantamento a partir do projeto executivo da obra. No entanto, pode-se, de maneira aproximada, utilizar os custos médios $\left(\mathrm{R} \$ / \mathrm{m}^{2}\right)$, fornecidos pelo Sistema Nacional de Pesquisa de Custos e Índices da Construção Civil, disponível no site do IBGE. É importante ressaltar que esses custos não são uniformes para todo o território brasileiro, sofrendo variações de acordo com o estado e com a região do país.

A disponibilidade e custo das utilidades públicas constituem fatores importantes, principalmente quando são consideradas, ao longo da análise, regiões que apresentam infra-estrutura precária. 
O critério acessibilidade trata não apenas a existência de estrutura viária no local, mas também da sua qualidade. Este critério ainda envolve os custos associados aos fluxos que integram as atividades da instalação. O custo do transporte é um fator que está ligado tanto aos produtos produzidos, armazenados ou comercializados na instalação, quanto à movimentação da mão-de-obra e de clientes.

É importante salientar que há uma relação de interdependência entre os vários critérios de localização estudados e, portanto, estes critérios não devem ser analisados isoladamente.

O mercado consumidor poder sofrer variações significativas em função da localização da instalação. No processo de análise de um local candidato é preciso identificar o tamanho e a proximidade do mercado consumidor, a tendência de estabilidade deste mercado, além de conhecer a concorrência que atua neste local. A avaliação dos fluxos de destino dos produtos pode auxiliar a identificação e caracterização do mercado consumidor.

Segundo Lisboa (2002), as questões ambientais são vistas como efeitos externos ou externalidades, que se expressam principalmente através de custos sociais provocados pela atividade econômica e não ressarcidos como, por exemplo, a poluição. Estes efeitos não são captados pelo mercado, porque não estão sujeitos a preço ou compensações financeiras (POMERANZ, 1992). Logo, uma tradicional análise custo/benefício dificilmente consideraria adequadamente estes importantes aspectos do projeto.

Ainda em relação às questões ambientais, o tráfego de veículos é uma causa significativa da degradação ambiental em áreas urbanas, contribuindo para poluição do ar e sonora, tanto quanto causando problemas de congestionamento, segurança e intrusão (HAYASHI; ROY, 1996). 
Quanto aos fatores extra-econômicos, relacionados com a ocupação urbana, a qualidade de vida e os aspectos físicos geográficos, é interessante questionar alguns pontos, como habitação e condições de vida oferecidas no local, impactos gerados pela instalação e características gerais do local.

Com o objetivo de dimensionar os recursos humanos disponíveis, para cada local candidato, realiza-se um estudo da área, incluindo extensão geográfica, população estimada e características econômicas, que possibilita a avaliação da disponibilidade de mão-de-obra. Ainda referente à mão-de-obra, outro aspecto importante está relacionado com o grau de sindicalização existente no local e também a legislação trabalhista vigente.

Depois da pesquisa realizada neste capítulo, foi possível elaborar uma Tabela para ilustrar a diversidade de fatores utilizados pelos diversos autores pesquisados. A Tabela 3, abaixo, mostra os fatores propostos em função dos seus autores. A Tabela apresentada contribui para a pesquisa de localização, por relacionar os diversos autores pesquisados com os critérios de localização utilizados em suas pesquisas. A última coluna da Tabela representa os fatores considerados importantes para a realização deste trabalho e que de alguma forma encontram-se discutidos ao longo do texto.

\subsection{Métodos ou Modelos para solução de problemas de localização das instalações}

Um dos objetivos deste trabalho é a utilização de métodos de apoio à decisão na análise do problema de localização. De forma genérica, poderiam ser utilizados os seguintes métodos: 
Tabela 3- Lista de Critérios para a Localização de Instalações.

\begin{tabular}{|c|c|c|c|c|c|c|c|c|c|}
\hline CRITÉRIOS & $\begin{array}{l}\text { ReVelle et } \\
\text { al (1970) }\end{array}$ & $\begin{array}{l}\text { Lopez; Henderson } \\
\text { (1989) }\end{array}$ & Chuang (2001) & Belcorso (2001) & $\begin{array}{l}\text { Bhatnagar; Jayaran; } \\
\text { Phua (2003) }\end{array}$ & $\begin{array}{c}\text { Kabir; Shinan } \\
\text { (2003) }\end{array}$ & $\begin{array}{r}\text { Galvão; Cunha; } \\
\text { Gualda (2003) }\end{array}$ & $\begin{array}{l}\text { Randhawa; West (1995) } \\
\text { apud Valim Fillo (2004) }\end{array}$ & Targa (2004) \\
\hline \multicolumn{10}{|l|}{ 1. Local: } \\
\hline $\begin{array}{l}\text { Custo da área (considerar eventuais custos de } \\
\text { desapropriação); }\end{array}$ & & $\checkmark$ & $\checkmark$ & & $\checkmark$ & & $\checkmark$ & $\checkmark$ & $\checkmark$ \\
\hline Disponibilidade de espaço necessário para $\circ$ Projeto; & & & $\mathrm{r}$ & & & & $\checkmark$ & $\checkmark$ & \\
\hline Custos associados à construçã̃o da instalação; & 2 & $\checkmark$ & $\checkmark$ & & & & & & \\
\hline Custo de operação da instalação; & 2 & & $\checkmark$ & & & & & & \\
\hline Possivel existência prévia de uma instalą̧ão; & & 2 & & & & & & & \\
\hline $\begin{array}{l}\text { Caracteristicas intrinsecas do local (atratividade do local, } \\
\text { Hexibilidade e dimensão da instalą̧âo); }\end{array}$ & & $\checkmark$ & & $\checkmark$ & & $\checkmark$ & & & \\
\hline Tempo consumido na construlqão. & & & & & & & & & $\checkmark$ \\
\hline \multicolumn{10}{|l|}{ 2. Utilidades Públicas: } \\
\hline Disponibilidade de fornecimento de água; & & 2 & & & & & $\checkmark$ & & \\
\hline Disponibilidade de instalaş̃̃es de coleta de esgoto; & & & & & & & $\checkmark$ & & \\
\hline Custos de fornecimento de água; & & $\checkmark$ & & & & & $\checkmark$ & & \\
\hline Custo de coleta de esgoto; & & $\checkmark$ & & & & & $\checkmark$ & & \\
\hline Custo de tratamento de água; & & $\checkmark$ & & & & & $\checkmark$ & & \\
\hline Custo de tratamento de esgoto; & & $\checkmark$ & & & & & $\checkmark$ & & \\
\hline $\begin{array}{l}\text { Distância dos recursos de água e esgoto (este critério } \\
\text { pode ser considerado no item de custo); }\end{array}$ & & & & & & & $\checkmark$ & & \\
\hline Disponibilidade de sistema de coleta de residuos (lixo); & & $\checkmark$ & I & (1י & & & & & \\
\hline $\begin{array}{l}\text { Disponibilidade e confiabilidade do sistema de energia } \\
\text { elétrica (ou outros tipos de fontes de energia, caso haja } \\
\text { necessidade); }\end{array}$ & & & & & 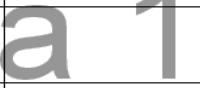 & & $\checkmark$ & & \\
\hline Custo do formecimento de energia elétrica; & & 2 & $\theta$ & & $\checkmark$ & & $\checkmark$ & & \\
\hline Custo de acessar as redes de energia; & & $\checkmark$ & & & & & $\checkmark$ & & \\
\hline $\begin{array}{l}\text { Distância às fontes ou redes de energia (este critério pode } \\
\text { ser considerado no item de custo); }\end{array}$ & & & & & & & $\checkmark$ & & \\
\hline Disponibilidade de instalarốes de telecomunicação; & & & & & $\checkmark$ & & & & \\
\hline Disponibilidade de gás natural; & & & & & & & $\checkmark$ & & \\
\hline Confiabilidade no fornecimento do gás natural; & & & & & & & $\checkmark$ & & \\
\hline Custo de fornecimento do gás natural; & & & & & & & $\checkmark$ & & \\
\hline $\begin{array}{l}\text { Disponibilidade, qualidade e preq̧o de utilidades e serviços } \\
\text { em geral. }\end{array}$ & & & $\checkmark$ & $\checkmark$ & & & & $\checkmark$ & $\checkmark$ \\
\hline \multicolumn{10}{|l|}{ 3. Acessibilidade: } \\
\hline $\begin{array}{l}\text { Disponibilidade e custo para a mão-de-obra chegar } \\
\text { (acessar) ao local; }\end{array}$ & & $\checkmark$ & & & & & & & \\
\hline $\begin{array}{l}\text { Disponibilidide (re gularidade) e custo de transporte dos } \\
\text { produtos (tanto entrada, quanto saida - no caso de } \\
\text { indústrias tem que considerar matéria-prima e produtos } \\
\text { acabados, separadamente); }\end{array}$ & $\checkmark$ & $\checkmark$ & $\checkmark$ & $\checkmark$ & $\checkmark$ & & & & \\
\hline Custo de infra-estrutura de transporte; & & & & & $\checkmark$ & & & & \\
\hline Distancias entre o local e os fornecedores e clientes; & & & $\checkmark$ & & & & & & \\
\hline Rotas de acesso (rodovia, ferrovia, hidrovia, áreo); & & & & & & & $\checkmark$ & $\checkmark$ & $\checkmark$ \\
\hline $\begin{array}{l}\text { Qualidade dos servicos de transporte que atendem a } \\
\text { regiaio; }\end{array}$ & & & $\checkmark$ & $\checkmark$ & $\checkmark$ & & & & \\
\hline Proximidade a instalaǎ̧es portuárias; & & $\checkmark$ & & & & & & & \\
\hline Precisão e Rapidez na distribuição. & & & $\checkmark$ & & & & & & \\
\hline
\end{tabular}


Continuação

\begin{tabular}{|c|c|c|c|c|c|c|c|c|c|}
\hline CRITÉrTOS & $\begin{array}{c}\text { ReVelle et } \\
\text { al (1970) }\end{array}$ & $\begin{array}{c}\text { Lopez; Henderson } \\
\text { (1989) }\end{array}$ & Chuang (2001) & Belcorso (2001) & $\begin{array}{c}\text { Bhathagar; Jayaram; } \\
\text { Pluna (2003) }\end{array}$ & $\begin{array}{c}\text { Kabir; Shiman } \\
(2003)\end{array}$ & $\begin{array}{l}\text { Galvấ; Cumla: } \\
\text { Gualda (2003) }\end{array}$ & $\begin{array}{l}\text { Randhawa; West (1995) } \\
\text { apud Valin Fillo (2004) }\end{array}$ & Targa (2004) \\
\hline $\begin{array}{l}\text { 4. Disponibilidade e custo da matéria-prima } \\
\text { (fomecedores). }\end{array}$ & & $\checkmark$ & & & $\checkmark$ & & $\checkmark$ & $\checkmark$ & \\
\hline 5. Mercado: & & & & & & & & & \\
\hline $\begin{array}{l}\text { Identificacăa de consumidores (tamanho e proximidades } \\
\text { aos mercados consumidores); }\end{array}$ & & $\checkmark$ & $\checkmark$ & & $\checkmark$ & & $\checkmark$ & $\checkmark$ & $\checkmark$ \\
\hline Estabilidade das condip̧̧es de mercrado; & 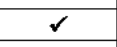 & & & & $\checkmark$ & & & & \\
\hline 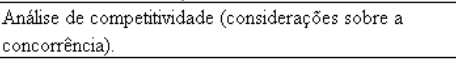 & $\checkmark$ & & & $\checkmark$ & $\checkmark$ & & $\checkmark$ & & \\
\hline Identificaąăo de Sazonalidade; & $\mathrm{r}$ & & & & & & & & \\
\hline $\begin{array}{l}\text { Acetiação do produto; } \\
\text { Estar previamente localizado ou já fazer neggócio no }\end{array}$ & & & & & & & & & \\
\hline estado; & & $\frac{1}{2}$ & & & & & & & \\
\hline Proximidade de centros de distribuiçăo; & & 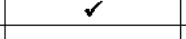 & & & & & & & \\
\hline Identificąăo de investimentos previstos para regiazo. & & & & & & & $\checkmark$ & & \\
\hline 6. Aspectos Ambientasis: & & & & $\checkmark$ & & & & 2 & \\
\hline 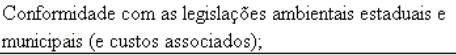 & & $\checkmark$ & & & & & $\checkmark$ & & \\
\hline 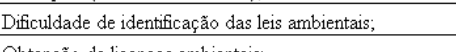 & & ك & $z$ & 마 & & & & & \\
\hline 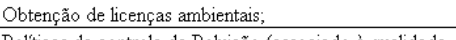 & & & & & & & $\checkmark$ & & \\
\hline $\begin{array}{l}\text { Polticias de controle da Poluiçắ (associado à qualidade } \\
\text { do art); }\end{array}$ & & $\checkmark$ & 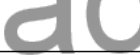 & & 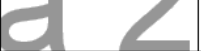 & & & & $\checkmark$ \\
\hline Impacto no sistema hidstico; & & $\mathrm{s}$ & 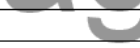 & & & & & & $\checkmark$ \\
\hline Impacto no ecossitema e ruido; & & & & & & $\checkmark$ & & & $\checkmark$ \\
\hline Preservação do meio ambiente da regiãa. & & & & & & & $\checkmark$ & & $\mathrm{s}$ \\
\hline 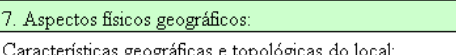 & & & & & & & & 4 & \\
\hline $\begin{array}{l}\text { Caracteristicas geográficas e top ológicas do local; } \\
\text { Cilmae temperatura; }\end{array}$ & 2 & & & & & & $\checkmark$ & $\checkmark$ & 2 \\
\hline Padrớes de chuvas e enchentes; & & & & & & & 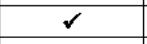 & & \\
\hline Ventos. & & & & & & & $\checkmark$ & & $\checkmark$ \\
\hline 8. Ocupąăa Urbana: & & & & & & & 2 & & \\
\hline 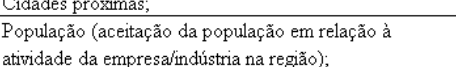 & $\checkmark$ & & & & & $\checkmark$ & $\checkmark$ & & \\
\hline $\begin{array}{l}\text { atividade da empresaínduststia na regiajo); } \\
\text { Desenvolvimento de projetos; }\end{array}$ & $\checkmark$ & & & & & $\checkmark$ & $\frac{a}{2}$ & & \\
\hline 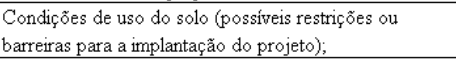 & $\checkmark$ & & & & & & & & $\checkmark$ \\
\hline Questốes econônmicas em geral; & $\checkmark$ & & & & & & & & \\
\hline 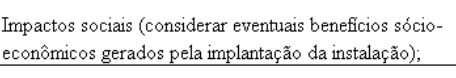 & & & & & & & $\checkmark$ & & $\checkmark$ \\
\hline 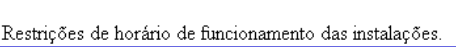 & $\checkmark$ & & & & & & & & \\
\hline
\end{tabular}


Continuação

\begin{tabular}{|c|c|c|c|c|c|c|c|c|c|}
\hline CRTTËRTOS & $\begin{array}{l}\begin{array}{l}\text { ReVelle et } \\
\text { al (1970) }\end{array} \\
\text { a }\end{array}$ & $\begin{array}{l}\text { Lopez; Henderson } \\
\text { (1989) }\end{array}$ & Chuang (2001) & Belcorso (2001) & $\begin{array}{l}\text { Bhatuagar; Jayaran; } \\
\text { Phua (2003) }\end{array}$ & $\begin{array}{c}\text { Kabir; Sliman } \\
(2003)\end{array}$ & $\begin{array}{l}\text { Galvăo; Culla; } \\
\text { Gualda (2003) }\end{array}$ & $\begin{array}{l}\text { Randlawa; West (1995) } \\
\text { apud Valin Fillo (2004) }\end{array}$ & Targa (2004) \\
\hline 9. Recursos humanos: & & & & & & & & & \\
\hline 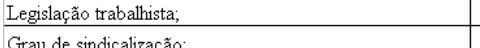 & & & & & & & $\checkmark$ & & \\
\hline 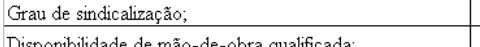 & & & & $\checkmark$ & & & & & \\
\hline Disponibilidade de mão-de-obra qualificada; & & $\frac{1}{2}$ & $\checkmark$ & & $\checkmark$ & & $s$ & $\checkmark$ & \\
\hline 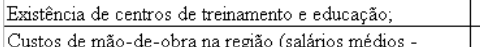 & & $\checkmark$ & & & & & $\checkmark$ & & \\
\hline 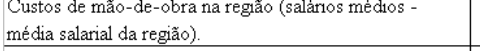 & & & & $\checkmark$ & $\checkmark$ & & $\checkmark$ & & \\
\hline Produluividade da mão-de-obra & & $\checkmark$ & & & & & & & \\
\hline Comunidade e ambiente de trabalho & & & $\checkmark$ & & & & & & \\
\hline Condiçoeses de trabalho & & & 2 & & & & & & \\
\hline 10. Qualidade de vida: & & & & $\checkmark$ & & $\checkmark$ & $\checkmark$ & & \\
\hline Habitaçăo, segurança e infa-estrutura social; & & & & $\mathrm{r}$ & & & 2 & $\checkmark$ & \\
\hline 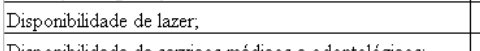 & & & & & & & 2 & & \\
\hline 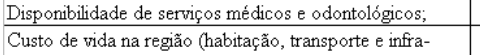 & & & & & & & $\checkmark$ & & \\
\hline estrutura); & & $\checkmark$ & & & & & $\checkmark$ & $\checkmark$ & \\
\hline \begin{tabular}{|l|l} 
Renda per capita da regăa.o. \\
\end{tabular} & & & & & & & & & $\checkmark$ \\
\hline $\begin{array}{l}\text { 11. Impostos e taxas (além de valores, } e \text { necessáritio avaliar } \\
\text { a estabildade das pollicas de impostos e tazasas. }\end{array}$ & & & ก & $\checkmark$ & 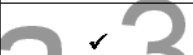 & & 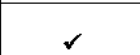 & & \\
\hline 12. Incentivos fiscais e tributários: & & & eco & 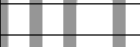 & D -1 & & & & \\
\hline Estadual; & & & & & & & $\checkmark$ & $\checkmark$ & \\
\hline$\frac{\text { Muncipipal }}{1.3 \text { Gereme. }}$ & & & & & & & $\checkmark$ & $\checkmark$ & \\
\hline$\frac{13}{\text { Presencemo: }}$ & & & & $\checkmark$ & & & & & \\
\hline $\begin{array}{l}\text { Presenna de a aências reguladoras; } \\
\text { Estabilidaded das polticas de govermo; }\end{array}$ & & & & & $\frac{a}{2}$ & & & & \\
\hline Proteçăa ao investimento estrangeiro; & & & & & $\checkmark$ & & & & \\
\hline Transparência e efciềncia administrativiva; & & $\checkmark$ & & & $\checkmark$ & & & & \\
\hline \begin{tabular}{|l|} 
Leis e regras polliticas \\
14
\end{tabular} & & & 2 & & & & & 2 & \\
\hline 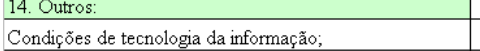 & & & $\checkmark$ & & $\frac{2}{2}$ & & & & \\
\hline Respostas rápidas às necessidades; & & & $\checkmark$ & & & & & & \\
\hline 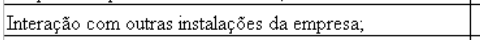 & & & & $\checkmark$ & & & & & \\
\hline Condirgoes de financiamento; & & & & 2 & & & & & \\
\hline Custo de servipos; & & & & & 2 & & & & \\
\hline $\begin{array}{l}\text { Disponbibidade e qualidade de servicos jurdicicos e } \\
\text { francerpos }\end{array}$ & & & & & $\checkmark$ & & & & \\
\hline $\begin{array}{ll}\text { Inanancersos } \\
\text { Custo untário }\end{array}$ & & & & & & $\checkmark$ & & & \\
\hline Técrnico (equipamento - instaląẵo e manutenņăo) & & & & & & $\checkmark$ & & & \\
\hline 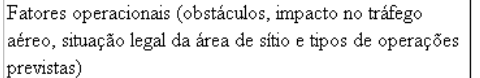 & & & & & & & & & $\checkmark$ \\
\hline
\end{tabular}


- Otimização ou programação linear: capazes de avaliar alternativas e encontrar a solução ótima para as condições apresentadas pelo modelo matemático;

- Heurísticas: encurtam o processo de busca da solução, porém não garantem a solução ótima para o problema;

- Simulação: permitem a avaliação do desempenho de diversas alternativas e também uma descrição detalhada do problema, tornando seu tratamento mais realista;

- $\quad$ Métodos multicritério.

Os modelos de otimização são baseados em procedimentos matemáticos precisos para avaliar alternativas e garantem que a solução ótima, ou a melhor alternativa, seja encontrada para o problema, como proposto matematicamente (BALLOU, 2001).

Na literatura pesquisada são discutidos, com freqüência, os seguintes modelos de otimização para a resolução de problemas de localização:

- Covering Model;

- $\quad$ Center Model;

- $\quad$ Median Model.

O modelo de Cobertura, ou Covering Model, possui como objetivo localizar instalações buscando garantir a cobertura de determinada região. A idéia central consiste em localizar as instalações de modo que todos os centros de demanda sejam atendidos dentro de um determinado nível de serviço. Este método é utilizado para a localização de centrais de resgate, bombeiros, polícia e demais serviços emergenciais.

O método do Centro de Gravidade, ou Center Model, busca minimizar o custo de locação de instalações minimizando a distância (ou custo, ou tempo) máxima entre a instalação e os centros de demanda atendidos. Este modelo considera restrições de níveis de serviço. 
O Problema das Medianas, ou Median Model, foi introduzido por Hakimi (1964) e sua função objetivo busca minimizar o custo total da distribuição. Este modelo trabalha com um número fixo de instalações e procura maximizar a acessibilidade e efetividade do sistema, por exemplo, utilizando-se uma ponderação entre as distâncias e demandas.

Segundo Ballou (2001), os modelos Heurísticos foram definidos, por Hinkle e Kuen (1967), como um atalho de processo de raciocínio, que busca uma solução satisfatória ao invés de uma ótima. A heurística, que reduz o tempo gasto na solução de um problema, compreende uma regra ou um procedimento computacional que restringe um número de soluções alternativas para o problema, baseado no processo análogo ao de tentativa e erro humano de pesquisar soluções aceitáveis em problemas para os quais algoritmos de otimização não estão disponíveis.

Hollaender (1978) afirma que as técnicas heurísticas parecem mais adequadas para resolver os problemas de localização de mais de um centro de distribuição, porque elas reduzem as dificuldades combinatórias desse tipo de problema e orientam a pesquisa de melhores soluções.

A simulação, em geral, baseia-se na experimentação das atividades que envolvem o sistema em estudo, observando-se as variações dos estados do sistema em cada instante de interesse e medindo-se suas propriedades. Ao final de um período de processamento do modelo de simulação que descreveu o sistema em estudo, podemse verificar os resultados pertinentes para a análise do sistema, determinando se certos objetivos foram alcançados. Pegden et al. (1995) apresenta a simulação como um processo de elaborar um modelo de um sistema real e conduzir experimentos, com o propósito de compreender o comportamento do sistema e/ou avaliar várias estratégias para operação do mesmo.

Com relação aos métodos multicritério, Iañez (2002) observa que estes são utilizados, geralmente, para auxiliar a tomada de decisão em problemas onde não 
existe solução ótima, devendo o tomador de decisão estar apto a avaliar os diversos trade-offs existentes e selecionar a melhor alternativa disponível.

Ao tratar-se de modelos matemáticos, estes ainda podem ser divididos, basicamente, em duas classes (GUALDA, 1995):

- Modelos determinísticos, não possuem variáveis aleatórias e são baseados, em particular, nas teorias de programação linear, da programação inteira, da programação geométrica, da programação não-linear, da programação dinâmica, da teoria dos grafos e de fluxos em redes;

- Modelos estocásticos, baseados, em particular, nas teorias dos processos estocásticos, das filas, dos jogos, das análises de decisão, de busca da programação dinâmica e de simulação. Segundo Gavira (2003), um modelo estocástico tem uma ou mais variáveis aleatórias como entrada; essas entradas levam a saídas aleatórias, as quais podem apenas ser consideradas como estimativas das verdadeiras características de um modelo.

Gualda (1995) ainda divide os métodos para tratamento dos problemas de localização em dois grupos:

- Métodos indutivos, que se baseiam em análise de dados e informações estatísticas, históricas e provenientes de pesquisa de campo (questionários), através do que se buscam razões ou indicações quanto à melhor localização para uma dada indústria (ou terminal, no caso do estudo conduzido por Gualda, 1995);

- Métodos dedutivos, que constituem no estabelecimento de um modelo representativo da realidade, passível de tratamento matemático, para resolver o problema da localização. Neste caso, dados históricos ou estatísticos são usados para testar os resultados obtidos nestes modelos.

Em um exemplo de problema de localização apresentado no artigo de Brimberg; ReVelle (1998), os dois objetivos do problema de localização das instalações seriam (1) minimizar o custo total de manufatura e distribuição e (2) maximizar a demanda servida. Os autores afirmam que a decisão de abrir e fechar instalações pode ser 
viável em certos casos, por exemplo, quando as instalações podem ser alugadas ou quando o maquinário pode ser reinstalado facilmente e a custos baixos em diferentes locais. Entretanto, a mudança das instalações normalmente envolve custos significativos, que devem ser identificados e avaliados.

De acordo com De Boer et al. (2001), os modelos baseados em programação matemática são mais objetivos que os modelos de comparação por pesos, pois levam o tomador de decisão a definir explicitamente uma função objetivo e variáveis de decisão de natureza numérica. Por outro lado, os modelos matemáticos normalmente não consideram critérios qualitativos.

\subsection{Modelos Multicritério}

Geralmente, uma das tarefas mais difíceis enfrentadas pelos agentes de decisão está em solucionar problemas complexos, os quais devem atender a objetivos múltiplos e, na maioria dos casos, conflitantes.

A essência da tomada de decisão multicritério é a escolha da melhor alternativa, a partir de um conjunto de alternativas competitivas que são avaliadas sob critérios conflitantes (CHO; CHO, 2003). Os critérios são denominados conflitantes quando a satisfação de um dos critérios impede a completa satisfação de um outro critério (HARTMAN; GOLTZ, 2002).

De acordo com Ensslin (2001), a pesquisa operacional tradicional se utiliza, em geral, de métodos de avaliação de alternativas com um único critério como, por exemplo, uma medida quantitativa de eficiência econômica. A melhor alternativa é aquela que otimiza uma determinada função matemática, a qual avalia o desempenho das alternativas segundo o critério considerado.

Ainda conforme Ensslin (2001), os métodos multicritério consideram mais de um aspecto e, portanto, avaliam as ações segundo um conjunto de critérios. Cada critério é uma função matemática que mede o desempenho das ações potenciais com relação 
a um determinado aspecto. E deseja-se “otimizar” essas funções de forma simultânea.

Entretanto, segundo Vincke (1992), o que deve ser notado quando se está lidando com este tipo de problema é que não existe, em geral, nenhuma decisão que é simultaneamente ótima sob todos os pontos de vista e atributos.

Belton; Stewart (2002) identificaram dois níveis de escolhas como parte do processo de planejamento estratégico. Nos primeiros estágios do processo de planejamento estratégico, a ênfase deve ocorrer na geração de alternativas. Em um segundo nível, a lista de alternativas precisa ser profundamente avaliada pelas partes afetadas e interessadas, com base em critérios quantitativos e qualitativos, alguns dos quais podem requerer julgamentos subjetivos.

Como afirmam Belton; Stewart (2002), em uma análise multicritério, assim como em qualquer forma de análise de problema, é importante reconhecer a existência e o impacto potencial dos stakeholders internos e externos. Os stakeholders são todas as pessoas, grupos ou instituições que possuem interesses nos resultados da decisão.

Apesar dos modelos multicritério parecerem, à primeira vista, simplistas, é necessário levar em consideração o trabalho que foi realizado, por trás do modelo, para torná-lo simples.

Malczewski (1999) divide a tomada de decisão multicritério (Multicriteria Decision Making - MCDM) em duas classes. A primeira recebe o nome de tomada de decisão multiatributo (Multiattribute Decision Making - MADM) e a segunda é conhecida como tomada de decisão multiobjetivo (Multiobjective Decision Making - MODM). Ambas as classes de problemas podem possuir um único agente de decisão ou um grupo de decisores. E estas duas categorias ainda são subdivididas em determinísticas, probabilísticas e fuzzy. 
A lógica fuzzy parte do princípio de que devem ser considerados, em certas situações, critérios qualitativos e que estes devem ser descritos em termos lingüísticos (baixo, médio, muito baixo, alto, muito alto, etc.) tanto em termos de seus valores quanto de seus pesos relativos. Essa técnica, entretanto, apesar de procurar ser abrangente em termos de tratamento de variáveis, não é uma abordagem que ganhou muito impulso no tratamento do problema de localização (VALLIM, 2004).

Com a finalidade de esclarecer as diferenças entre as duas classes da tomada de decisão multicritério, explicar-se-á os termos atributo e objetivo.

O termo atributo refere-se às características, fatores, qualidades, índices de desenvolvimento ou parâmetros de alternativas que regem o processo decisório, por exemplo, produção de sedimentos e concentrações de nitratos da água. Um atributo propicia um meio para a avaliação do nível de atendimento para um objetivo, podendo ser definido como um aspecto mensurável de julgamento, pelo qual as variáveis de decisão ou alternativas consideradas podem ser caracterizadas. Essa caracterização é feita pela determinação de um indicador empírico para cada atributo. Nos problemas de decisão multicritério a solução consiste em encontrar a "melhor" alternativa descrita em termos dos seus atributos (DUCKSTEIN; PARENT, 1994).

Objetivos são declarações sobre o estado desejado de um sistema considerado, por exemplo, a otimização da qualidade ambiental, suprimento de água e qualidade da água. O objetivo é considerado em uma função $\mathrm{F}(\mathrm{x})$, de maximização ou minimização, onde x representa os atributos ou variáveis de decisão associados a um objetivo. Os objetivos são conflitantes, porque a melhora de um objetivo só pode ser alcançada em detrimento de outro, e também não são facilmente medidos em unidade comum. Os problemas multicriteriais relacionados a objetivos são contínuos e a “melhor” solução se encontra dentro de uma região de soluções viáveis (DUCKSTEIN; PARENT, 1994 e MALCZEWSKI, 1999).

Ainda na visão de Malczewski (1999), os problemas de tomada de decisão multicritério envolvem seis componentes: 
1. Objetivo ou conjunto de objetivos;

2. Decisor ou grupo decisor, juntamente com suas preferências em relação à avaliação dos critérios;

3. Conjunto de critérios de decisão, com base no qual os agentes de decisão avaliam o curso das alternativas;

4. Conjunto de alternativas, que representam as variáveis de decisão ou ação;

5. Conjunto de estados da natureza reúne as variáveis incontroláveis, ou ambiente de decisão;

6. Conseqüências da decisão.

A tomada de decisão é um processo que envolve uma seqüência de atividades, com ponto de partida no reconhecimento do processo de decisão e com ponto final nas recomendações (MALCZEWSKI, 1999). O fluxograma abaixo, apresentado na Figura 2, ilustra uma proposta de estrutura para a análise de decisão multicritério.

Algumas técnicas qualitativas de auxílio à tomada de decisão são sugeridas (GOMES et al., 2002):

- Brainstorm;

- Matriz de prioridade;

- $\quad$ Diagrama espinha de peixe;

- $\quad$ Árvores de decisão ou diagrama da árvore;

- Mapas cognitivos.

Segundo Enssilin (2001), um mapa cognitivo é uma forma de representar o problema do decisor, bem como lidar com grupo de decisores, cada qual com o seu próprio problema. Sob o seu ponto de vista, um problema é uma construção pessoal que o indivíduo faz sobre os eventos associados ao contexto decisório.

Os mapas cognitivos servem para auxiliar a representar e definir este problema. Através deles é possível capturar idéias de forma dinâmica e realizar análises posteriores. 


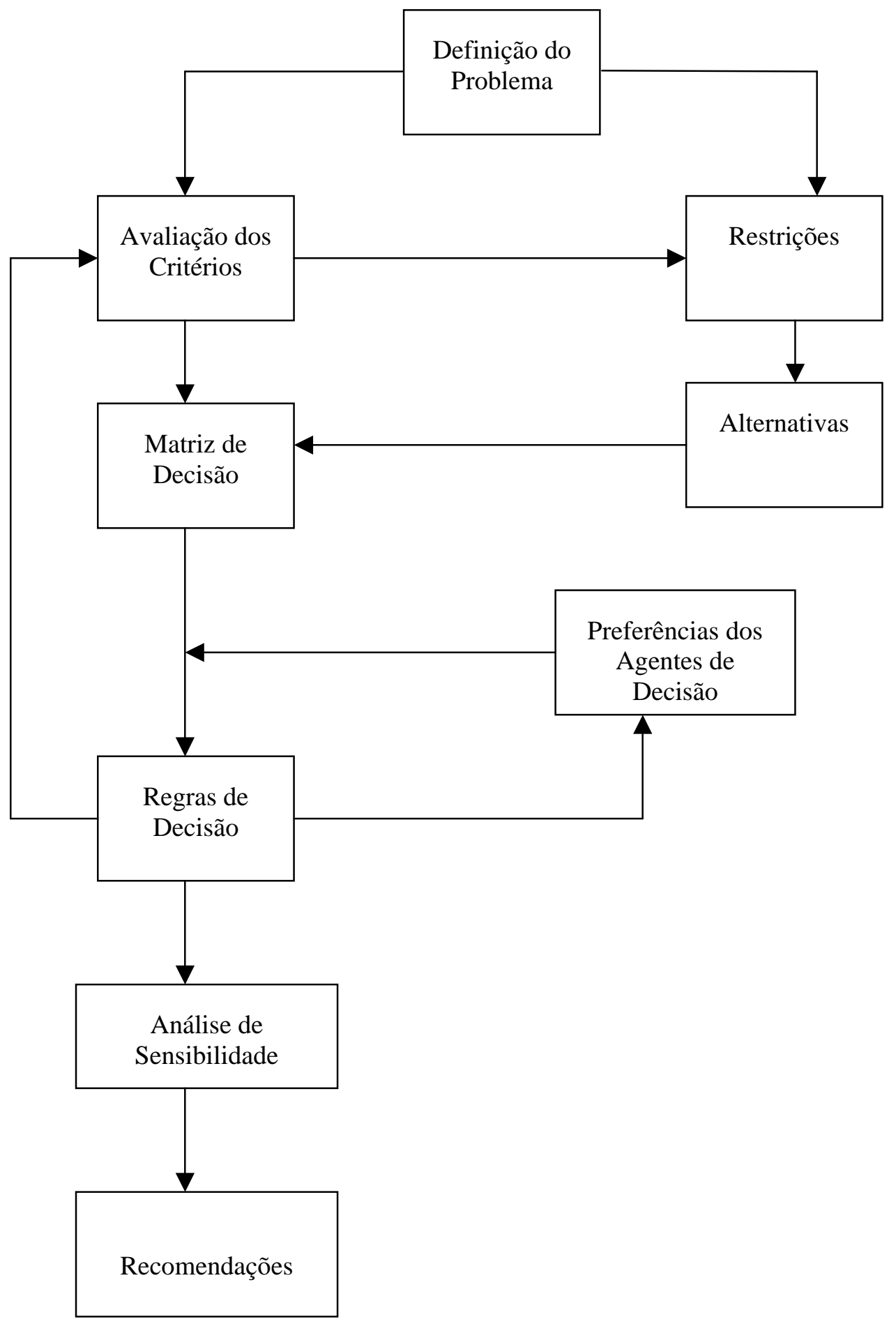

Figura 2. Estrutura de Análise de Decisão Multicritério.

Fonte: Malczewski (1999).

Os métodos multicritério passaram a receber crescente atenção por parte de especialistas e pesquisadores no final da década de 70. Alguns dos métodos 
multicritério mais utilizados que podem ser encontrados na literatura são os seguintes:

- $\quad$ AHP (Analytic Hierarchy Process);

- $\quad$ MAUT (Multiattribute Utility Theory);

- $\quad$ PROMETHEE (Preference Ranking Organization Method);

- $\quad$ TODIM (Tomada de Decisão Interativa e Múlticritério);

- $\quad$ TOPSIS (Technique Order Preference by Similarity to Ideal Solution);

- $\quad$ Electre I;

- $\quad$ Electre II;

- $\quad$ Electre III.

O AHP (Analytic Hierarchy Process) foi desenvolvido pelo matemático Thomas Lorie Saaty, da Wharton Scholl da Universidade da Pensilvânia (EUA), na década de 70. Neste método, um sistema decisório complexo deve ser definido através de uma estrutura hierárquica. Ele permite considerar simultaneamente atributos quantitativos e qualitativos e, também, incorporar a experiência e a preferência dos tomadores de decisão.

A família dos métodos MAUT (Multiattribute Utility Theory), ou Teoria da Utilidade de Múltiplos Atributos, trabalha com a agregação de diferentes pontos de vista e atributos em uma única função, que deve ser otimizada. Este método aceita apenas variáveis quantitativas.

Os métodos AHP e MAUT possuem muitas similaridades na sua implementação, uma vez que ambos são baseados na avaliação de alternativas em termos de uma função de preferência acumulativa (BELTON; STEWART, 2002).

O método PROMETHEE constrói uma relação de classificação, através da comparação entre pares de atributos. Este método busca empregar conceitos e parâmetros, que permitam interpretação numérica. 
O método TODIM, como apresentado em Caixeta-Filho; Martins (2001), introduz o conceito de "Fator de Contingência”, o qual permite a análise das alternativas mesmo quando são totalmente independentes. Este método permite a utilização de atributos quantitativos e qualitativos, e a incorporação de julgamentos de preferência dos tomadores de decisão. Sua principal desvantagem encontra-se na dificuldade da definição dos fatores de contingência.

O TOPSIS é uma técnica que permite a ordenação de alternativas por meio da utilização do conceito de similaridade, e possui características que permitem sua classificação como um método de ranqueamento. Não são encontrados exemplos de aplicação deste método em casos onde há a necessidade de consideração de atributos qualitativos para a análise de decisão (IAÑEZ, 2002).

Segundo Iañez, o trabalho de Roy (1977), lançou as bases para a primeira metodologia efetivamente estruturada para a análise de alternativas com múltiplos objetivos, gerando a família de métodos ELECTRE (Elimination et Choix Traduissant la Realité).

Os métodos ELECTRE (Elimination et Choix Traduissant la Realité) são baseados na avaliação de dois índices, chamados de índice de concordância e índice de discordância. O ELECTRE I é definido como modelo de partição e funciona como auxiliar na identificação da alternativa preferida. O ELECTRE II, desenvolvido logo depois do ELECTRE I, possui como objetivo produzir um ranking de alternativas, no lugar de simplesmente indicar a preferida. O ELECTRE III permite maior sofisticação na modelagem das preferências em critérios individuais. Esta última versão considera diferenças e preferências entre os atributos, associando-lhes pesos. São realizadas comparações entre pares de atributos, com o objetivo de representar a importância relativa entre eles (BELTON; STEWART, 2002).

As principais vantagens da família dos métodos ELECTRE, segundo Iañez (2002), referem-se à consistência de sua base conceitual e à possibilidade de incorporação de 
atributos quantitativos e qualitativos. Suas principais desvantagens estão na falta de controle da sua consistência e a subjetividade nos parâmetros utilizados.

Diferentes técnicas de análise multicriterial produzem resultados diferentes quando aplicadas a um mesmo problema, embora assumindo o mesmo conjunto de limitações, pesos, Tabelas, escalas e outras medidas de preferência. Essas diferenças podem ser causadas por (BOGARDI, NACHTNEBEL, 1994):

- Diferentes formas de inserir as preferências;

- Seqüências distintas na introdução das preferências;

- $\quad$ Diferentes números de parâmetros que descrevem as preferências;

- Definições inadequadas do problema;

- $\quad$ Negligências ao estabelecer o conjunto de decisões (relevância);

- $\quad$ Aplicações de métodos inapropriados ao problema em questão.

Entretanto, as diferenças entre os resultados obtidos, para um determinado problema, devem estar dentro de um limite aceitável.

\subsection{Conclusão do Capítulo}

Os problemas de localização constituem um tema já bastante abordado na literatura. Entretanto, este problema oferece ainda excelentes oportunidades para exploração, devido à existência de diferentes métodos, ou modelos, que podem ser aplicados na sua resolução e também pela crescente importância do tema dentro das organizações.

Uma lista genérica dos fatores relevantes na seleção de locais foi elaborada com base na bibliografia pesquisada e nas diversas listas dos trabalhos citados anteriormente, encerrando um conjunto representativo dos fatores relevantes aos diversos problemas de localização. Adiante, neste trabalho, será elaborada uma lista específica, que atenda as necessidades do caso proposto.

É possível observar que as ferramentas fundamentadas no conceito de Análise Multicritério são adequadas no auxílio da tomada de decisão de problemas 
complexos. Essas ferramentas propiciam a estruturação dos problemas e tornam transparentes seus processos de resolução. Outrossim, permitem agregar valores quantitativos e qualitativos.

Nos capítulos seguintes, explorar-se-á o significado das descobertas acima descritas e suas implicações, tanto do ponto de vista geral, quanto do caso específico tratado no estudo de caso.

Primeiramente, no próximo capítulo, será estabelecida a metodologia para a resolução do problema proposto, com base na literatura pesquisada. E, a seguir, o método escolhido será aplicado ao estudo de caso. Ainda, serão discutidos os resultados, tecidas as conclusões gerais e mencionadas propostas para trabalhos futuros. 


\section{METODOLOGIA ADOTADA}

\subsection{Introdução}

A metodologia, segundo o conceito desenvolvido por Goldenberg (1997), busca estudar os caminhos a serem seguidos e os instrumentos a serem utilizados para a solução de um determinado problema. A metodologia proporciona o questionamento crítico a respeito da construção do objeto científico.

A metodologia apresentada neste trabalho será estruturada da seguinte forma: caracterização do problema, justificativa da escolha do método selecionado para resolução deste problema e apresentação mais detalhada deste método.

A partir da revisão da literatura, avaliou-se que o método AHP (Método da Análise Hierárquica) seria apropriado para a aplicação ao problema proposto, perante suas características e aplicações anteriores.

A Figura 3, a seguir, explica resumidamente os passos de realização deste trabalho, envolvendo desde a primeira etapa da execução do trabalho, que consistiu na definição do plano de pesquisa, até a definição do estudo de caso.

\subsection{Caracterização do Problema de Localização de Plataformas Logísticas}

A caracterização inicial do problema tem a função de deixar explícito o enunciado do problema, delineando a origem e o objetivo que deve ser perseguido.

Neste trabalho as plataformas logísticas são caracterizadas como instalações que reúnem um conjunto de atividades logísticas tais como, transporte, armazenagem e comercialização, encerrando a oferta de bens e serviços à população. 


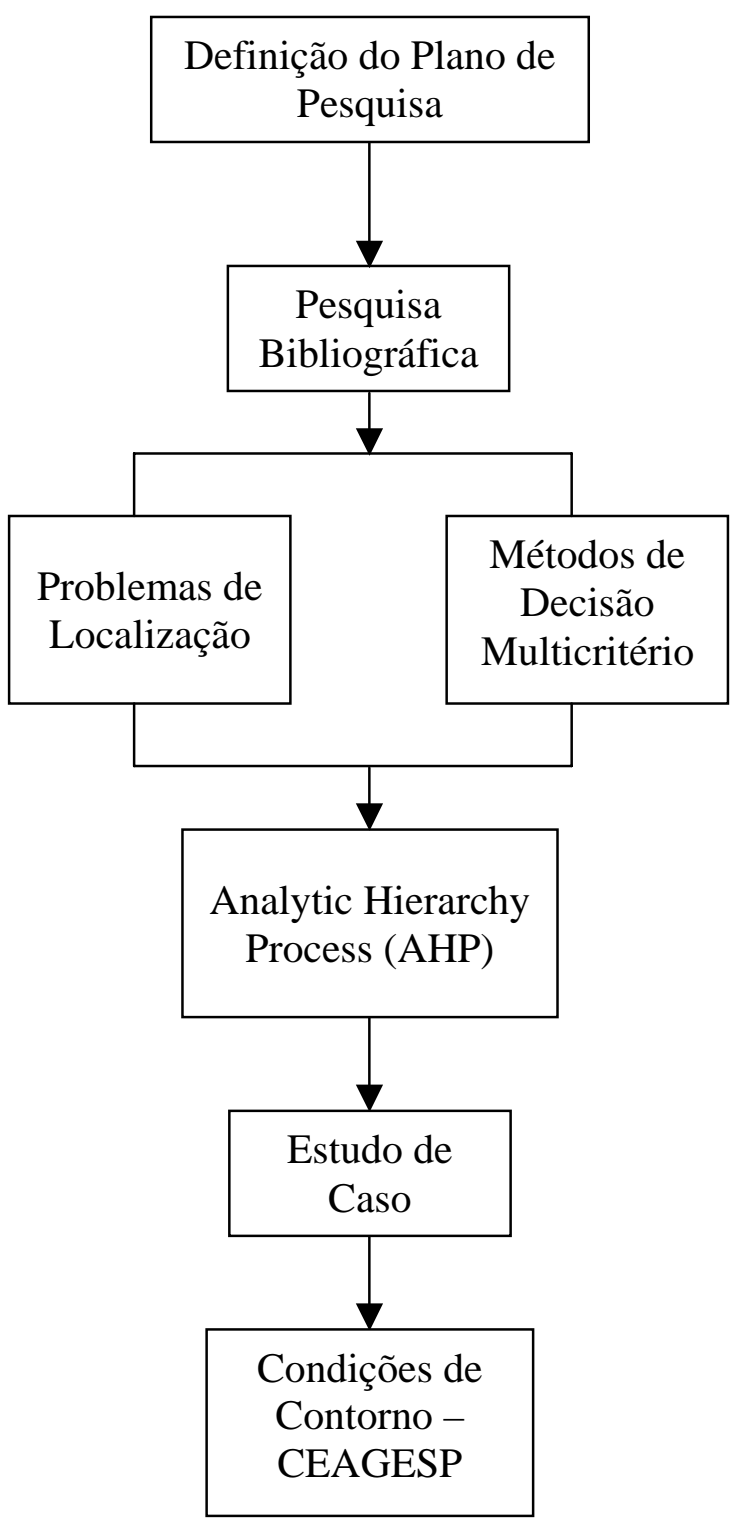

Figura 3. Fluxograma de Apresentação da resolução do problema.

A visão do problema de localização, aplicada às plataformas logísticas, presente neste trabalho estabelece as seguintes diretrizes:

- Definição dos locais candidatos à localização da instalação;

- Determinação dos critérios relevantes no processo de escolha da localização;

- Classificação dos candidatos;

- Escolha da melhor alternativa de localização. 
De uma maneira geral, as diretrizes apresentadas acima fazem parte da metodologia proposta para a resolução de problemas de localização de plataformas logísticas.

Os locais candidatos podem ser selecionados através de uma análise macro, considerando, por exemplo, regiões ou bairros, ou de uma análise micro, por ruas ou terrenos específicos. A análise para a seleção dos locais candidatos no problema proposto foi realizada através de uma visão macro e fundamentada por questões levantadas, por diversos stakeholders, durante a elaboração do trabalho.

Em relação à determinação dos critérios relacionados ao problema, é importante citar todos aqueles envolvidos com o problema e a forma como estes são afetados. Os critérios relevantes para a classificação da “melhor” localização de uma plataforma logística foram selecionados a partir da lista genérica dos fatores relevantes na seleção de locais apresentada no capítulo 2 (item 2.3), de acordo com a sua importância frente ao assunto tratado. Com base nesta lista fundamentada na literatura pesquisada, foram escolhidos aqueles fatores que deveriam ser levados em consideração em um problema genérico de localização de plataformas logísticas. E apenas após o estabelecimento das condições de contorno do caso do ETSP da CEAGESP esta lista genérica foi customizada para atender as particularidades do caso proposto.

Após o estudo dos métodos disponíveis na literatura, e baseando-se em um conjunto de pré-requisitos exigidos pelo problema, selecionou-se a metodologia analítica baseada no AHP (SAATY, 1991) com o objetivo de obter a classificação das alternativas para a localização de plataformas logísticas. A justificativa, mais detalhada, para a escolha do método será explorada no próximo item.

\subsection{Justificativa do Método Selecionado}

Através da revisão da literatura foi possível constatar a existência de inúmeros modelos matemáticos que aderem à questão de localização, envolvendo modelos de otimização, heurísticas, simulação, multicritério, entre outros. A opção pela 
utilização de um método baseado na comparação de pesos, como o AHP, possui diversas justificativas.

Ao se tratar de um problema de uma empresa inserida no setor público, os custos e benefícios não monetários possuem uma relevância significativa e devem ser considerados. Desta forma, os aspectos qualitativos ganham importância e torna-se evidente a necessidade de um método de resolução que seja capaz de tratar tanto aspectos tangíveis quanto intangíveis.

Na visão de Morita (1998), o método AHP se difundiu principalmente devido à reunião de algumas características como simplicidade na aplicação, naturalidade no trato de aspectos subjetivos e a flexibilidade de uso.

No AHP podem ser integradas as questões econômica, social e ambiental. E através deste método há a possibilidade de lidar com múltiplos objetivos conflitantes, sem restrições.

Na medida em que os fatores ambientais, por exemplo, vêm ganhando importância na seleção da localização das instalações, ao mesmo tempo em que grande parte desses fatores ambientais só pode ser avaliada qualitativamente, a comparação por pares, presente no método AHP, mostra-se capaz de capturar a importância relativa entre estes fatores de maneira confiável. É importante ressaltar que apesar da potencialidade do método na captura da importância relativa entre os diversos fatores, a subjetividade presente na avaliação dos critérios pode ocasionar um resultado com alguma imprecisão.

O AHP permite a estruturação de problemas complexos levando em consideração suas particularidades. A elaboração de uma hierarquia de decisão facilita o entendimento da dimensão do problema.

Este método apóia-se no princípio de que os humanos possuem maior facilidade de trabalhar com medidas relativas do que absolutas, ou seja, estabelece a comparação 
entre as alternativas, com o objetivo de indicar aquela que proporciona mais benefícios. E desta forma, possibilita a classificação das alternativas.

Na visão de Nogueira (2002), a maioria dos problemas complexos, envolvendo múltiplos critérios, vários decisores, diversos períodos, pode ser estruturada hierarquicamente pelo AHP. Este é um processo flexível, que permite incluir e medir fatores importantes, quantitativa e qualitativamente.

Entre as desvantagens do AHP, há o risco de inconsistência inerente ao processo decisório. Essa inconsistência deve ser sempre avaliada durante o processo de resolução do problema. Outra dificuldade consiste na quantidade de informações que devem ser buscadas para tornar o problema mais realista.

Porém, a principal justificativa para a utilização do método consiste na possibilidade de tratamento de múltiplos critérios, abrangendo aspectos tangíveis e intangíveis, o que é uma característica fundamental na análise de candidatos sob uma ótica mais ampla.

Para Yang; Lee (1997), o modelo de decisão AHP oferece flexibilidade de combinar as preferências da maioria dos stakeholders envolvidos na decisão de características específicas de localização, e ainda é capaz de incorporar a experiência gerencial e os julgamentos dos agentes de decisão.

Segundo Min (1994), o AHP ajuda o agente de decisão a analisar os diversos tradeoffs entre os critérios conflitantes.

\subsection{O Método Selecionado (AHP)}

O método da análise hierárquica (ou Analytic Hierarchy Process - AHP), primeiramente desenvolvido em 1971, por Saaty, consiste em uma ferramenta de apoio à tomada de decisão para problemas multicritério. O AHP busca estruturar o

problema de maneira hierárquica e permite tratar aspectos quantitativos e 
qualitativos. Através do AHP é possível tratar, de modo quantitativo, aspectos subjetivos.

Este método permite a quebra do problema em partes menores e então os tomadores de decisão, através de uma série de comparações em pares, expressam a intensidade do impacto dos elementos na hierarquia.

Para Saaty (1991), em geral, a tomada de decisão envolve os seguintes tipos de cuidados:

- Planejamento;

- Geração de conjunto de alternativas;

- $\quad$ Estabelecimento de prioridades;

- Escolha da melhor política, após a definição do conjunto de alternativas;

- Alocação de recursos;

- Determinação dos requisitos;

- $\quad$ Previsão dos resultados;

- $\quad$ Projeto dos sistemas;

- $\quad$ Avaliação do desempenho;

- $\quad$ Garantia de estabilidade do sistema;

- Otimização; e, finalmente,

- Resolução de conflitos.

Segundo Saaty (1991) para sermos realistas, nossos modelos têm que incluir e medir todos os fatores importantes, qualitativa e quantitativamente mensuráveis, sejam eles tangíveis ou intangíveis. Um dos objetivos do AHP é aumentar a objetividade e diminuir, ao máximo, a subjetividade.

Resumidamente, segundo Armacost; Hosseini; Javalgi (1990), há três elementos básicos no uso do AHP:

1. Descrever problemas de decisão complexos através de uma hierarquia;

2. Utilizar comparações paritárias para estimar a importância relativa entre os vários critérios, em cada nível da hierarquia; 
3. Integrar as comparações paritárias para desenvolver uma avaliação geral das alternativas.

Através da representação do problema por meio de uma hierarquia é possível estabelecer as interações existentes entre os diversos elementos e verificar as prioridades e as influências entre esses elementos.

A hierarquia é estruturada da seguinte forma: o objetivo geral ou meta do problema encontra-se no topo da hierarquia; abaixo deste nível estão os critérios e sub-critérios que contribuem para a decisão; o último nível encerra as alternativas de decisão selecionadas. A decomposição em níveis hierárquicos facilita a compreensão e avaliação do problema. Na Figura 4 pode ser observado um desenho esquemático de uma hierarquia, representando um problema genérico.

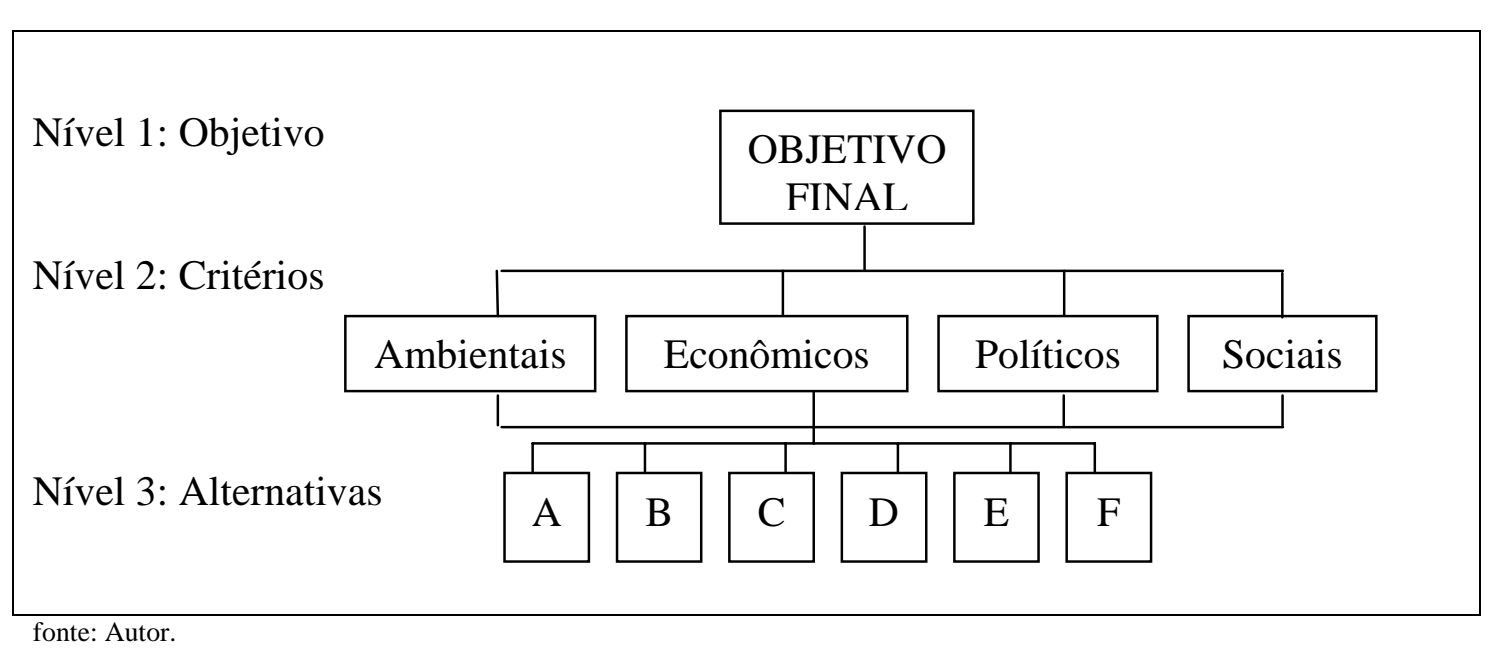

Figura 4. Representação de uma Hierarquia.

Soares (2002) afirma que, no caso de problemas complexos, a possibilidade de constituição de uma hierarquia de decisão, conforme proposto pelo modelo AHP, auxilia o entendimento de objetivos complexos, uma vez que há a possibilidade de decomposição em alvos menores. A visualização do problema através de uma estrutura hierárquica facilita o entendimento da dimensão do problema. 
A identificação da hierarquia de decisão constitui a verdadeira chave do sucesso no uso do AHP. O enfoque sistêmico, tratado previamente na revisão bibliográfica, está claramente ligado à hierarquia dos componentes.

Saaty (1991) estabelece como vantagem básica da hierarquia o fato desta proporcionar a busca do entendimento de seus níveis mais altos a partir das interações entre os vários níveis da hierarquia, ao invés de diretamente entre os elementos dos níveis. E aponta as seguintes vantagens das hierarquias:

- A representação hierárquica de um sistema pode ser usada para descrever como as mudanças em prioridades nos níveis mais altos afetam as prioridades nos níveis mais baixos;

- Oferecem grandes detalhes de informação sobre a estrutura e as funções de um sistema nos níveis mais baixos, permitindo uma visão geral dos atores e de seus propósitos nos níveis mais altos;

- Os sistemas naturais montados hierarquicamente, isto é, através da construção modular e montagem final de módulos, desenvolvem-se muito mais eficientemente do que aqueles montados de um modo geral;

- Eles são estáveis e flexíveis: estáveis porque pequenas modificações têm efeitos pequenos; e flexíveis porque adições a uma hierarquia bem estruturada não perturbam o desempenho.

Depois de definida a hierarquia do problema, os elementos, para cada um dos níveis hierárquicos, são comparados dois a dois, com base nos critérios do nível superior.

Saaty (1991) constata que:

A abordagem de autovalor para comparações paritárias permite um modo de ajustar uma escala numérica, particularmente em áreas novas em que medidas e comparações qualitativas sejam ainda inexistentes. A medida de consistência nos permite retornar aos julgamentos para modificá-los em alguns pontos a fim de melhorar a consistência geral. A participação de várias pessoas permite a compensação entre dados diferentes. Pode ainda favorecer a criação de um diálogo sobre qual deveria ser a relação real: um verdadeiro compromisso entre vários julgamentos representando experiências diversas. 
Segundo Saaty (1991) as fases do processo seguem a seqüência abaixo:

(1) Descrever o problema;

(2) Colocar o problema em um contexto amplo, se necessário, posicionando em um sistema maior, incluindo outros atores, seus objetivos e produtos;

(3) Identificar o critério que influenciaria o desenrolar do problema;

(4) Estruturar uma hierarquia de critério, sub-critério, propriedades das alternativas e as próprias alternativas;

(5) Em um problema com muitas partes, os níveis podem referir-se ao ambiente, atores, objetivos e política dos atores e resultados, dos quais podemos obter o resultado composto;

(6) Para remover as ambigüidades, cada elemento da hierarquia deve ser cuidadosamente definido;

(7) Priorizar os critérios básicos com relação aos seus impactos no objetivo geral denominado foco;

(8) Definir claramente a questão para comparações paritárias sobre cada matriz. Prestar atenção à orientação de cada questão, por exemplo, custos baixam, benefícios aumentam;

(9) Priorizar os sub-critérios com relação aos seus critérios;

(10) Inserir os julgamentos das comparações paritárias e forçar os recíprocos correspondentes;

(11) Calcular as prioridades adicionando os elementos de cada coluna e dividindo cada elemento pelo total da coluna. Tirar a média das linhas da matriz resultante para obter o vetor prioridade;

(12) No caso de cenários, calibrar suas variáveis de estado em uma escala oscilando de -8 a +8 , no quanto eles possam diferir da situação atual, que teria valor zero;

(13) Compor os pesos na hierarquia, para obter as prioridades compostas e também os valores compostos das variáveis de estado, que coletivamente definirão o resultado composto;

(14) No caso de escolha entre as alternativas, selecionar a alternativa de mais alta prioridade; 
(15) No caso de alocação de recursos, avaliar o custo das alternativas, computar a razão custo/benefício e alocar os recursos de acordo com tais resultados. Em um problema de priorização de custos, alocar os recursos proporcionalmente às prioridades.

Os julgamentos consideram os números absolutos de 1 a 9, que constituem uma escala de razão. A Tabela 4 esclarece o significado de cada um dos valores adotados.

Tabela 4- Escala de Razão.

\begin{tabular}{|c|c|c|}
\hline $\begin{array}{l}\text { Intensidade de } \\
\text { Importância }\end{array}$ & Definição & Explicação \\
\hline 1 & mesma importância & $\begin{array}{l}\text { as duas atividades contribuem igualmente } \\
\text { para o objetivo }\end{array}$ \\
\hline 3 & importância pequena de uma sobre a outra & $\begin{array}{l}\text { a experiência e o julgamento favorecem } \\
\text { levemente uma atividade em relação a outra }\end{array}$ \\
\hline 5 & importância grande ou essencial & $\begin{array}{l}\text { a experiência e o julgamento favorecem } \\
\text { fortemente uma atividade em relação a outra }\end{array}$ \\
\hline 7 & importância grande ou demonstrada & $\begin{array}{l}\text { uma atividade é muito fortemente favorecida } \\
\text { em relação a outra; sua dominação de } \\
\text { importância é demonstrada na prática. }\end{array}$ \\
\hline 9 & importância absoluta & $\begin{array}{l}\text { a evidência favorece uma atividade em } \\
\text { relação a outra com o mais alto grau de } \\
\text { certeza. }\end{array}$ \\
\hline $2,4,6,8$ & valores intermediários entre os valores adjacentes & $\begin{array}{l}\text { quando se procura uma condição de } \\
\text { compromisso entre duas definiçõos. }\end{array}$ \\
\hline $\begin{array}{l}\text { recíprocos dos } \\
\text { valores acima de } \\
\text { zero }\end{array}$ & $\begin{array}{l}\text { se a atividade i recebe uma das designações diferentes } \\
\text { acima de zero, quando comparada com a atividade j, então } \\
\text { tem o valor recíproco quando comparada com i }\end{array}$ & uma designação razoável \\
\hline racionais & razões resultantes da escala & $\begin{array}{l}\text { se a consistência tiver que ser forçada para } \\
\text { obter valores numéricos n, para completar a } \\
\text { matriz. }\end{array}$ \\
\hline
\end{tabular}

Fonte: Saaty (1991).

Há quatro tipos de questões que costumam ser lançadas com relação ao processo de julgamento: (1) efeito primário, ou se o julgamento pode tender a dar preferência ao que for examinado primeiro; (2) efeito do mais recente, ou influência da informação mais recente sobre o que ocorreu antes; (3) comportamento dos leigos, onde pessoas assumem funções de outras e apresentam julgamentos por elas sem uma análise total das pessoas por ele representadas; e (4) tendência a aceitar a influência pessoal durante a participação em tomadas de decisão em grupo (SAATY, 1991).

Para introduzir o conceito de prioridade de interdependência como um simples número, inicialmente observa-se que as atividades podem ser interdependentes do 
ponto de vista de algumas propriedades apresentadas na hierarquia, porém não todas. Por exemplo, na produção as atividades podem depender entre si no fluxo dos materiais físicos, entretanto não em suas contribuições particulares para a economia, defesa ou bem-estar (SAATY, 1991).

Os números de prioridade de interdependência são computados do seguinte modo: cada linha de matriz tipo entrada e saída é outra vez ponderada, elemento por elemento, pelo peso independente da atividade recipiente correspondente. A razão para isso é que, se somarmos cada linha para obtermos que o material flui de uma atividade para todas as outras atividades, como uma indicação da prioridade de sua dependência nisto, devemos pesar a quantidade recebida pela importância da atividade recebedora (SAATY, 1991).

De outro modo, uma atividade de baixa prioridade que forneça uma grande quantidade de material para outra atividade de baixa prioridade, receberia uma prioridade alta. Obviamente o recebimento pode, em retorno, fornecer material para uma atividade de alta prioridade. De modo a se levarem em consideração todas as interações de segunda ou mais alta ordem, é necessário aumentar a ordem da matriz resultante para potências mais altas e, em relação às prioridades, deve-se obter a soma normalizada das linhas da matriz limite.

A matriz de comparação é preenchida com base na escala apresentada acima e, desta forma, calcula-se o autovalor e o autovetor da matriz. A ordem de prioridade dos critérios estabelecidos é resultado do autovetor correspondente.

Para a formação das matrizes são realizados julgamentos paritários, dois a dois, de cada fator de um nível, em relação a sua importância no nível superior.

Por convenção, a matriz é sempre preenchida comparando-se a característica que aparece na coluna à esquerda em relação à característica que aparece na linha superior. Depois de preenchidas todas as comparações paritárias, ter-se-á, como o exemplo da Figura 5, abaixo, uma matriz 4 x 4 . 


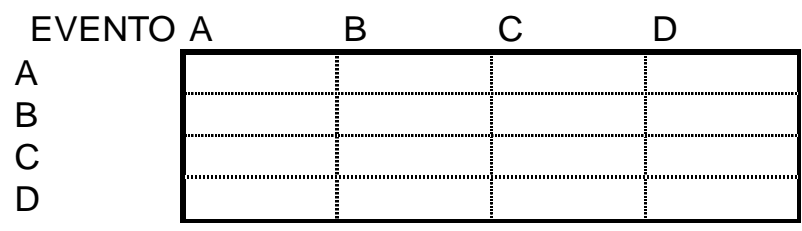

Figura 5. Exemplo de preenchimento de uma matriz de comparação.

Para ilustrar o preenchimento da matriz, tem-se que, dados os elementos A e B, os números escolhidos são os seguintes:

- $\quad$ Se A e B forem iguais em importância, inserir 1;

- $\quad$ Se A for um pouco mais importante que B, inserir 3;

- $\quad$ Se A for muito mais importante que B, inserir 5;

- $\quad$ Se A for claramente ou fortemente mais importante que B, inserir 7;

- $\quad$ Se A for absolutamente mais importante do que B, inserir 9, na posição (A,B) onde a linha A encontra a coluna B.

Na posição (A,A) coloca-se 1. No caso geral, a diagonal principal é preenchida com valores unitários, pois cada elemento, quando comparado consigo mesmo, possui o mesmo nível de importância.

Este procedimento é realizado apenas para matriz retangular superior e, na matriz inferior são inseridos os valores inversos, ou seja, $a_{i j}=\frac{1}{a_{j i}}$. Na posição (B,A), escrevem-se os valores recíprocos apropriados $(1,1 / 3, \ldots, 1 / 9)$. Desta forma, cada par de critérios é julgado apenas uma única vez, gerando $\frac{[n(n-1)]}{2}$ julgamentos, para cada grupo de n elementos.

Os números 2, 4, 6, 8 e seus recíprocos são usados para facilitar compromissos entre julgamentos levemente diferentes daqueles apresentados acima.

Resumindo, o correspondente valor quantitativo, na comparação paritária das matrizes, é o número de vezes que o elemento A é preferível em relação ao elemento 
B. Cada par é comparado sob o ponto de vista de um determinado critério do nível hierárquico superior.

O próximo passo é o cálculo do autovetor, que consiste na representação dos critérios de decisão normalizados. Os anexos A, B e C apresentam, respectivamente, Formas de Cálculo da MCP, Utilização do Autovetor e Cálculo Aproximado do Autovetor.

O AHP é capaz de lidar e absorver julgamentos inconsistentes (MORITA, 1998). A consistência é um critério importante, o qual requer uma avaliação cuidadosa para validar a realidade.

Morita (1998) afirma que o índice de consistência de uma matriz de comparação paritária é usado para mostrar quanto o valor de $\lambda$ máx desta matriz está afastado do valor esperado. O valor teórico esperado de $\lambda$ máx é n, onde n representa o número de fatores de decisão, portanto seu desvio é dado por ( $\lambda$ máx - n). Esta diferença é medida relativamente ao número de graus de liberdade desta matriz (n - 1). Assim podemos definir o índice de consistência de uma MCP como um valor não negativo:

$$
I C=\frac{(\lambda m a ́ x-n)}{(n-1)}
$$

A Tabela 5 mostra os valores dos índices randômicos (I.R.) conforme a ordem das matrizes (n).

Tabela 5- Valores de IR em função da Ordem da Matriz.

\begin{tabular}{|l|r|r|r|r|r|r|r|r|r|r|r|r|r|r|r|}
\hline $\mathrm{n}$ & 1 & 2 & 3 & 4 & 5 & 6 & 7 & 8 & 9 & 10 & 11 & 12 & 13 & 14 & 15 \\
\hline $\mathrm{IR}$ & 0,00 & 0,00 & 0,58 & 0,90 & 1,12 & 1,24 & 1,32 & 1,41 & 1,45 & 1,49 & 1,51 & 1,48 & 1,56 & 1,57 & 1,59 \\
\hline
\end{tabular}

De forma simplificada, Saaty (1991), apresenta os valores do índice de consistência em função da ordem da matriz. A Tabela 6 mostra essa relação.

Tabela 6- Valores de IC máximo em função da ordem da matriz.

\begin{tabular}{l|r|r|r|}
\hline $\mathrm{n}$ & \multicolumn{1}{|c|}{3} & \multicolumn{1}{|c|}{4} & $5 \mathrm{ou}+$ \\
\hline ICmax & $5 \%$ & $8 \%$ & $10 \%$ \\
\hline
\end{tabular}




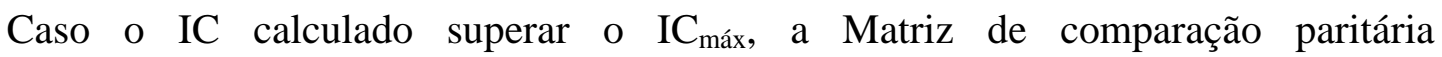
correspondente deve ser revista.

A razão de IC para a IR, média, nas matrizes de mesma ordem, é chamada razão de consistência (RC). Uma razão de consistência de 0,10 ou menor é considerada aceitável.

Em seu trabalho, Iañez (2002) aponta que fica evidenciada a virtude do AHP, de simplificar o trabalho da mente humana em decisões complexas, através da comparação e ponderação de pares de elementos.

Para a aplicação do estudo ao caso de um problema real foi utilizado o software Expert Choice 11, na versão estudantil.

O Expert Choice é um sistema de suporte à decisão que possibilita o tomador de decisão visualizar a estrutura multifacetada do problema na forma de uma hierarquia e então permite que o julgamento aos pares seja realizado de maneira interativa (LIEBOWITZ, 1990).

O software modela automaticamente as matrizes de comparação, conforme a hierarquia de decisão definida pelo usuário. Embora o programa seja reconhecido pela sua eficácia no tratamento dos problemas de decisão, existem outras ferramentas para implementação do AHP. Há a possibilidade de desenvolver o método em planilhas de cálculo, presentes, por exemplo, em programas como o Excel.

\subsection{Conclusão do Capítulo}

Através da caracterização do problema e da definição mais precisa do seu enunciado foi possível escolher, entre os métodos apresentados na revisão bibliográfica, um método para a resolução de problemas de localização de plataformas logísticas. 
O AHP, método selecionado, apresenta-se como um método eficaz na estruturação de problemas de maneira hierárquica e permite tratar aspectos quantitativos e qualitativos simultaneamente.

No capítulo seguinte, será exposta a aplicação do AHP ao problema proposto, seguindo as etapas descritas na metodologia.

O ETSP da CEAGESP surgiu como uma ótima oportunidade de aplicação da teoria estudada. O Entreposto constitui, dentro do conceito previamente definido, um modelo de plataforma logística e está inserido no setor público. Esta última característica confere ao Entreposto a necessidade da avaliação da sua localização através de fatores quantitativos e qualitativos.

Os estudos de localização e uso do solo dependem fortemente da disponibilidade de dados para o tratamento do problema. Esta necessidade também motivou a escolha do ETSP da CEAGESP para o estudo de caso. O trabalho realizado pelo LPT/EPUSP em 2003/2004, para a CEAGESP, possibilitou a utilização dos dados disponíveis na aplicação da teoria. 


\section{CARACTERIZAÇÃO DO PROBLEMA PROPOSTO - O ETSP DA CEAGESP}

A partir do estudo do conceito de plataformas logísticas, buscou-se um modelo deste tipo de instalação para a aplicação da metodologia sugerida. Apesar de haver no Brasil algumas experiências isoladas de implantação de plataformas logísticas, é particularmente difícil encontrar uma instalação deste tipo com infra-estrutura intermodal, por exemplo. A idéia inicial de pautar o problema estudado desta dissertação no ETSP da CEAGESP surgiu depois do conhecimento da proposta de transferir o ETSP para a região do Rodoanel, e a preocupação da administração do ETSP com a melhoria no funcionamento do Entreposto. O Entreposto pode ser considerado um caso particular de plataforma logística, por encerrar em sua estrutura diversas atividades típicas deste tipo de instalação.

A escolha dos locais candidatos à localização do Entreposto foi baseada, em parte, no material do Projeto "Estudos Básicos para Elaboração do Plano Diretor do ETSP da CEAGESP”, realizado pelo LPT/EPUSP (Laboratório de Planejamento e Operação de Transportes / Escola Politécnica da Universidade de São Paulo) em 2003/2004, além de outras fontes de informação disponíveis. Uma das etapas deste projeto foi dedicada ao estudo dos fluxos gerados pelo Entreposto. Foram coletadas informações sobre a origem e o destino das mercadorias comercializadas. Além dos locais de origem e destino, há informações sobre a natureza do destinatário, os tipos de carga, os tipos de veículo utilizados e os horários de movimentação no Entreposto. Todos esses dados ajudaram a definir melhor o problema inicialmente proposto.

Com base nessas informações e ainda em discussões com especialistas e interessados diretos no caso, foi possível estabelecer três cenários de estudo. O primeiro deles privilegia o atual posicionamento do ETSP da CEAGESP, na Vila Leopoldina, região Oeste da cidade de São Paulo. O segundo sugere a mudança do Entreposto para a região do Rodoanel, seguindo discussões levantadas previamente. E o terceiro cenário propõe a descentralização do ETSP da CEAGESP, com uma proposta inicial 
de a ativação de uma nova unidade na região da zona Leste do município de São Paulo.

\subsection{Histórico do ETSP da CEAGESP}

O ETSP da CEAGESP é considerado o maior Entreposto de hortifrutícolas do Brasil e da América Latina. Atualmente, o Entreposto comercializa produtos provenientes de 1278 municípios (32,21\% do total dos municípios brasileiros), 22 estados e 9 países. Através do ETSP comercializa-se $24,56 \%$ de todo o volume comercializado nas centrais de abastecimento do país, abastecendo cerca de $60 \%$ da região Metropolitana de São Paulo e parte do país.

A história da CEAGESP começou com a CAGESP (Cia. de Armazéns do Estado de S. Paulo), criada em 1930 com objetivo de estabelecer, construir e comprar armazéns.

Em 31 de maio de 1969 ocorreu a fusão entre a CEASA (Central Estadual de Abastecimento S/A.) e a CAGESP (Cia. de Armazéns Gerais do Estado de S. Paulo), dando origem à CEAGESP - Companhia de Entrepostos e Armazéns Gerais de São Paulo, que passou a acumular as funções da CEASA, locando espaços para a comercialização de produtos hortigranjeiros, além de armazenagem e comercialização de pescado, e as da CAGESP, realizando a locação de espaços voltados para a armazenagem e conservação de grãos e outros produtos, bem como administrando o exercício dessas atividades.

A CEAGESP, hoje vinculada ao Ministério da Agricultura e do Abastecimento, possui a maior rede de armazéns do Estado de São Paulo. Sua rede de armazéns é composta por 40 unidades localizadas em todo o Estado de São Paulo, com capacidade estática de 1,3 milhões de toneladas. A cobrança dos serviços prestados mantém a CEAGESP. 
Desde 1999, as mercadorias estocadas na CEAGESP podem ser negociadas através do sistema de Leilão Eletrônico do Banco do Brasil S.A., que está conectado a todas as Bolsas de Mercadorias existentes no país.

A sede da CEAGESP, com área de aproximadamente $700 \mathrm{mil} \mathrm{m}^{2}$, localizada na Vila Leopoldina, concentra hoje a comercialização de mais de 10 mil toneladas de alimentos por dia. Há uma circulação diária no local de aproximadamente 50 mil pessoas e 10 mil caminhões. É importante ressaltar que $90 \%$ do transporte, dos produtos comercializados, é realizado por caminhões.

Além de sua atividade atacadista, a CEAGESP também atua no comércio varejista de hortifrutigranjeiros e outros produtos. São 47 unidades varejistas que respondem pela comercialização de mais de 11 mil toneladas por mês. Nos varejões, sacolões e comboios, o consumidor pode comprar produtos cuja qualidade e preços são fiscalizados diariamente pela CEAGESP, que estabelece o limite de lucro do comerciante: $20 \%$ sobre o valor do atacado. No ano de 2004, o fluxo financeiro diário do Entreposto atingiu o valor de R \$ 9,7 milhões.

Produtores rurais, órgãos governamentais, empresas exportadoras e importadoras, cooperativas, empresas rurais e usinas destacam-se como os principais clientes dos armazéns da CEAGESP.

No caso mais específico do ETSP da CEAGESP podem-se considerar ainda os fornecedores, permissionários e consumidores (atacadistas e varejistas) pertencentes ao grupo de clientes.

O conjunto das dimensões que devem ser consideradas e analisadas quando se refere aos clientes incluem: qualidade, preço e disponibilidade. A ponderação destas dimensões pode ser verificada na lista de fatores relevantes no problema de localização do Entreposto. 


\subsection{CEAGESP como Plataforma Logística}

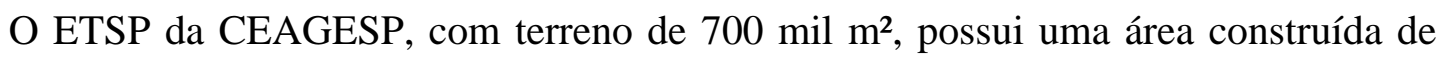
$271 \mathrm{mil} \mathrm{m}^{2}$. O volume de comercialização deste Entreposto é de, em média, 240 mil toneladas por mês.

O ETSP da CEAGESP ajusta-se ao conceito, discutido anteriormente, de plataforma logística. O ETSP da CEAGESP é uma instalação que reúne várias atividades logísticas tais como, transporte, armazenagem e comercialização, encerrando a oferta de bens e serviços à população.

O objetivo do ETSP, como plataforma logística, está em fazer uso eficaz e eficiente do seu espaço, porém a eficiência das suas instalações está longe de ser um fato e há um esforço da gerência atual do Entreposto em alcançar este objetivo.

O Entreposto constitui uma instalação responsável pela geração de impactos de ordem social, econômica, ambiental, e política, na região do seu entorno. É possível que uma instalação deste porte contribua para geração de empregos, aumento do tráfego urbano e degradação do entorno.

Além dos serviços de comercialização que acontecem no entreposto, os serviços prestados pelos armazéns da CEAGESP incluem:

- Armazenagem e estocagem;

- Transbordo;

- $\quad$ Amostragem de grãos;

- Limpeza;

- Secagem;

- $\quad$ Tratamento fito sanitário - expurgo;

- Aeração;

- Venda através de leilão.

Apesar do Entreposto não possuir a característica da intermodalidade, presente nas plataformas logísticas européias, ele constitui um ponto de chave da cadeia logística, 
onde estão concentradas atividades e funções que agregam valor aos produtos comercializados.

\subsection{Características do ETSP da CEAGESP}

Ao longo deste estudo algumas premissas serão adotadas com base na pesquisa exploratória do ETSP da CEAGESP, realizada pelo LPT/EPUSP em 2003/2004. Esta pesquisa fez parte do trabalho "Estudos básicos para a elaboração do plano diretor do ETSP”, que foi coordenado pelo Prof. Dr. Nicolau D. Fares Gualda.

Em uma primeira análise, o trabalho, realizado pelo LPT/EPUSP, apontou que a atual localização do ETSP da CEAGESP, na Vila Leopoldina, é estratégica. Além disso, uma outra conclusão extraída consiste no seguinte fato: caso haja uma reorganização espacial, é possível aumentar a capacidade do Entreposto e, desta forma, aumentar também a eficácia na execução das suas atividades.

Este estudo ainda aponta que aproximadamente $68 \%$ do total comercializado no ETSP, chega pelas rodovias Regis Bittencourt, Presidente Castello Branco, Raposo Tavares, Bandeirantes e Anhanguera. Tais rodovias estão orientadas para a região do Jaguaré e da Vila Leopoldina, onde o Entreposto está localizado, com acesso pela marginal ou pelo Rodoanel.

Abaixo são apresentados alguns resultados obtidos com a Pesquisa de Campo Exploratória realizada pelo LPT/EPUSP na CEAGESP no dia 17 de maio de 2004, no período das 09 h00 às $16 \mathrm{~h} 00$, no ETSP. Esta pesquisa gerou alguns resultados através de entrevistas realizadas com os usuários da CEAGESP. A amostragem dos entrevistados foi aleatória, com base no universo de compradores, em cada setor de comercialização.

Um total de 291 entrevistas foi realizado. Depois do devido tratamento dos dados, restaram 280 entrevistas para a análise. Na etapa de tratamento dos dados foram eliminadas as entrevistas com incoerências no item de destino das mercadorias. A 
equipe que realizou a entrevista também cadastrou 1177 veículos, os quais se encontravam nos estacionamentos e áreas de carregamento e descarregamento dos pavilhões.

Apesar de o universo amostral parecer reduzido, através desta pesquisa foi possível fazer uma fotografia do funcionamento do Entreposto, incluindo suas atividades e movimentações.

Os dados das entrevistas aos usuários da CEAGESP foram agrupados com o objetivo de levantar informações a respeito do funcionamento do Entreposto. Nas Tabelas abaixo, se encontram dados sobre a participação relativa dos diversos tipos de usuários, segundo os municípios de destino das mercadorias comercializadas, sobre a tipologia dos veículos utilizados, sobre os diversos destinatários e sobre tipos de mercadorias comercializadas.

Em relação ao destino das mercadorias, a Tabela 7 mostra a distribuição dos usuários da CEAGESP, de acordo com as regiões, incluindo Brasil e América do Sul. As respostas caracterizadas como “não identificadas”, referem-se aos entrevistados que não possuíam informações a respeito do destino da carga.

Tabela 7- Regiões, Brasil e Mercosul, de Destino das Mercadorias.

\begin{tabular}{|l|r|r|}
\hline \multicolumn{1}{|c|}{ Regiões } & Quant & \multicolumn{1}{c|}{$\%$} \\
\hline \hline Região Norte & 2 & 0,71 \\
\hline Região Nordeste & 1 & 0,36 \\
\hline Região Centro-Oeste & 4 & 1,43 \\
\hline Região Sul & 19 & 6,79 \\
\hline Região Sudeste & 107 & 38,21 \\
\hline Grande São Paulo & 142 & 50,71 \\
\hline Mercosul & 1 & 0,36 \\
\hline Não Identificado & 4 & 1,43 \\
\hline TOTAL & 280 & 100,00 \\
\hline
\end{tabular}

(1) Região Sudeste exceto a Grande São Paulo (Município de São Paulo, ABCD, Osasco e Guarulhos) Fonte: Pesquisa de Campo realizada em 17/05/2004, pelo LPT/EPUSP.

A Tabela 8 apresenta a distribuição das mercadorias para os estados da região Sudeste. É importante salientar que, o dado referente ao Estado de São Paulo exclui 
as mercadorias que possuem como destino a Região Metropolitana de São Paulo, que inclui, além do próprio Município de São Paulo, as cidades do ABCD, Osasco e Guarulhos.

Tabela 8- Estados, da Região Sudeste, de Destino das Mercadorias.

\begin{tabular}{|l|r|r|}
\hline \multicolumn{1}{|c|}{ Estado } & Quant & $\%$ \\
\hline \hline Rio de Janeiro & 6 & 5,61 \\
\hline Minas Gerais & 8 & 7,48 \\
\hline Espírito Santo $^{1}$ & 2 & 1,87 \\
\hline São Paulo & 91 & 85,05 \\
\hline TOTAL & 107 & 100,00 \\
\hline
\end{tabular}

(1) Estado de São Paulo exceto a Grande São Paulo (Município de São Paulo, ABCD, Osasco e Guarulhos) Fonte: Pesquisa de Campo realizada em 17/05/2004, pelo LPT/EPUSP.

Através dos dados apresentados verifica-se que há uma concentração geográfica dos destinos das mercadorias comercializadas no ETSP para a Região Metropolitana de São Paulo, que representam 51,7\% do total de usuários do mercado. O município de São Paulo concentra 39,3\% do total de usuários. O Estado de São Paulo é destino de 233 dos entrevistados.

As Tabelas 9 e 10, respectivamente, mostram o destino das mercadorias para as Regiões e Municípios do Estado de São Paulo e para a Região Metropolitana de São Paulo.

Tabela 9- Regiões e Municípios, do Estado de São Paulo, de Destino das Mercadorias.

\begin{tabular}{|l|r|r|}
\hline Regiões e Municípios & Quant & \multicolumn{1}{c|}{$\%$} \\
\hline \hline Interior & 80 & 34,33 \\
\hline Litoral & 11 & 4,72 \\
\hline SubTotal & 91 & 39,06 \\
\hline Município de São Paulo & 110 & 47,21 \\
\hline ABCD & 15 & 6,44 \\
\hline Osasco & 8 & 3,43 \\
\hline Guarulhos & 9 & 3,86 \\
\hline Grande São Paulo & 142 & 60,94 \\
\hline TOTAL & 233 & 100,00 \\
\hline
\end{tabular}

Fonte: Pesquisa de Campo realizada em 17/05/2004, pelo LPT/EPUSP. 
Tabela 10- Destino das Mercadorias por Zonas e Municípios da Região Metropolitana de São Paulo.

\begin{tabular}{|l|r|r|}
\hline \multicolumn{1}{|c|}{ Zonas e Municípios } & Quant & $\%$ \\
\hline \hline Zona Leste & 20 & 14,08 \\
\hline Zona Oeste & 29 & 20,42 \\
\hline Zona Sul & 33 & 23,24 \\
\hline Zona Norte & 15 & 10,56 \\
\hline Centro & 8 & 5,63 \\
\hline Mais de uma Zona & 5 & 3,52 \\
\hline Município de São Paulo & 110 & 77,46 \\
\hline ABCD & 15 & 10,56 \\
\hline Osasco & 8 & 5,63 \\
\hline Guarulhos & 9 & 6,34 \\
\hline Região Metropolitana de São Paulo & 142 & 100,00 \\
\hline
\end{tabular}

Fonte: Pesquisa de Campo realizada em 17/05/2004, pelo LPT/EPUSP.

A Tabela 11 mostra a distribuição dos usuários do ETSP segundo a natureza e tipos dos equipamentos de destino das mercadorias comercializadas. É importante observar a grande diversidade de tipos de destinatário, pertencentes tanto ao varejo quanto ao atacado. Apesar da diversidade de tipos de destinatário, nota-se que o cliente atacadista ainda é o foco do negócio do Entreposto, pois ele aparece como a maior parte do destino das mercadorias.

A Tabela 12 mostra a participação relativa dos diversos tipos de cargas no destino das mercadorias comercializadas no ETSP. Observa-se a participação expressiva das frutas dentre as mercadorias.

A Tabela 13 apresenta a participação relativa dos diversos tipos de cargas na origem das mercadorias comercializadas no ETSP. Neste caso, é importante ressaltar a grande participação de Veículos que chegaram ao ETSP vazios ou que transportavam apenas caixas vazias. 
Tabela 11- Destino das Mercadorias Comercializadas, segundo a Natureza do Destinatário.

\begin{tabular}{|c|c|c|}
\hline Destinatário & Quant & $\%$ \\
\hline Sem especificação & 47 & $\overline{16,79}$ \\
\hline Feira-livre & 36 & 12,86 \\
\hline Supermercado & 35 & 12,50 \\
\hline Sacolão & 34 & 12,14 \\
\hline Mercado & 21 & 7,50 \\
\hline Produtor & 20 & 7,14 \\
\hline Varejão & 18 & 6,43 \\
\hline Distribuidora & 13 & 4,64 \\
\hline Restaurante/Hotel & 12 & 4,29 \\
\hline Outros Ceasas & 12 & 4,29 \\
\hline Quitanda & 8 & 2,86 \\
\hline Armazém & 5 & 1,79 \\
\hline Hospital/Escola & 3 & 1,07 \\
\hline Entregas & 3 & 1,07 \\
\hline Ambulantes & 2 & 0,71 \\
\hline Diversos & 5 & 1,79 \\
\hline Lojas & 2 & 0,71 \\
\hline Empresa & 1 & 0,36 \\
\hline Firma de exportação & 1 & 0,36 \\
\hline Frigorífico & 1 & 0,36 \\
\hline Frutaria & 1 & 0,36 \\
\hline TOTAL & 280 & 100,00 \\
\hline
\end{tabular}

Fonte: Pesquisa de Campo realizada em 17/05/2004, pelo LPT/EPUSP

Tabela 12- Destino das Mercadorias Comercializadas, segundo o Tipo de Carga.

\begin{tabular}{|l|r|r|}
\hline \multicolumn{1}{|c|}{ Tipo de Carga } & Quant & \multicolumn{1}{c|}{$\%$} \\
\hline \hline Várias & 67 & 23,93 \\
\hline Frutas & 59 & 21,07 \\
\hline Vazio & 31 & 11,07 \\
\hline Frutas e Legumes & 29 & 10,36 \\
\hline Legumes & 27 & 9,64 \\
\hline Frutas, Legumes e Verduras & 26 & 9,29 \\
\hline Caixas Vazias & 21 & 7,50 \\
\hline Não Identificado & 8 & 2,86 \\
\hline Cebola, Batata e Mandioca & 5 & 1,79 \\
\hline Verduras & 3 & 1,07 \\
\hline Outros (Tinta, Adubo, etc) & 3 & 1,07 \\
\hline Legumes e Verduras & 1 & 0,36 \\
\hline Flores & - & 0,00 \\
\hline SOMA & 280 & 100,00 \\
\hline
\end{tabular}

Fonte: Pesquisa de Campo realizada em 17/05/2004, pelo LPT/EPUSP. 
Tabela 13- Origem das Mercadorias Comercializadas, segundo o Tipo de Carga.

\begin{tabular}{|l|r|r|}
\hline \multicolumn{1}{|c|}{ Tipo de Carga } & Quant & \multicolumn{1}{c|}{$\%$} \\
\hline \hline Vazio & 159 & 56,79 \\
\hline Caixas Vazias & 31 & 11,07 \\
\hline Frutas & 23 & 8,21 \\
\hline Legumes & 22 & 7,86 \\
\hline Não Identificado & 13 & 4,64 \\
\hline Cebola, Batata e Mandioca & 12 & 4,29 \\
\hline Verduras & 5 & 1,79 \\
\hline Várias & 5 & 1,79 \\
\hline Outros (Tinta Adubo Bobina) & 5 & 1,79 \\
\hline Frutas e Legumes & 3 & 1,07 \\
\hline Mandioca e Verdura & 1 & 0,36 \\
\hline Frutas, Legumes e Verduras & 1 & 0,36 \\
\hline Flores & - & 0,00 \\
\hline SOMA & 280 & 100,00 \\
\hline
\end{tabular}

Fonte: Pesquisa de Campo realizada em 17/05/2004, pelo LPT/EPUSP.

A Tabela 14 mostra a distribuição da frota de veículos utilizada pelos usuários do CEAGESP, por tipo de veículo. Os caminhões são os veículos de transporte predominantemente utilizados pelos compradores em geral, com maior participação para os caminhões com dois e três eixos.

Tabela 14- Veículos de Transporte Utilizados pelos Usuários.

\begin{tabular}{|l|r|r|}
\hline \multicolumn{1}{|c|}{ Veículo } & Quant & \multicolumn{1}{c|}{$\%$} \\
\hline \hline Passeio & 1 & 0,36 \\
\hline Pick-up & 6 & 2,14 \\
\hline Van & 0 & 0,00 \\
\hline Furgão & 10 & 3,57 \\
\hline Kombi & 19 & 6,79 \\
\hline Caminhão ${ }^{1}$ & 81 & 28,93 \\
\hline $\mathrm{C}(2, \mathrm{~A})$ & 47 & 16,79 \\
\hline $\mathrm{C}(2, \mathrm{~B})$ & 2 & 0,71 \\
\hline $\mathrm{C}(2, \mathrm{~F})$ & 82 & 29,29 \\
\hline $\mathrm{C}(3, \mathrm{~A})$ & 16 & 5,71 \\
\hline $\mathrm{C}(3, \mathrm{~B})$ & 2 & 0,71 \\
\hline $\mathrm{C}(3, \mathrm{~F})$ & 1 & 0,36 \\
\hline $\mathrm{C}(4, \mathrm{~A})$ & 0 & 0,00 \\
\hline $\mathrm{C}(4, \mathrm{~B})$ & 0 & 0,00 \\
\hline $\mathrm{C}(4, \mathrm{~F})$ & 3 & 1,07 \\
\hline $\mathrm{C}(5, \mathrm{~A})$ & 2 & 0,71 \\
\hline $\mathrm{C}(5, \mathrm{~B})$ & 1 & 0,36 \\
\hline $\mathrm{C}(5, \mathrm{~F})$ & 0 & 0,00 \\
\hline $\mathrm{C}(6, \mathrm{~A})$ & 4 & 1,43 \\
\hline $\mathrm{C}(6, \mathrm{~B})$ & 1 & 0,36 \\
\hline $\mathrm{C}(6, \mathrm{~F})$ & 2 & 0,71 \\
\hline Não Identificado & 280 & 100,00 \\
\hline SOMA & & \\
\hline
\end{tabular}

(1) No caso dos Caminhões foi adotada a seguinte notação $C(e, t)$, onde e é o $n^{\circ}$ de eixos do caminhão e t é o tipo da carreta (Aberta, Baú ou Frigorífico).

Fonte: Pesquisa de Campo realizada em 17/05/2004, pelo LPT/EPUSP. 
O conjunto de informações fornecido pelas Tabelas apresentadas acima auxilia a caracterização do problema e do ambiente no qual ele está inserido.

A Figura 6 abaixo mostra de forma ilustrativa os fluxos de entrada das mercadorias comercializadas no ETSP da CEAGESP. Os resultados desta ilustração refletem os dados fornecidos pelo departamento de informática do ETSP e traduzem os dados extraídos das notas, das quantidades de notas, por município de origem, referente ao ano de 2000. É importante notar que a somatória das porcentagens que aparecem na Figura não alcança $100 \%$, isso porque apenas $84,71 \%$ do total de notas recebidas no ano de 2000 possuía informações que atendiam os objetivos desta análise. A Tabela 15 mostra como os dados foram processados.

Tabela 15- Resumo das Quantidades, em kg e em notas, por Via de Acesso a São Paulo.

\begin{tabular}{|l|r|r|r|r|}
\hline \multirow{2}{*}{ VIA DE ACESSO } & \multicolumn{3}{|c|}{2000} \\
\cline { 2 - 5 } & quant. (notas) & \% (em notas) & quant. (em kg) & \% (em kg) \\
\hline \hline SP 270 - Raposo Tavares & 216.643 & 26,88 & 405.282 .439 & 15,48 \\
\hline SP 330 - Anhanguera & 136.046 & 16,88 & 703.362 .782 & 26,87 \\
\hline SP 280 - Castello Branco & 113.050 & 14,03 & 229.051 .240 & 8,75 \\
\hline BR 116 (sul) - Regis Bittencourt & 53.663 & 6,66 & 193.721 .937 & 7,40 \\
\hline BR 116 (norte) - Via Dutra & 47.355 & 5,88 & 263.789 .586 & 10,08 \\
\hline SP 066 - (Suzano/Mogi) & 44.332 & 5,50 & 27.295 .131 & 1,04 \\
\hline BR 381 - Fernão Dias & 42.867 & 5,32 & 94.473 .368 & 3,61 \\
\hline SP 348 - Bandeirantes & 25.048 & 3,11 & 39.014 .285 & 1,49 \\
\hline SP 150 - Via Anchieta & 3.760 & 0,47 & 7.751 .938 & 0,30 \\
\hline Totais Computados & 682.764 & 84,71 & 1.963 .742 .706 & 75,02 \\
\hline Não Identificado & - & 0,00 & 4.165 .748 & 0,16 \\
\hline Transferência & 69.043 & 8,57 & 384.581 .145 & 14,69 \\
\hline São Paulo & 3.340 & 0,41 & 857.872 & 0,03 \\
\hline Totais Analisados & 755.147 & 93,69 & 2.353 .347 .471 & 89,91 \\
\hline TOTAIS MOVIMENTADOS & 805.989 & 100,00 & 2.617 .540 .770 & 100,00 \\
\hline
\end{tabular}




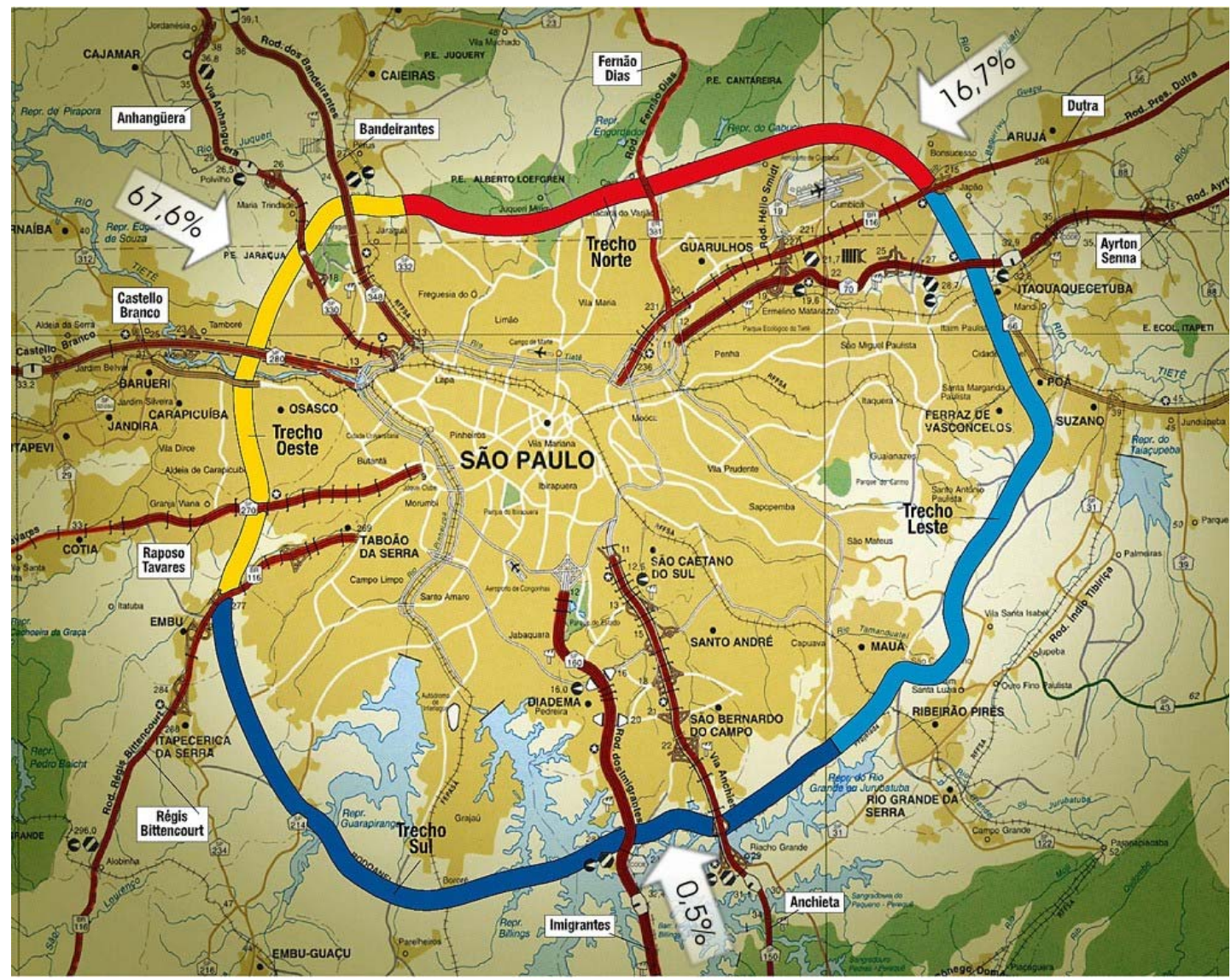

Figura 6. Ilustração dos fluxos de origem das mercadorias comercializadas pelo ETSP da CEAGESP.

Ainda com base no Projeto "Estudos Básicos para Elaboração do Plano Diretor do ETSP da CEAGESP”, realizado pelo LPT/EPUSP (Laboratório de Planejamento e Operação de Transportes / Escola Politécnica da Universidade de São Paulo) em 2003/2004, para a companhia, foram identificados três objetivos centrais da CEAGESP:

1. Contribuir para o abastecimento de produtos (flores, frutas, legumes, etc), com qualidade adequada, disponibilidade e preço justo para o consumidor;

2. Regular o mercado (Estado de São Paulo), em termos de quantidades e preços, através de atuação na governança das cadeias de abastecimento. Este objetivo possui um caráter social que visa o mercado como um todo;

3. Obter remuneração para os recursos empregados e gerar excedente (margem) que permita realizar investimentos na CEAGESP, nas cadeias de abastecimento e na sociedade. 
É importante, ao longo de todo o estudo, cuidar do conjunto de objetivos da organização. Evidentemente, esse conjunto de objetivos deve ser buscado de maneira balanceada, de forma a garantir a sustentabilidade do negócio a longo prazo. Entende-se que a CEAGESP tem como missão servir como central de abastecimento de determinados produtos (frutas, legumes, verduras) notadamente para o Estado de São Paulo, operando no estágio de atacado e, dependendo do produto, também em outros estágios (semi-atacado, varejo, etc).

O Estudo ainda aponta para possíveis dificuldades estratégicas e operacionais que ocasionaram problemas no direcionamento de longo prazo, com uma conseqüente perda de foco de atuação da organização. Em função disso, com o passar do tempo, o valor gerado para os stakeholders em geral e, em particular, para os clientes, diminui, podendo ter levado, em muitos casos, à perda de clientes. A situação se complica em função de o cliente ter presença física junto às instalações da organização.

A perda de foco presente na CEAGESP se deve ao fato das operações do Entreposto não se limitarem apenas às atividades típicas de uma central de abastecimento, estendendo-se a outras como, por exemplo, comércio de roupa, alimentos, etc. Além disso, há grandes deficiências nas atividades de manutenção, nos horários de funcionamento adotados, no layout da instalação e nos sistemas de informação, entre outros.

O problema do ETSP da CEAGESP foi trabalhado através de uma visão macro. Na perspectiva macro, o problema possui como unidades de análise as regiões da cidade de São Paulo e seu entorno (Região Metropolitana de São Paulo). Neste caso, a visão micro poderia ser representada pela análise com base em ruas, restringindo a solução do problema. A escolha da análise em nível macro justifica-se na adequação desta visão aos fatores escolhidos para a avaliação das alternativas.

Como o problema de localização está inserido no nível estratégico de planejamento, é aconselhável trabalhar com dados de forma agregada, pois ao longo do tempo podem ocorrer mudanças que tornem o estudo obsoleto, caso ele tenha sido trabalhado ponto a ponto. Uma análise levando-se em consideração a visão micro 
poderia se tornar exaustiva, por ser muito detalhada, com alternativas muito pontuais e com muitas particularidades.

A determinação dos critérios relevantes para a classificação da "melhor” localização do ETSP da CEAGESP partiu da lista genérica dos fatores relevantes na seleção de locais apresentada no capítulo 2 (item 2.3) e de forma resumida na Tabela 2 (pg. 22). No capítulo cinco, serão detalhados os passos que resultaram na lista específica para o estudo de caso deste trabalho.

\subsection{Conclusão do Capítulo}

A escolha do ETSP da CEAGESP para o estudo de caso da presente pesquisa surgiu a partir da discussão a respeito da transferência do ETSP para a região do Rodoanel, e suas possíveis conseqüências.

O Entreposto é uma instalação de grande porte, responsável pela geração de impactos sociais, econômicos, ambientais e políticos. E a questão da sua localização pode gerar grande conflito de interesses. Fornecedores, permissionários e consumidores (atacadistas e varejistas) pertencem ao grupo de clientes e interessados nas questões que envolvem o ETSP da CEAGESP. As decisões tomadas por esta organização atingem, direta ou indiretamente, outros grupos da sociedade.

A escolha dos locais candidatos e a determinação dos critérios relevantes à localização do Entreposto foram baseadas no material do Projeto "Estudos Básicos para Elaboração do Plano Diretor do ETSP da CEAGESP”, realizado pelo LPT/EPUSP, em reuniões com os envolvidos diretamente nas questões da CEAGESP e também na pesquisa bibliográfica previamente realizada. 


\section{APLICAÇÃO AO PROBLEMA PROPOSTO - O ETSP DA CEAGESP}

Neste capítulo, aplica-se o AHP para a análise da questão de localização de uma plataforma logística. Neste estudo, a plataforma logística considerada consiste em uma central de abastecimento pública muito conhecida em todo Estado de São Paulo, a CEAGESP. Mais especificamente, o sítio analisado é o Entreposto Terminal São Paulo, localizado na zona Oeste do município de São Paulo.

\subsection{Parâmetros Empregados}

Num primeiro instante, a fim de facilitar a exposição, foi admitida uma série de suposições bastante simplificadas, a partir das quais se construiu um modelo inicial aplicável às plataformas logísticas. Em seguida, buscou-se maior aproximação com a realidade, principalmente através de discussões do problema com pessoas pertencentes à administração do ETSP da CEAGESP e com base em dados reais.

A definição dos locais candidatos à localização das instalações consiste em um passo crucial para o sucesso da resolução do problema. Porém, Vallim Filho (2004) afirma que a literatura é muito escassa em procedimentos quantitativos para a seleção de candidatos. O tratamento que vem sendo dado ao assunto tem um viés acentuadamente qualitativo. Os textos que são encontrados apresentam, em geral, determinadas condições que os locais potenciais devem ter, sugerindo, por exemplo, que o zoneamento da região deve permitir instalações industriais e circulação de veículos de carga, que os locais devem possuir infra-estrutura adequada, deve haver disponibilidade de mão-de-obra, etc.

Como mencionado anteriormente, uma primeira resolução do problema foi trabalhada com dados fictícios e impressões próprias, baseadas na pesquisa bibliográfica realizada e nos dados disponíveis. Com o propósito de validar a ferramenta de auxílio à tomada de decisão, o método AHP, um caso real de 
localização de plataforma logística, baseado no problema de localização do Entreposto Terminal São Paulo (ETSP) da CEAGESP, foi estruturado como um caso piloto.

A resolução do caso piloto pode ser consultada no anexo D e sua principal função foi validar a metodologia escolhida na aplicação de um estudo de plataforma logística. Após a validação da metodologia, foram feitos alguns ajustes na estrutura hierárquica para a resolução do problema proposto, além de análises do problema real baseadas na opinião dos stakeholders envolvidos.

A fim de buscar informações adicionais sobre as preferências dos decisores, devem ser listados os grupos diretamente envolvidos ou que possuem alguma influência sobre o processo decisório. Além disso, é necessário identificar aqueles que, apesar de não possuírem poder de decisão, são influenciados pela decisão que será tomada. Essa lista deve ser específica à situação a ser avaliada.

Uma vez identificados os atores, aqueles relacionados direta ou indiretamente ao problema, estes podem ser classificados em relação a dois aspectos:

(1) Grau de poder relativo que o ator possui em relação à decisão a ser tomada; e

(2) Grau de interesse relativo que o ator possui em relação à decisão a ser tomada.

No caso do ETSP foram considerados três grupos de interessados, ou atores, que incluíam a administração do Entreposto, os permissionários e os clientes. $\mathrm{Na}$ hierarquia do problema, os grupos de interessados serão identificados como os atores do sistema. Para cada ator, foram apontados todos os atributos relevantes com base nas entrevistas realizadas e seus objetivos.

Em relação às alternativas da estrutura hierárquica, para esta aplicação, serão delineados três cenários distintos. Um cenário é uma representação de uma idéia particular de um assunto, sendo enfatizado com uma representação adequada de sua interação com fatores ambientais, sociais, políticos, tecnológicos e econômicos (SAATY, 1991). 
Analisando-se a situação do ETSP da CEAGESP, surge a questão sobre o seu posicionamento atual, e se este está adequado. As controvérsias sobre a localização atual do ETSP surgiram juntamente com uma proposta política de transferência do Entreposto para a região do Rodoanel.

Como citado anteriormente, no caso aplicado ao ETSP da CEAGESP, os cenários de análise serão limitados às seguintes possibilidades:

(1) Manutenção da localização atual;

(2) Mudança de local da instalação;

(3) Descentralização das atividades do ETSP.

É importante ressaltar que no caso da alternativa de manutenção do ETSP na sua localização atual, torna-se mandatória a realização de reformas, readequação e ampliação de suas instalações, o que implica custos e esforços consideráveis.

A revitalização do ETSP teria como objetivo principal gerar uma maior eficiência operacional e solucionar problemas da atual estrutura do Entreposto como, por exemplo, aquele relacionado à circulação interna de veículos, incluindo controle de acesso de veículos, pessoas e mercadorias e, também, controle de tempos de permanência dos veículos no ETSP.

No segundo cenário, ao tratar-se a mudança do local da instalação, será considerado, a princípio, apenas um novo candidato à localização. Essa alternativa abordará a transferência do Entreposto para a região do Rodoanel, o que implicaria a desmobilização total da instalação atual.

O terceiro cenário caracteriza a descentralização, e a conseqüente instalação de novas unidades em pontos estratégicos da Região Metropolitana de São Paulo. A Zona Leste aparece como a primeira alternativa para a instalação de uma nova unidade de comercialização e armazenagem da CEAGESP. 
Primeiramente, para cada um dos cenários possíveis, foram levantadas vantagens e desvantagens. Com o objetivo de apontar as diversas características dessas alternativas, empregou-se a técnica de análise SWOT (Strengths, Weaknesses, Opportunities e Threats), geralmente utilizada em processos de planejamento estratégico, na avaliação do posicionamento da organização e da sua capacidade competitiva. Esta análise apresenta como resultado pontos fortes, pontos fracos, oportunidades e ameaças da organização e do mercado onde ela atua. A análise é dividida em duas partes: o ambiente externo à organização (oportunidades e ameaças) e o ambiente interno à organização (pontos fortes e pontos fracos).

As próximas Figuras mostram a análise de cada um dos cenários, com base no estudo prévio do problema e detalhes do funcionamento do Entreposto, empregando a técnica SWOT. As entrevistas realizadas com os diversos atores envolvidos com o problema também contribuíram para a definição dos pontos fortes e fracos, oportunidades e ameaças pertencentes a cada um dos cenários propostos. É importante destacar que esta análise SWOT foi fundamentada, predominantemente, no ponto de vista do grupo da diretoria do Entreposto.

A Figura 7 ilustra o cenário de manutenção da localização atual do ETSP da CEAGESP na Vila Leopoldina:

\begin{tabular}{|c|c|}
\hline Pontos Fortes & Pontos Fracos \\
\hline Manutenção dos clientes atuais & Poluição causada pelo tráfego de veículos \\
\hline Proximidade aos centros consumidores & \multirow{2}{*}{$\begin{array}{l}\text { Baixa eficiência causada pela precariedade } \\
\text { das instalações }\end{array}$} \\
\hline Acessibilidade & \\
\hline Pólo Gerador de empregos & Transtornos causados por possíveis reformas \\
\hline Oportunidades & Ameaças \\
\hline Modernização e aumento da capacidade das & \multirow{4}{*}{$\begin{array}{l}\text { Especulação Imobiliária } \\
\text { Cultura dos permissionários e usuários } \\
\text { (criando barreiras para implantação de } \\
\text { inovações) }\end{array}$} \\
\hline instalações & \\
\hline Criação de novos negócios dentro do ETSP & \\
\hline Programas de redução de perdas & \\
\hline
\end{tabular}

Fonte: elaborado pelo autor.

Figura 7. Análise SWOT para o ETSP na Vila Leopoldina. 
A localização do Entreposto na Vila Leopoldina garante a estabilidade do mercado consumidor atual, pois sua localização é estratégica, de fácil acesso e próxima aos centros consumidores. Há ainda muitas oportunidades de implantação de melhorias no atual ETSP, através da modernização e conseqüente possibilidade de aumento de capacidade das suas instalações, implementação de programas de melhorias contínuas e também através da criação de novos negócios dentro do ETSP. Sobre este último aspecto, por exemplo, vem sendo desenvolvido um projeto de "central de negócios”, em parceria com o mercado de Milão, com o objetivo de criar um espaço para receber clientes e demonstrar produtos.

Apesar da potencialidade desta instalação, há alguns pontos fracos que devem ser combatidos neste cenário, tais como a baixa eficiência causada pela precariedade das instalações, a baixa aceitação da comunidade da região em relação ao mercado e a degradação ambiental causada principalmente pela poluição veicular gerada pela circulação de veículos pesados. Entre as ameaças sofridas por esta alternativa, a especulação imobiliária presente na região é um ponto que merece destaque.

A Figura 8 ilustra o cenário de mudança da localização atual do Entreposto para a região do Rodoanel:

\begin{tabular}{|l|l|}
\hline \multicolumn{1}{|c|}{ Pontos Fortes } & \multicolumn{1}{c|}{ Pontos Fracos } \\
\hline \hline Redução do tráfego na região do ETSP & Aumento da distância até os centros consumidores \\
\hline Desenvolvimento da região & Alto custo de instalação \\
\hline $\begin{array}{l}\text { Possibilidade de construção de um "mercado } \\
\text { ideal" }\end{array}$ & Problemas Ambientais \\
\cline { 2 - 2 } & Possível perda de clientes / concorrência \\
\hline \multicolumn{1}{|c|}{ Oportunidades } & \multicolumn{1}{c|}{ Ameaças } \\
\hline \hline Construção de instalações mais modernas & $\begin{array}{l}\text { Impacto social causado por alterações em relação à } \\
\text { mão-de-obra }\end{array}$ \\
\hline Liberação da área do ETSP para outros fins & Aumento no preço dos produtos \\
\hline
\end{tabular}

Fonte: elaborado pelo autor.

Figura 8. Análise SWOT para ETSP no Rodoanel.

Em relação à mudança do Entreposto para a região do Rodoanel, destaca-se a oportunidade de construção de um entreposto mais moderno, que ofereça níveis de serviço mais elevados. Outro ponto positivo desta mudança está na possibilidade de desenvolvimento sócio-econômico da região do Rodoanel. Porém, a mudança 
também causa alguns receios como a perda de clientes provocada pelo aumento das distâncias aos centros consumidores, a possível alta no preço dos produtos, alta nos custos para os permissionários, além de problemas ambientais na implantação.

A Figura 9 ilustra o cenário de descentralização do ETSP da CEAGESP:

\begin{tabular}{|l|l|}
\hline \multicolumn{1}{|c|}{ Pontos Fortes } & \multicolumn{1}{c|}{ Pontos Fracos } \\
\hline \hline \multirow{2}{*}{$\begin{array}{l}\text { Maior proximidade em relação aos } \\
\text { consumidores finais }\end{array}$} & Aumento do tráfego de veículos pesados (fornecedores) \\
\cline { 2 - 2 } & Geração de ociosidade na atual instalação do ETSP \\
\hline \hline \multicolumn{1}{|c|}{$\begin{array}{l}\text { Omeração de empregos em regiões onde há } \\
\text { mão-de-obra disponível }\end{array}$} & $\begin{array}{l}\text { Problemas relacionados com a regulação dos preços das } \\
\text { mercadorias }\end{array}$ \\
\hline Modernização de instalações & Dificuldades para controlar os Entrepostos \\
\hline & \\
\hline
\end{tabular}

Fonte: elaborado pelo autor.

Figura 9. Análise SWOT para descentralização do ETSP.

As principais vantagens obtidas com uma descentralização das atividades do Entreposto são as seguintes: a maior proximidade em relação aos consumidores finais e o aproveitamento de mão-de-obra ociosa nas regiões de instalação dos entrepostos. Entretanto, haveria um problema em relação à regulação dos preços dos produtos e o gerenciamento das diversas unidades. Para os fornecedores este cenário também pode não ser o ideal, pois além do problema de formação de preços, eles enfrentariam maiores distâncias caso abastecessem várias unidades do Entreposto.

Após a análise do ambiente interno e externo do entreposto inserido nos três cenários propostos, foram discutidas as considerações assumidas em relação aos fatores relevantes à localização do ETSP da CESGESP. E, a seguir, serão explicados os critérios e sub-critérios presentes no modelo.

A Tabela 16 apresenta, genericamente, os critérios que devem ser levados em consideração e quais as particularidades que devem ser analisadas para cada um dos critérios propostos. Por exemplo, em relação ao critério área, é necessário levar em consideração características como o custo e a disponibilidade. Por outro lado, a principal preocupação em relação ao critério ambiental está relacionada aos impactos 
gerados para o meio ambiente. Esta Tabela foi o primeiro passo para a construção da estrutura hierárquica do problema.

Tabela 16- Resumo da lista inicial de Critérios para a Localização de Instalações, relevantes para o estudo de caso da CEAGESP.

\begin{tabular}{|c|c|c|c|c|}
\hline Critério & $\begin{array}{l}0 \\
\frac{5}{0} \\
\end{array}$ & 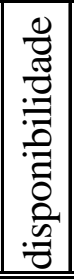 & 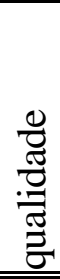 & 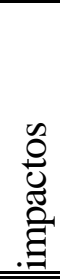 \\
\hline transporte & $\chi$ & $X$ & $X$ & \\
\hline área & X & $X$ & & \\
\hline utilidades públicas & X & $x$ & & \\
\hline mercado & & & & \\
\hline ambiental & & & & \\
\hline uso do solo & & & & \\
\hline mão de obra & $x$ & $x$ & $x$ & \\
\hline impacto social & & & & $凶$ \\
\hline tributos & 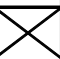 & & & X \\
\hline
\end{tabular}

fonte: autor.

A partir dos critérios selecionados na Tabela 16 e da lista genérica dos fatores relevantes na seleção de locais, apresentada na Tabela 2 (pg.22), foram selecionados os fatores significativos para o problema específico apresentado. A Tabela 17, abaixo, mostra os fatores selecionados, considerando-se os três cenários envolvidos.

Na tentativa de modelar o problema de forma mais completa possível, existe a tendência de identificar um grande número de critérios. Enquanto esta ação permite uma melhor definição do problema, ocorre um aumento significativo na quantidade de trabalho na realização das comparações paritárias. Uma alternativa é criar uma grande lista de critérios e, posteriormente, arranjá-los em grupos significativos.

Inicialmente, todas as variáveis que tem algum efeito no julgamento a ser feito, sugeridas pelo decisor ou grupo de decisores, são aceitas. Ao longo do procedimento, algumas poderão ser ignoradas, por sua baixa prioridade, ou por apresentar duplicidade em relação à outra variável. 
Tabela 17- Lista de Critérios para a Localização de Instalações, relevantes para o estudo de caso da CEAGESP.

\begin{tabular}{|c|c|c|c|c|}
\hline CRITÉRIOS & SUB-CRITÉRIOS & Cenário 1 & Cenário 2 & Cenário 3 \\
\hline \multirow[t]{3}{*}{ 1. Área para implementação: } & Custo da área (considerar eventuais custos de desapropriação); & $\checkmark$ & $\checkmark$ & $\checkmark$ \\
\hline & Disponibilidade de espaço necessário para o Projeto; & & $\checkmark$ & $\checkmark$ \\
\hline & Custos associados à construção da instalação. & & $\checkmark$ & $\checkmark$ \\
\hline \multirow[t]{13}{*}{ 2. Utilidades Públicas: } & Disponibilidade de fornecimento de água; & & & \\
\hline & Disponibilidade de instalações de coleta de esgoto; & & & \\
\hline & Custos de fornecimento de água; & & & \\
\hline & Custo de coleta de esgoto; & & & \\
\hline & Custo de tratamento de água; & & & \\
\hline & Custo de tratamento de esgoto; & & & \\
\hline & $\begin{array}{l}\text { Distância dos recursos de água e esgoto (este critério pode ser } \\
\text { considerado no item de custo); }\end{array}$ & & & \\
\hline & Disponibilidade de sistema de coleta de resíduos (lixo); & & & \\
\hline & $\begin{array}{l}\text { Disponibilidade e confiabilidade do sistema de energia elétrica (ou outros } \\
\text { tipos de fontes de energia, caso haja necessidade); }\end{array}$ & & & \\
\hline & Custo do fornecimento de energia elétrica; & & & \\
\hline & Custo de acessar as redes de energia; & & & \\
\hline & $\begin{array}{l}\text { Distância às fontes ou redes de energia (este critério pode ser considerado } \\
\text { no item de custo); }\end{array}$ & & & \\
\hline & \begin{tabular}{|l|} 
Disponibilidade de instalações de telecomunicação. \\
\end{tabular} & & & \\
\hline \multirow[t]{5}{*}{ 3. Acessibilidade: } & Disponibilidade e custo para a mão-de-obra chegar (acessar) ao local; & & $\checkmark$ & \\
\hline & $\begin{array}{l}\text { Disponibilidade e custo de transporte dos produtos (tanto entrada, quanto } \\
\text { saída - no caso de indústrias tem que considerar matéria-prima e produtos } \\
\text { acabados, separadamente); }\end{array}$ & $\checkmark$ & $\checkmark$ & $\checkmark$ \\
\hline & Distâncias entre o local e os fornecedores e clientes; & $\checkmark$ & $\checkmark$ & $\checkmark$ \\
\hline & Rotas de acesso (rodovia, ferrovia, hidrovia); & $\checkmark$ & $\checkmark$ & $\checkmark$ \\
\hline & Qualidade dos serviços de transporte que atendem a região. & & & \\
\hline \multicolumn{5}{|c|}{ 4. Disponibilidade e custo da matéria-prima; } \\
\hline \multirow[t]{3}{*}{ 5. Mercado: } & $\begin{array}{l}\text { Identificação de consumidores (tamanho e proximidades aos mercados } \\
\text { consumidores); }\end{array}$ & $\checkmark$ & $\checkmark$ & $\checkmark$ \\
\hline & Estabilidade das condições de mercado; & $\checkmark$ & $\checkmark$ & $\checkmark$ \\
\hline & Análise de competitividade (considerações sobre a concorrência). & $\checkmark$ & $\checkmark$ & $\checkmark$ \\
\hline \multirow[t]{5}{*}{ 6. Aspectos Ambientais: } & Conformidade com as legislações ambientais estaduais e municipais; & & & \\
\hline & Obtenção de licenças ambientais; & & & \\
\hline & Políticas de controle da Poluição (associado à qualidade do ar); & $\checkmark$ & $\checkmark$ & $\checkmark$ \\
\hline & Impacto no sistema hídrico; & & $\checkmark$ & $\checkmark$ \\
\hline & Preservação do meio ambiente da região. & $\checkmark$ & $\checkmark$ & $\checkmark$ \\
\hline \multirow[t]{4}{*}{ 7. Aspectos físicos geográfico } & Características geográficas e topológicas do local; & & & \\
\hline & Clima e temperatura; & & & \\
\hline & Padrões de chuvas e enchentes; & & & \\
\hline & Ventos. & & & \\
\hline \multirow[t]{5}{*}{ 8. Ocupação Urbana: } & Cidades próximas; & & & \\
\hline & $\begin{array}{l}\text { População (aceitação da população em relação à atividade da } \\
\text { empresa/indústria na região); }\end{array}$ & $\checkmark$ & $\checkmark$ & $\checkmark$ \\
\hline & Desenvolvimento de projetos; & & & \\
\hline & $\begin{array}{l}\text { Condições de uso do solo (possíveis restrições ou barreiras para a } \\
\text { implantação do projeto); }\end{array}$ & & $\checkmark$ & $\checkmark$ \\
\hline & $\begin{array}{l}\text { Impactos sociais (considerar eventuais benefícios sócio-econômicos } \\
\text { gerados pela implantação da instalação). }\end{array}$ & $\checkmark$ & $\checkmark$ & $\checkmark$ \\
\hline \multirow[t]{5}{*}{ 9. Recursos humanos: } & Legislação trabalhista; & & & \\
\hline & Grau de sindicalização; & & & \\
\hline & Disponibilidade de mão-de-obra qualificada; & & $\checkmark$ & \\
\hline & Existência de centros de treinamento e educação; & & & \\
\hline & $\begin{array}{l}\text { Custos de mão-de-obra na região (salários médios - média salarial da } \\
\text { região). }\end{array}$ & $\checkmark$ & $\checkmark$ & $\checkmark$ \\
\hline \multirow[t]{3}{*}{ 10. Qualidade de vida: } & Habitação, segurança e infra-estrutura social; & & & \\
\hline & Disponibilidade de lazer; & & & \\
\hline & Disponibilidade de serviços médicos e odontológicos; & & & \\
\hline
\end{tabular}


Após a seleção dos critérios considerados relevantes ao estudo de caso do ETSP da CEAGESP, ainda foram realizadas algumas discussões com o objetivo de construirse a estrutura hierárquica do problema de forma mais simplificada.

Durante o processo de construção da estrutura hierárquica mais adequada, foram realizadas reuniões com a diretoria do ETSP da CEAGESP, para balizar os critérios e sub-critérios realmente relevantes na formulação do problema.

A Figura 10, a seguir, ilustra a composição dos níveis inseridos na hierarquia e apresenta algumas alterações em relação à hierarquia utilizada no piloto da aplicação do problema proposto. O objetivo das mudanças realizadas foi de tornar o questionário o mais claro e simples possível, propiciando maior praticidade para respondê-los. Em alguns momentos foram incorporadas sugestões colocadas pelos próprios atores.

Em relação ao critério “área”, os sub-critérios de custo da área e custo de construção foram substituídos por um item referente ao investimento necessário. Essa decisão foi tomada com base em argumentações da própria diretoria da CEAGESP que haveria uma grande dificuldade em estimar custos para construção de uma nova instalação, ou mesmo para reformas na instalação atual, sem um projeto mais detalhado. No entanto, seria possível mensurar, ainda que de forma qualitativa, um montante aproximado de investimento necessário para cada uma das alternativas. O sub-critério “disponibilidade” refere-se à disponibilidade de espaço físico para a necessidade atual do Entreposto.

A questão da acessibilidade foi tratada sob dois pontos de vista, primeiramente o custo de acessar o local e, depois, a facilidade de acesso, para cada um dos envolvidos diretamente com essa questão incluindo clientes, funcionários, abastecimento de mercadorias e distribuição dos produtos. Esta divisão surgiu da preocupação que nem sempre que o custo de acesso é o menor significa que a opção de acesso vinculada a este custo é a melhor, em termos de tempo e qualidade do acesso. 


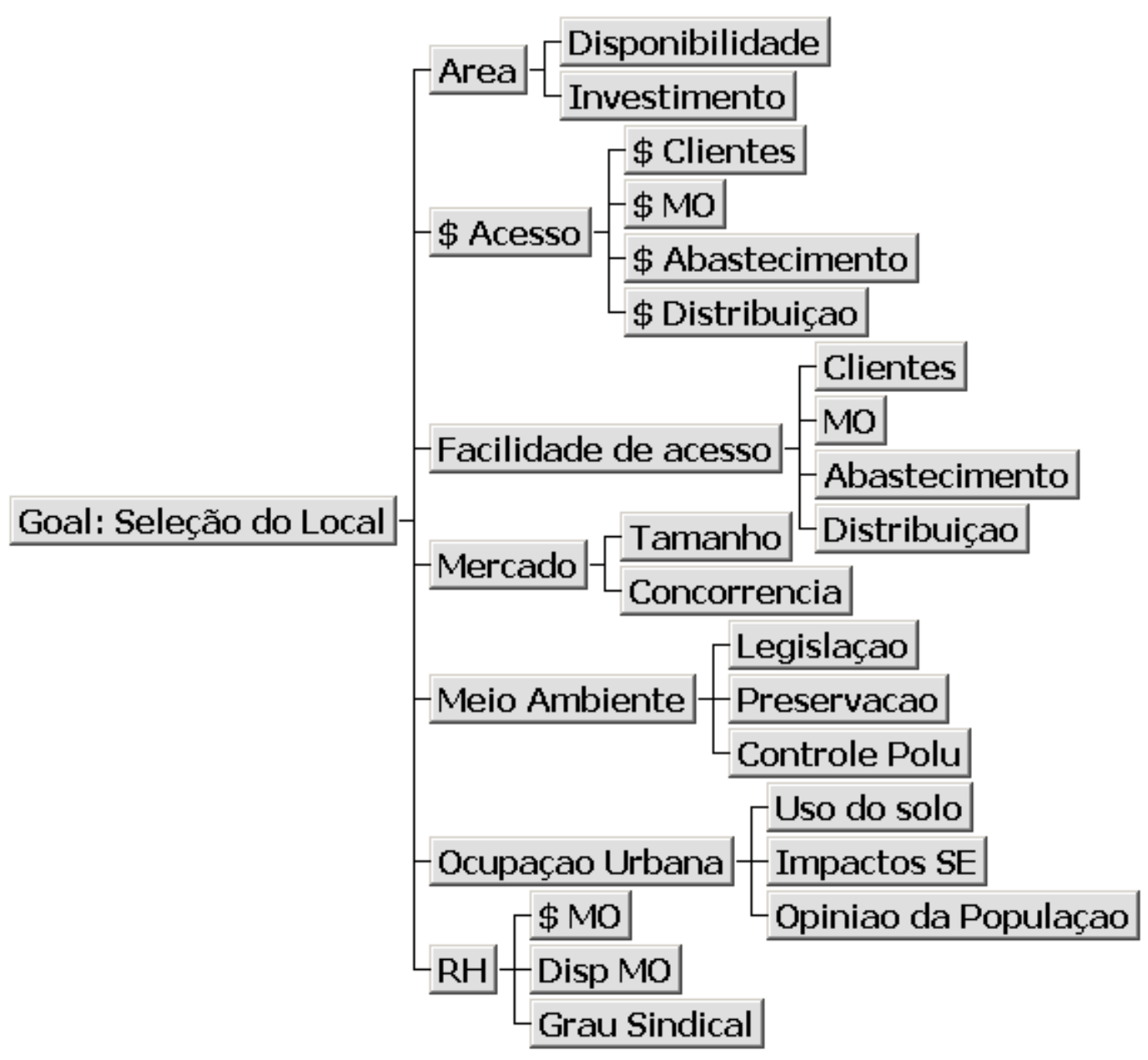

Figura 10. Representação da Hierarquia do Problema do ETSP da CEAGESP.

Foram também eliminadas duplicidades encontradas no critério relacionado ao mercado consumidor. Identificou-se que a principal preocupação dos interessados está relacionada à concorrência atual de outros entrepostos, incluindo a comercialização clandestina de produtos, de mercados localizados na região de São Paulo. Além da concorrência, a análise da expansão do mercado consumidor foi considerada primordial na escolha da localização do Entreposto.

As questões ambientais consideradas relevantes passam pela legislação, considerando respeito e adequação às leis vigentes, controle da poluição, 
considerando exclusivamente a poluição veicular, e preservação, que avalia os impactos do Entreposto no seu entorno.

O critério "ocupação urbana” trata aspectos tais como o "uso do solo", ou existência de possíveis barreiras, leis de zoneamento ou restrições físicas para a implantação da plataforma, “impactos sócio-econômicos” positivos, considerando o desenvolvimento da região e “opinião da população" da região em relação às atividades do Entreposto, considerando vantagens e desvantagens criadas por uma instalação deste porte.

E por fim, o critério "RH" trata das questões relacionadas ao fator humano, que incluem custo da mão-de-obra, disponibilidade da mão-de-obra e grau de sindicalização dos funcionários.

A seguir, aparecem os apontamentos que surgiram durante a construção e aplicação do problema ao caso do ETSP da CEAGESP.

\subsection{Aplicação e Resultados}

Para a implementação do problema ao caso do ETSP da CEAGESP foi utilizado o software Expert Choice 11, na versão estudantil. O software Expert Choice modela automaticamente as matrizes de comparação, conforme a hierarquia de decisão definida pelo usuário.

A versão estudantil criou algumas barreiras para a implementação desejada, sendo esta adaptada aos recursos disponíveis. Um fator limitante, por exemplo, foi o número de níveis hierárquicos permitidos pelo software. Adiante serão discutidas as implicações destas limitações.

A primeira etapa da aplicação do método AHP consiste na estruturação dos objetivos, critérios e alternativas em uma hierarquia, do geral para o mais específico. 
O problema do ETSP da CEAGESP gerou uma estrutura hierárquica de quatro níveis, objetivo, critérios, sub-critérios e alternativas. Quando os critérios ocupam mais de um nível, assim como no caso apresentado, os critérios inferiores são mais específicos do que aqueles que se encontram no nível superior.

A demanda por um quinto nível hierárquico foi gerada ao longo das aplicações dos questionários, quando foi constatada a necessidade de dividir os respondentes em grupos, a fim de atribuir o peso de cada um dos grupos no processo decisório. Porém, como o software permitia a utilização de hierarquias com, no máximo, quatro níveis hierárquicos, não foi possível realizar esta análise.

Apesar da versão utilizada do programa não ter permitido a obtenção de um resultado único através da análise conjunta dos diversos grupos de atores. Houve a possibilidade de analisar os critérios importantes para cada um dos atores e observar as peculiaridades existentes no problema proposto, além de obter a ordenação das alternativas para cada um dos grupos separadamente.

Com o objetivo de visualizar as diferenças na ponderação dos critérios existentes entre os grupos, foram feitas três implementações, uma para cada grupo, através da combinação dos questionários dos indivíduos pertencentes a determinado grupo. Os respondentes foram divididos da seguinte forma: administração, permissionários e clientes.

Na segunda fase da aplicação do método, são atribuídos valores de julgamentos relativos por comparação paritária. Cada par é comparado sob o ponto de vista de um determinado critério do nível hierárquico superior. Depois de obter as matrizes de comparação paritária de todos os elementos da hierarquia, é necessário determinar as prioridades relativas dos pesos dos fatores de decisão, em cada nível ou grupo, até o nível das alternativas. 
Através da hierarquia estruturada previamente, foi elaborado um questionário para aplicação e obtenção dos valores das comparações paritárias para respostas individuais. O questionário utilizado se encontra detalhado no anexo E.

Os questionários foram aplicados durante entrevistas individuais com cada um dos respondentes. Essas entrevistas tinham como objetivo, além de obter as respostas aos questionários, entender melhor as peculiaridades envolvidas com o problema.

É importante destacar que o resultado obtido nesta avaliação é função de uma série de fatores, como a escolha dos critérios, a estruturação desses critérios, os julgamentos de preferências por pares e o método empregado na resolução do problema.

A escolha dos respondentes foi realizada de forma a contemplar todos os interessados diretos do problema. Apesar da quantidade de entrevistados não ser numerosa, foram selecionadas pessoas que representavam os grupos de stakeholders e que estavam ligadas ao negócio do Entreposto. Desta forma foi possível representar nos resultados as opiniões diversas que envolvem o problema.

Entre os respondentes estavam membros da diretoria atual do ETSP, o responsável pela gerência do Entreposto, representantes de sindicatos dos permissionários, permissionários e representantes dos clientes.

A Tabela 18 mostra o resultado obtido com os questionários individuais. O tema de localização do Entreposto envolve opiniões e interesses divergentes e mesmo analisando os questionários isoladamente, é possível perceber o viés presente nas respostas dos interessados. Esse viés, que é dificilmente controlável, resulta no alto índice de inconsistência presente. Antes de aplicar qualquer correção ou ajuste para a redução das inconsistências, foi realizada a análise combinada por grupos. Como citado anteriormente, os questionários individuais foram reunidos e combinados em três grupos de interessados no problema. 
A Tabela 18 mostra a composição do julgamento das alternativas, com o peso atribuído a cada uma das alternativas nos questionários individuais e também apresenta a inconsistência associada ao resultado de cada um dos respondentes. A alternativa que recebeu o maior peso, sendo considerada a melhor alternativa, aparece em destaque.

Tabela 18- Resultado final da avaliação das alternativas para as respostas individuais.

\begin{tabular}{|c|c|c|c|c|c|c|c|c|c|c|}
\hline Respondente & 1 & 2 & 3 & 4 & 5 & 6 & 7 & 8 & 9 & 10 \\
\hline జ్త్ర đ Vila Leopoldina & 0,345 & 0,630 & 0,308 & 0,356 & 0,558 & 0,249 & 0,314 & 0,410 & 0,413 & 0,397 \\
\hline R̃ Rodoanel & 0,123 & 0,189 & 0,280 & 0,362 & 0,366 & 0,498 & 0,293 & 0,293 & 0,499 & 0,334 \\
\hline$\frac{\pi}{U} \frac{\pi}{0}$ Descentralização & 0,532 & 0,181 & 0,412 & 0,281 & 0,076 & 0,253 & 0,393 & 0,296 & 0,088 & 0,269 \\
\hline Inconsistência & 0,44 & 0,32 & 0,08 & 0,21 & 0,37 & 0,10 & 0,20 & 0,29 & 0,26 & 0,12 \\
\hline
\end{tabular}

Através das entrevistas individuais foi possível captar características específicas de cada um dos grupos de atores, além daquelas mais gerais relacionadas ao problema.

Uma grande parte dos respondentes avaliou que a alternativa de descentralização não cabe para o negócio do Entreposto. A centralização é fundamental para que o mercado de abastecimento mantenha sua função de regulador de preço, ou seja, o sistema de formação de preços dos produtos "hortifruti”. Apenas a comercialização de varejo, que não constitui o foco deste tipo de instalação, funcionaria mesmo com uma estrutura descentralizada.

Um exemplo de fracasso do sistema descentralizado de abastecimento foi relatado por um representante dos permissionários, ao serem abertas mais três unidades do Entreposto (Itaquera, Santo Amaro e Santana) no passado. Quando algum produto estava em falta em algum dos mercados, o preço deste produto neste local subia. No dia seguinte, os fornecedores resolviam concentrar a entrega do produto nesta unidade e, conseqüentemente, havia um excedente de oferta e o resultado era a queda dos preços. Este fenômeno desregulava o mercado e essas unidades foram desativadas. 
Além disso, na visão dos permissionários, a descentralização não funcionaria devido às especificidades das atividades desenvolvidas nas centrais de abastecimento. A maior concentração de produtos e fornecedores aumenta o poder de escolha do consumidor e também de negociação de preços.

Em relação à manutenção da localização atual, foram apontadas algumas considerações sobre as dificuldades geradas durante uma possível remodelação da instalação da vila Leopoldina. Alguns permissionários acham que qualquer tipo de intervenção causaria um grande transtorno, pois seria necessário interditar áreas e provavelmente restringir o tráfego, o que poderia ocasionar prejuízos aos negócios em determinados pontos de comercialização. Outra preocupação em relação a esta alternativa consiste na necessidade futura de expansão do Entreposto e a dúvida de que a área atual atenderia a esta exigência.

A alternativa de transferência para a região do Rodoanel possui como principal vantagem, sob o ponto de vista dos permissionários, a oportunidade de construção de um mercado inserido em um modelo “ideal”, modernizado e com oportunidade de expansão, porém esta idéia provoca bastante receio, devido ao aumento das distâncias de acesso para o cliente e também à existência de uma concorrência desleal, ou comércio paralelo que funciona em outras regiões da Grande São Paulo.

O aumento excessivo das distâncias poderia ocasionar a perda de clientes. Porém, no caso de uma nova localização, o cliente provavelmente aceitaria um pequeno incremento na distância para acessar o Entreposto desde que houvesse uma sensível melhora no nível de serviço.

A partir dos questionários individuais, os respondentes foram divididos em três grupos de atores, a fim de analisar a opinião do conjunto de interessados. Por uma limitação do software foram combinados, por grupo, no máximo três participantes. Como não seria possível utilizar todos os questionários obtidos, foram escolhidos, para cada grupo, os três indivíduos mais representativos para aquele grupo. Caso 
ainda houvesse alguma dúvida do indivíduo a escolher, a eliminação seria avaliada através da inconsistência.

A combinação dos questionários individuais permitiu a redução do índice de inconsistência no resultado final de avaliação das alternativas, dispensando a necessidade de ajustes para tornar os julgamentos consistentes. A Tabela 19, a seguir, mostra a classificação das alternativas e seus respectivos índices de inconsistência.

Tabela 19- Resultado final da avaliação das alternativas para os grupos.

\begin{tabular}{|c|c|c|c|c|}
\hline \multicolumn{2}{|c|}{ Respondente } & Administração & Permissionários & Clientes \\
\hline \multirow{3}{*}{ 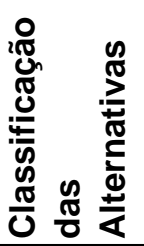 } & Vila Leopoldina & 0,500 & 0,474 & 0,249 \\
\hline & Rodoanel & 0,239 & 0,352 & 0,498 \\
\hline & Descentralização & 0,261 & 0,174 & 0,253 \\
\hline & onsistência & 0,06 & 0,06 & 0,10 \\
\hline
\end{tabular}

Como é possível observar, a melhor alternativa varia acompanhando os interesses particulares de cada um dos grupos e caracterizando uma situação de conflito de interesses. Esta situação ilustra o fato que cada ator possui visões e objetivos não necessariamente comuns.

É importante lembrar que apesar da existência de um conflito de interesse entre os diversos atores, foi adotado o mesmo conjunto de atributos para a ordenação das alternativas. O principal objetivo deste método consiste em avaliar um conjunto de critérios para a seleção da melhor localização do Entreposto sob os diversos pontos de vista e analisar as principais diferenças entre os grupos selecionados.

Como pode ser observado na Tabela 19, através dos resultados obtidos juntamente com as conversas individuais, nota-se que tanto os responsáveis pela administração, quanto os permissionários possuem como preferência a manutenção do Entreposto na Vila Leopoldina. Entretanto os clientes, representados pela APAS (Associação Paulista de Supermercados), classificam como melhor alternativa a mudança do 
Entreposto para uma nova instalação na região do Rodoanel. No caso dos clientes, o principal interesse está no aumento do nível de serviço e redução do tempo de permanência no Entreposto para aquisição das mercadorias. É importante destacar que ao expressar opiniões favoráveis à permanência do Entreposto no local atual, todos respondentes deixaram clara a necessidade de remodelação do mercado atual para um atendimento com nível de serviço mais adequado. E, além disso, eles consideram que o Entreposto possui uma vida útil e, a longo prazo, a instalação atual não comportaria possíveis expansões.

A fim de solucionar a divergência dos resultados gerados pelo conflito de interesses apontado na Tabela 19, seria necessário atribuir pesos aos grupos e, desta forma, estabelecer a importância relativa entre cada grupo. Esta ação poderia resultar na apresentação da melhor alternativa para o conjunto de grupos de interessados. Porém, como explicado anteriormente, as restrições impostas pelo software Expert Choice impediram a visualização desta análise.

Após a obtenção da classificação das alternativas, foi realizada uma análise de sensibilidade para os resultados obtidos. Abaixo, nas Figuras 11 a 16, apresentam-se alguns resultados extraídos do software Expert Choice, na aplicação ao caso do ETSP da CEAGESP.

As Figuras 11, 12 e 13 mostram o desempenho de todos os critérios em cada um dos cenários avaliados, para os três grupos de stakeholders, administração, permissionários e clientes, separadamente. Estes gráficos facilitam a visualização dos pontos fortes e fracos de cada uma das alternativas no processo de escolha dos atores participantes.

Em relação à avaliação dos critérios, através destes gráficos, é possível verificar os pesos de contribuição de cada um dos critérios no objetivo final do problema apresentado e também o comportamento de cada uma das alternativas perante os critérios. 
De maneira mais geral, o critério relacionado ao mercado consumidor possui um peso importante no resultado para todos os grupos analisados e, mais especificamente, este critério aparece como fator determinante na escolha da localização para o grupo dos clientes.

A Figura 11 mostra o resultado da ordenação das alternativas sob o ponto de vista da administração da CEAGESP. Primeiramente, é possível observar o resultado global, onde a Vila Leopoldina é considerada a melhor alternativa, mas também é possível avaliar o desempenho das alternativas em cada um dos critérios considerados relevantes na avaliação. Os maiores pesos para a decisão foram atribuídos aos critérios de custo de acesso, facilidade de acesso e mercado consumidor, e nestes três critérios a alternativa da Vila Leopoldina foi a mais bem avaliada comparativamente às outras duas alternativas.

Em relação ao critério área para a implantação do Entreposto, que também possui um peso relevante na decisão, a Vila Leopoldina consistia na melhor alternativa. E detalhando um pouco mais este critério, foi apontado que o sub-critério disponibilidade possui uma importância essencial comparativamente ao investimento, pois o investimento necessário para construção ou remodelação do Entreposto pode ser diluído entre possíveis investidores, em acordos de concessões, tanto para uso quanto gerenciamento. A administração do Entreposto comentou a existência de interesses externos de investidores participarem da modernização do Entreposto.

Ainda sob o ponto de vista da administração, o Rodoanel aparece como melhor alternativa apenas nos critérios referentes ao meio ambiente e ocupação urbana, o que reflete a oportunidade criada pela mudança de localização de desenvolvimento sócio-econômico gerado na região e também, o aspecto positivo de eliminar o tráfego de veículos pesados da região da Vila Leopoldina. 


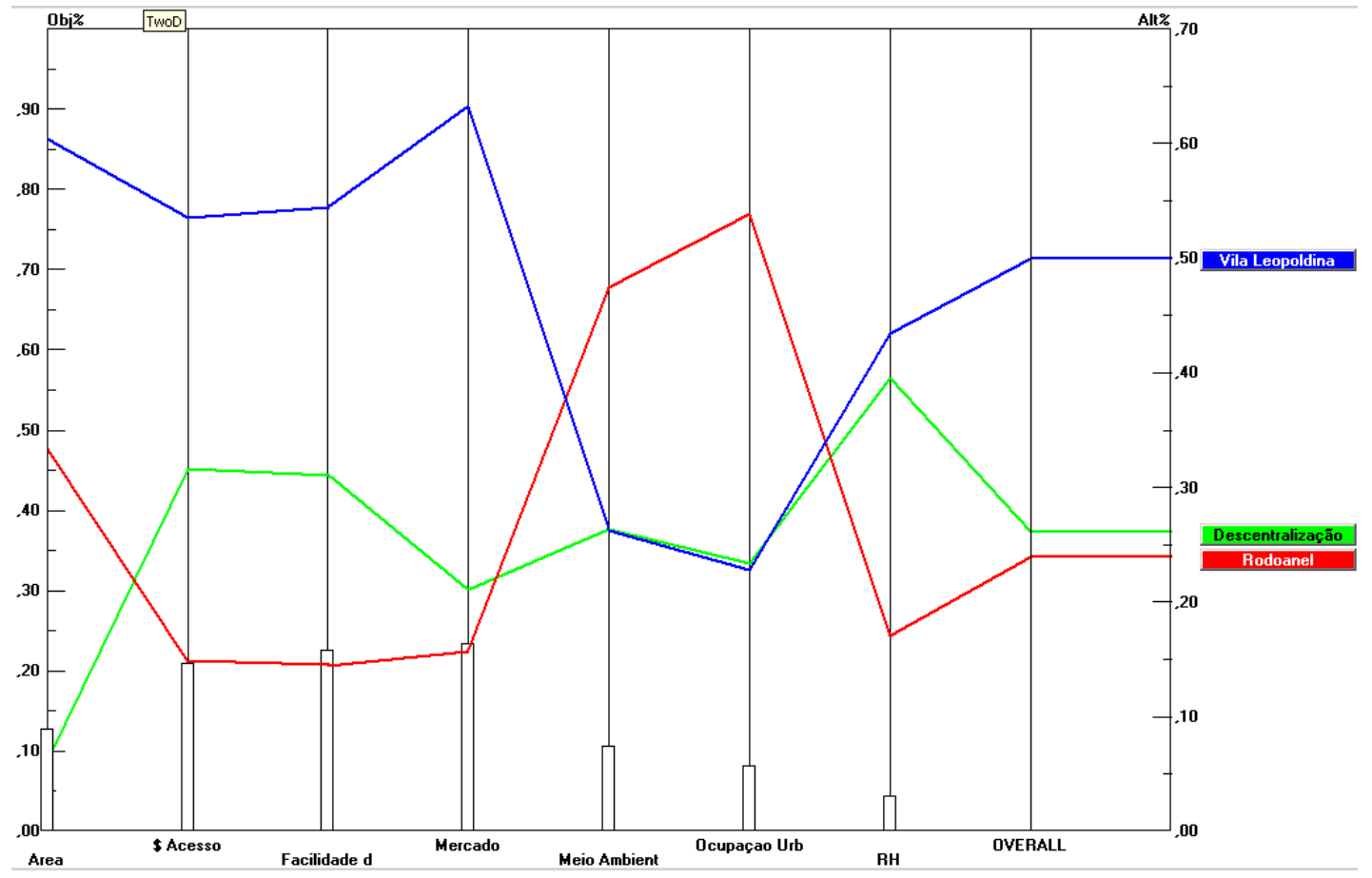

Figura 11. Administração - Gráfico de desempenho dos critérios, para cada uma das alternativas.

A Figura 12 apresenta o resultado da ordenação das alternativas sob o ponto de vista dos permissionários da CEAGESP. Para este grupo, a Vila Leopoldina também é a melhor alternativa na avaliação global. É importante notar que os itens relacionados a facilidade de acesso e mercado foram priorizados e receberam os maiores pesos na avaliação dos permissionários. Isso reflete o interesse deste grupo, que possui como foco principal a comercialização das mercadorias, e tem como preocupações o fornecimento de produtos ao custo mais baixo possível e atração do mercado consumidor, características ligadas à acessibilidade.

A Vila Leopoldina obteve o melhor desempenho praticamente em todos os critérios de avaliação, a única exceção aconteceu no item referente ao mercado consumidor. No critério "mercado", o Rodoanel foi avaliado pelos permissionários como a melhor alternativa pelo fato da possibilidade de atração de novos clientes, inclusive clientes que realizam suas compras em centrais de abastecimento de cidades do interior do Estado de São Paulo como, por exemplo, usuários da Ceasa de Campinas. Mesmo com o alto peso atribuído ao critério “mercado” na avaliação dos permissionários, 
considerando o objetivo global do problema, a alternativa da Vila Leopoldina manteve-se como a melhor alternativa.

A principal preocupação dos permissionários está na administração do Entreposto que permanece nas mãos do governo. Este grupo considera que a administração pública é a maior responsável pelo estado atual de abandono do Entreposto, pelo histórico de mais de uma década sem investimentos nas instalações. E avalia a captação de investimentos externos e privados como uma alternativa para a modernização e adequação das instalações. Alguns permissionários inclusive citaram a possibilidade dos próprios permissionários, como pequenos empresários, investirem na melhoria das instalações, em troca da concessão de utilização por um período determinado.

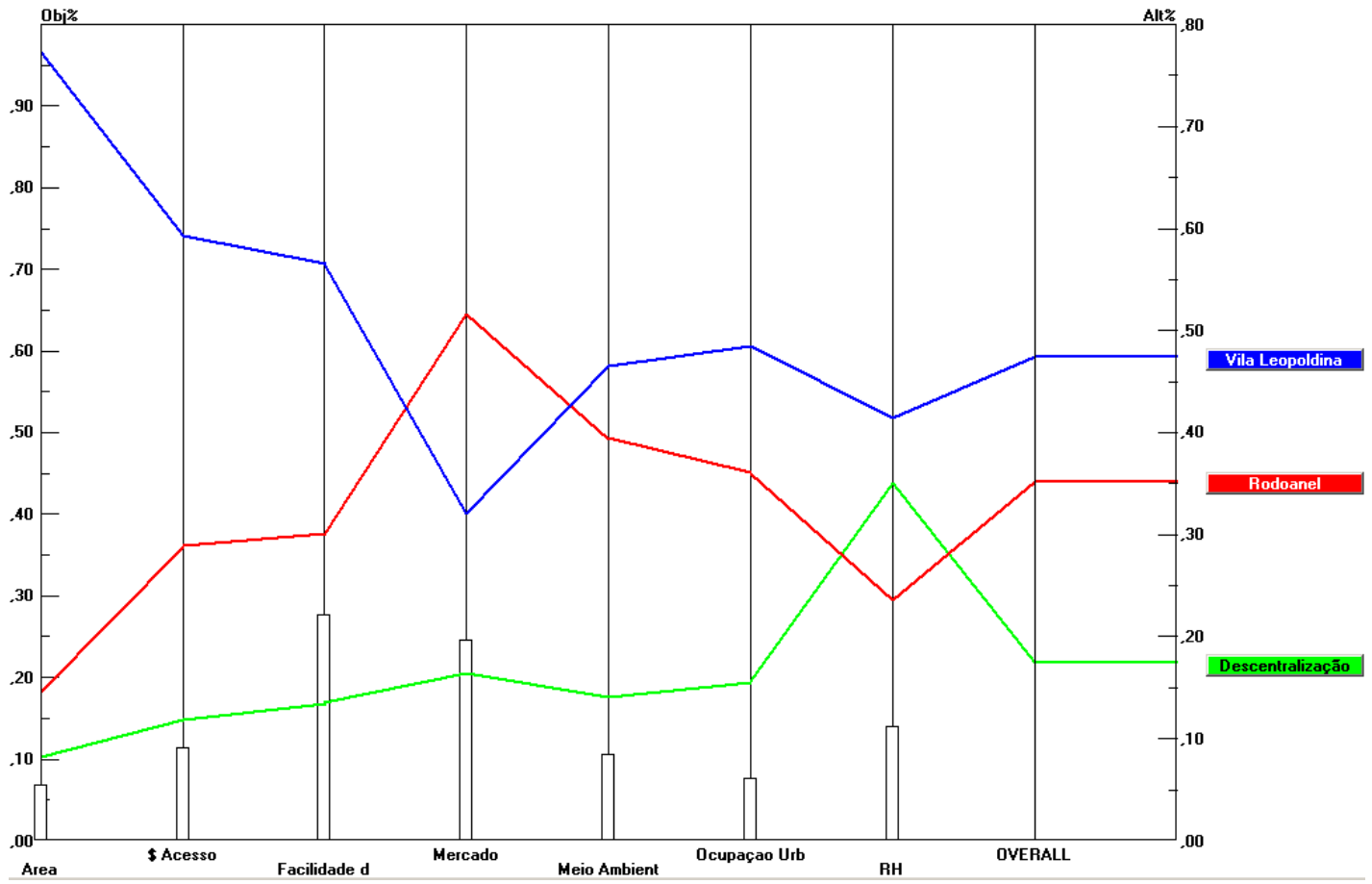

Figura 12. Permissionários - Gráfico de desempenho dos critérios, para cada uma das alternativas.

A Figura 13 mostra o resultado da classificação das alternativas sob o ponto de vista do grupo de clientes da CEAGESP. É possível observar o resultado global onde, diferente dos grupos anteriores, a alternativa do Rodoanel é considerada a melhor 
dentre os cenários apresentados. Além disso, há também a possibilidade de avaliar o desempenho das alternativas em cada um dos critérios considerados relevantes na avaliação.

O maior peso para a decisão foi atribuído ao critério relacionado ao mercado consumidor, o que significa dizer a importância atribuída pelos clientes ao seu próprio grupo. Os clientes do Entreposto enxergam a mudança do local para a região do Rodoanel como uma possibilidade de modernização do mercado e elevação do nível de serviço. Com o aumento do nível de serviço, este grupo espera uma redução do tempo gasto dentro do Entreposto e a diversificação dos produtos oferecidos.

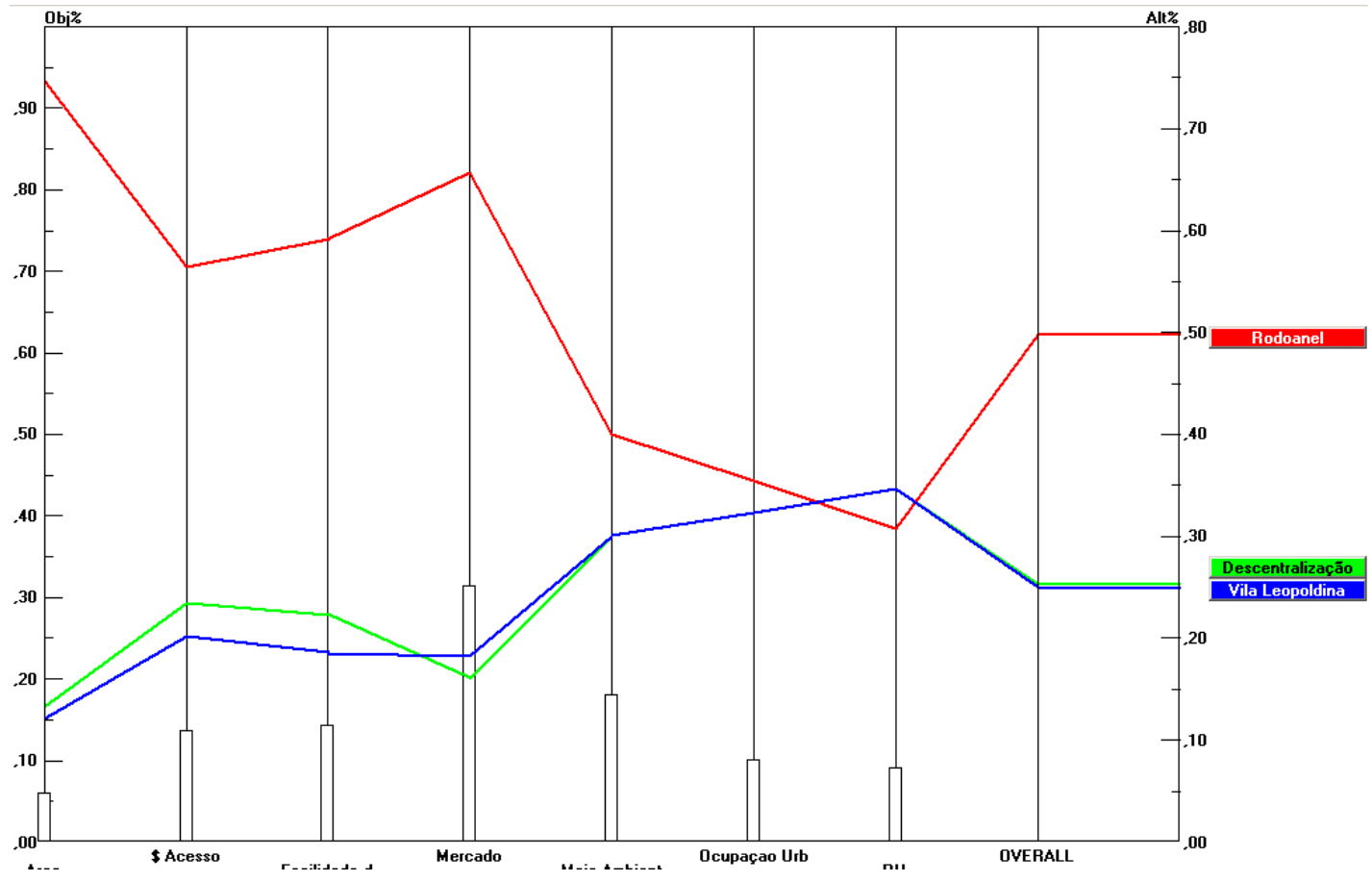

Figura 13. Clientes - Gráfico de desempenho dos critérios, para cada uma das alternativas.

Mesmo para os critérios relacionados ao custo e facilidade de acesso, que possuem um peso significativo no objetivo global do problema, a alternativa do Rodoanel aparece em destaque. Este cenário reflete a opinião do grupo dos clientes que avalia que um pequeno aumento nas distâncias para acessar o novo mercado seria aceitável desde que esta instalação oferecesse uma melhoria no nível de serviço. O único critério onde as alternativas da Vila Leopoldina e de descentralização aparecem 
melhor classificadas é aquele relacionado ao fator humano. Isso reflete o julgamento da possível baixa disponibilidade de mão-de-obra na região do Rodoanel.

As Figuras 14, 15 e 16 resumem, para cada um dos grupos considerados separadamente, o resultado da ordenação das alternativas no quadro da direita e, do outro lado, o peso de cada um dos critérios na decisão do objetivo final.

Na Figura 14, o gráfico de sensibilidade dos pesos para cada um dos critérios, para a administração do Entreposto, mostra que os critérios relacionados ao mercado consumidor (22,9\%), a facilidade de acesso $(22,1 \%)$ e o custo de acesso $(20,6 \%)$ constituem critérios com os maiores pesos na decisão.

A composição de julgamentos pela administração, apresentada na Figura 14, resultou na priorização da manutenção do Entreposto na Vila Leopoldina (50,0\%) e, em seguida, a descentralização (26,1\%), com peso próximo ao da alternativa de mudança da localização para a região do Rodoanel (23,9\%).
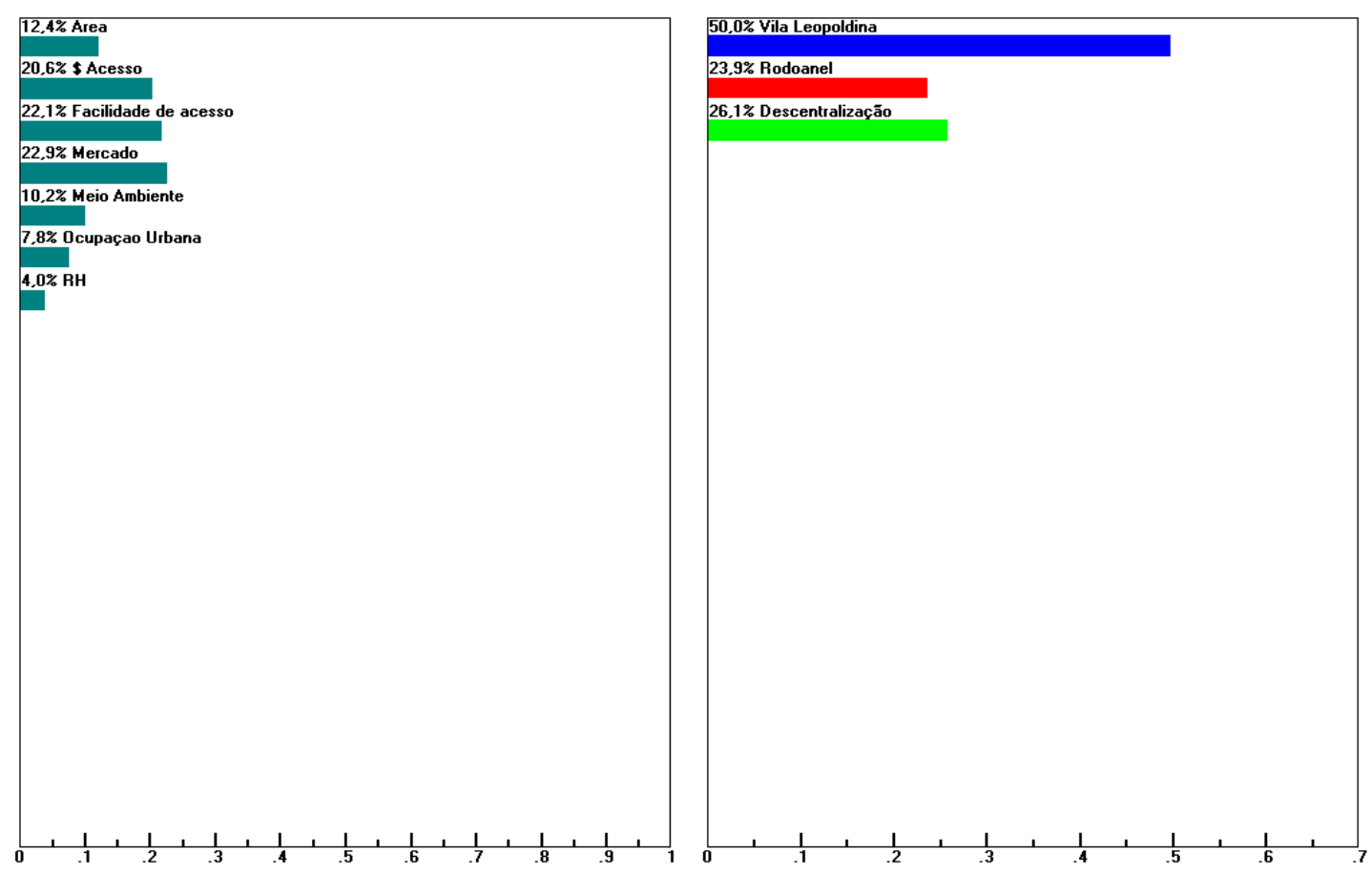

Figura 14. Administração - Gráfico de sensibilidade dos critérios e alternativas. 
A Figura 15 ilustra que, sob o ponto de vista dos permissionários, o fator determinante, juntamente ao mercado consumidor (24,2\%), é a facilidade de acesso (27,3\%). Este critério traduz a insegurança deste grupo frente a possível mudança de localização e conseqüente perda de clientes para mercados paralelos e ilegais que se estabeleceriam para atender a demanda.

No resultado da ordenação das alternativas, o grupo dos permissionários avalia como melhor alternativa a permanência na Vila Leopoldina $(47,4 \%)$. O segundo maior peso foi atribuído à alternativa de mudança para o Rodoanel (35,2\%), seguida da opção de descentralização $(17,4 \%)$.
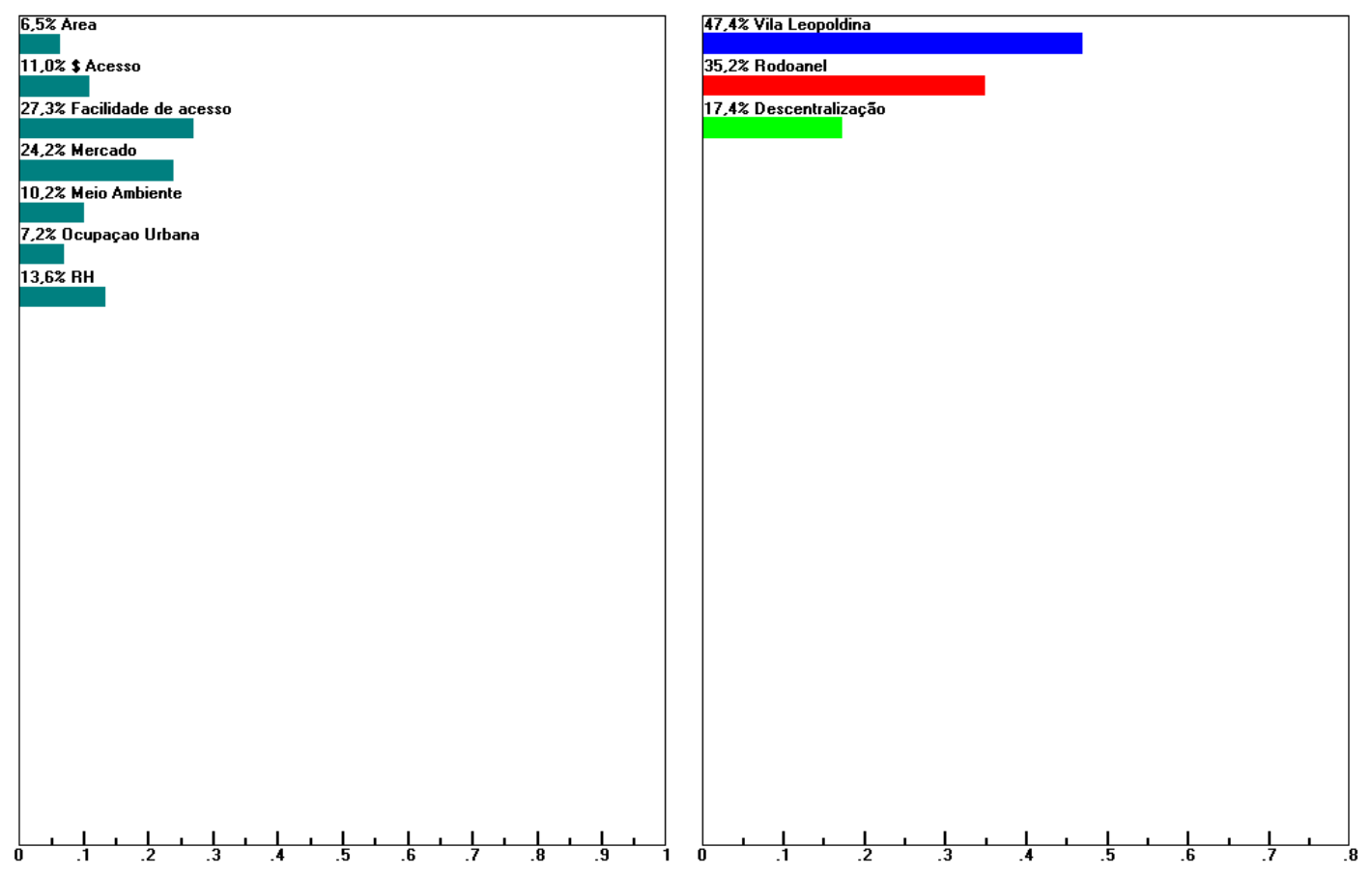

Figura 15. Permissionários - Gráfico de sensibilidade dos critérios e alternativas.

Na Figura 16, o gráfico de sensibilidade dos pesos para cada um dos critérios, para o grupo de clientes da CEAGESP, mostra que o critério relacionado ao mercado consumidor (31,1\%), constitui o critério com maior peso na decisão. Outros critérios que receberam pesos mais baixos, mas também possuem importância significativa para o processo de decisão são o custo de acesso (13,3\%), a facilidade de acesso $(13,9 \%)$ e o meio ambiente $(17,7 \%)$. 
A composição de julgamentos pelos clientes resultou na priorização da mudança da localização do Entreposto para a região do Rodoanel (49,8\%), seguida pela descentralização (25,3\%), com peso próximo ao da alternativa de manutenção do Entreposto na Vila Leopoldina (24,9\%).
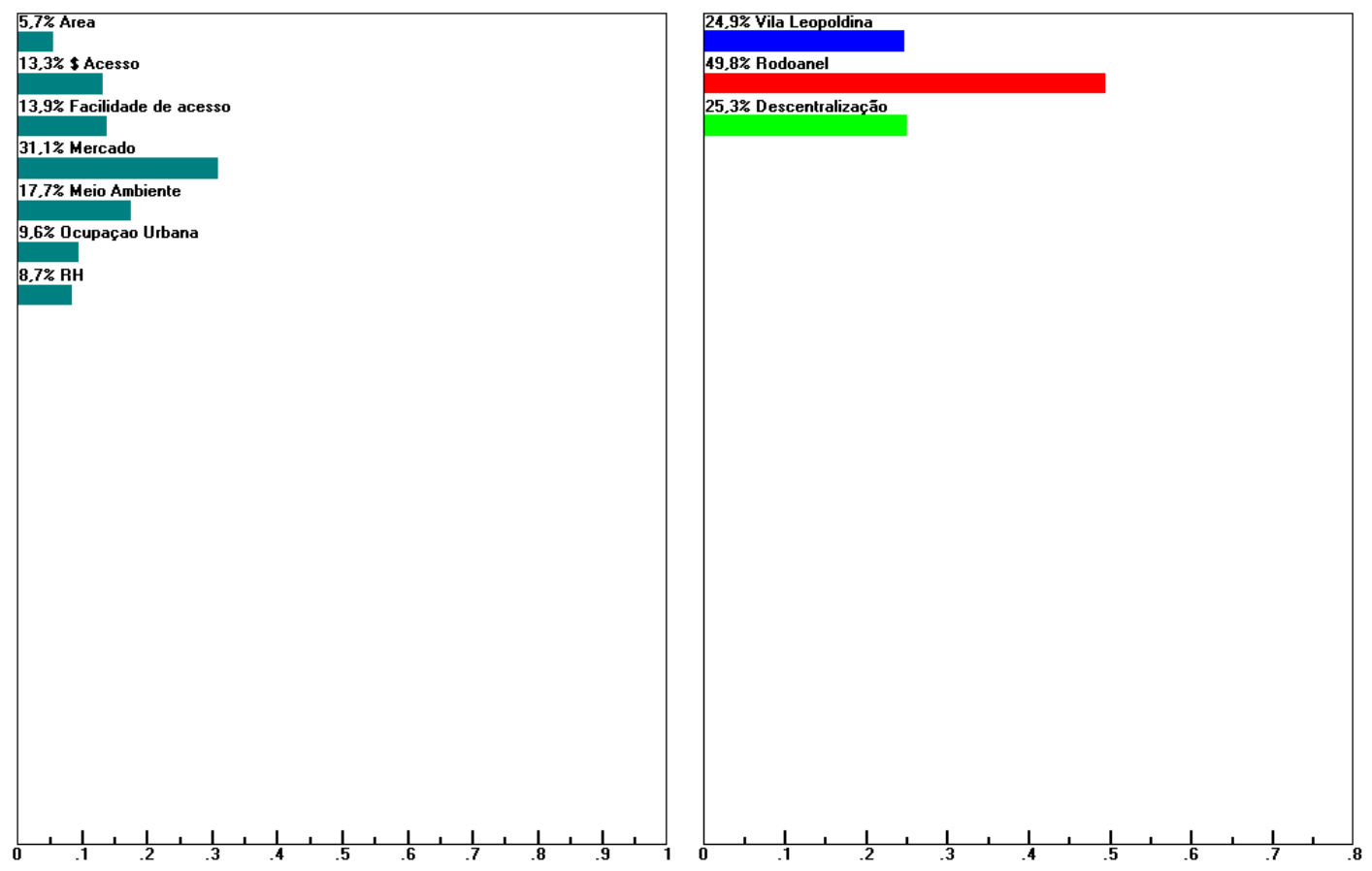

Figura 16. Clientes - Gráfico de sensibilidade dos critérios e alternativas.

\subsection{Conclusão do Capítulo}

Como citado anteriormente, neste estudo de caso, ocorreu a análise de três cenários possíveis:

(1) Manutenção da localização atual;

(2) Mudança de local da instalação;

(3) Descentralização das atividades do ETSP.

Primeiramente foi empregada a técnica de análise SWOT, na qual foram levantadas as vantagens e desvantagens para cada um dos cenários possíveis, com a finalidade de delinear as diversas características de cada uma das alternativas. 
A fase de estruturação do problema foi de grande importância para o desenvolvimento de toda a análise, devido à necessidade de entender o contexto do problema, objetivos e particularidades para se aproximar o máximo possível da realidade.

A seleção dos critérios considerados relevantes ao estudo de caso do ETSP da CEAGESP possibilitou a construção da estrutura hierárquica do problema, cujos julgamentos permitiram a composição dos pesos das alternativas para cada um dos grupos de atores considerados na análise.

Para a obtenção do julgamento dos pesos para a construção das matrizes de comparação paritária dos critérios e sub-critérios considerados no problema foram aplicados questionários, em entrevistas pessoais, para os stakeholders envolvidos no problema. A ponderação dos pesos e ordenação das alternativas foi realizada individualmente e, em seguida, em grupos representativos.

Finalmente, o resultado da aplicação do método AHP, através do software Expert Choice 11, pôde ser verificado pelos gráficos e Figuras apresentados. Foram também discutidas as limitações da versão estudantil do software que impuseram algumas restrições ao longo da resolução do problema.

É importante ressaltar que os resultados da composição dos julgamentos apontam que a melhor alternativa, tanto para a administração do Entreposto como para os permissionários, está na manutenção da localização atual. Este ponto de vista foi também captado durante as entrevistas, e notou-se que todos aqueles que relatavam sua preferência pela localização do Entreposto na Vila Leopoldina também estavam cientes da necessidade de remodelação e modernização das suas instalações. Já sob o ponto de vista dos clientes, o Rodoanel seria a melhor alternativa, principalmente por apresentar uma oportunidade de aumento do nível de serviço.

O exemplo desenvolvido neste capítulo pode servir como modelo para aplicação de outros casos de localização de plataformas logísticas, ilustrando a maneira de 
estruturação deste tipo de problema e alguns dos critérios relevantes a serem levados em consideração.

A importância do ETSP da CEAGESP se apóia no seu papel para a comunidade, com a ressalva que este papel deve ser estudado e ajustado, buscando adequação à urbanização e à comunidade do entorno.

Em relação a eventuais erros contidos nesta avaliação, apesar de ser esperado que o julgamento humano não seja completamente consistente, segundo Morita (1998), o AHP requer um nível mínimo de consistência para que o resultado obtido pelo método seja significativo. Caso necessário, a recomendação para a redução do nível de inconsistência está na revisão dos julgamentos da matriz de comparação paritária (MCP) correspondente. Caso a inconsistência persista, duas hipóteses devem ser consideradas: se o conhecimento dos fatores de decisão é insuficiente ou se os fatores de transição são regidos pela transitividade. 


\section{6 . CONSIDERAÇÕES FINAIS}

\subsection{Resumo}

A contribuição que este trabalho pretende oferecer consiste na apresentação e validação de um método de seleção de locais para instalações de plataformas logísticas. As Plataformas Logísticas compreendem as instalações que reúnem diversas atividades logísticas, tais como transporte, armazenagem e comercialização, encerrando a oferta de bens e serviços à população.

O ponto central do trabalho está em lidar com fatores conflitantes de localização, e uma das tarefas de maior relevância consiste na escolha apropriada destes fatores. É importante destacar que o resultado obtido nesta avaliação é função de uma série de detalhes, como a escolha dos critérios, a estruturação desses critérios, os julgamentos de preferências por pares e o método empregado na resolução do problema.

A partir do estudo do conceito de plataformas logísticas, buscou-se um modelo deste tipo de instalação para a aplicação da metodologia sugerida. A idéia inicial de pautar o estudo de caso desta dissertação no ETSP da CEAGESP surgiu depois do conhecimento da proposta de transferir o ETSP para a região do Rodoanel, e a preocupação da administração do Entreposto com a melhoria do seu funcionamento. O Entreposto pode ser considerado um caso particular de plataforma logística, por encerrar em sua estrutura diversas atividades típicas deste tipo de instalação e por constituir um ponto de chave da cadeia logística de produtos hortifrutigranjeiros, onde estão concentradas atividades e funções que agregam valor aos produtos comercializados.

Para a resolução do problema proposto buscaram-se métodos de auxílio à tomada de decisão com enfoque multicritério. Primeiramente é necessário ter consciência que o conceito de ótimo não existe em uma estrutura multicritério e sua análise não pode ser justificada dentro do paradigma freqüentemente adotado na pesquisa operacional tradicional. 
A metodologia de análise multicritério conhecida por Analytic Hierarchy Process ou AHP foi considerada eficaz na estruturação de problemas complexos e também capaz de tratar os aspectos qualitativos e quantitativos inseridos nesta análise.

Através das informações obtidas em estudos anteriores e ainda em discussões informais, foi possível estabelecer três cenários de estudo. O primeiro deles privilegia o atual posicionamento do ETSP da CEAGESP na Vila Leopoldina, região Oeste da cidade de São Paulo, contemplando reformas e readequação da sua estrutura. O segundo sugere a mudança do Entreposto para a região do Rodoanel, com a construção de uma instalação totalmente remodelada. E o terceiro cenário propõe a descentralização do ETSP da CEAGESP, com a possível ativação de uma nova unidade na região da zona Leste, como alternativa inicial.

Primeiramente, foi realizado um piloto para a resolução do problema. O resultado obtido no caso piloto não deve ser levado em consideração de forma absoluta, uma vez que alguns critérios foram estimados ou considerados hipoteticamente. Porém, através deste piloto, foi possível validar a metodologia selecionada para aplicações em problemas de localização de plataformas logísticas.

Depois de validada, a metodologia foi aplicada ao caso real do ETSP da CEAGESP, melhor caracterizando os stakeholders e aplicando questionários para elaboração das MCPs, de forma a obter as preferências reais dos tomadores de decisão. Para a obtenção dos resultados do caso do ETSP da CEAGESP foi utilizado o software Expert Choice 11, na versão estudantil.

No caso do ETSP da CEAGESP, foi essencial considerar os diversos stakeholders envolvidos com o problema: administração, permissionários e consumidores, pertencentes ao grupo dos clientes.

As respostas obtidas com a aplicação dos questionários foram analisadas individualmente e também foram considerados por grupos de interessados. $\mathrm{Na}$ 
análise individual foram detectados altos índices de inconsistência, porém antes de realizar qualquer ajuste a fim de tornar os julgamentos consistentes, os participantes foram divididos e combinados buscando a classificação das alternativas por grupos de interesse. Desta forma, foi possível reduzir as inconsistências e também obter os resultados por grupos de interesse, evidenciando a diferença na ponderação dos fatores para a decisão. Por fim, utilizou-se a análise de sensibilidade em relação aos pesos designados aos critérios de avaliação, o que permitiu visualizar a incerteza associada à importância relativa dos pesos, além de verificar a contribuição dos critérios na composição do resultado final.

Como pode ser observado nos resultados obtidos, juntamente com as entrevistas individuais, nota-se que tanto os responsáveis pela administração quanto os permissionários possuem como preferência a manutenção do Entreposto na Vila Leopoldina; entretanto, os clientes representados pela APAS (Associação Paulista de Supermercados) classificam como melhor alternativa a mudança do Entreposto para uma nova instalação na região do Rodoanel.

É importante destacar, que ao expressar opiniões favoráveis à permanência do Entreposto no local atual, todos os respondentes deixaram clara a necessidade de remodelação do mercado atual para um atendimento com nível de serviço mais adequado. E, além disso, consideram que a instalação atual do Entreposto, a longo prazo, não comportaria possíveis expansões.

Ainda sobre o Entreposto da Vila Leopoldina, o estudo realizado pelo LPT/EPUSP apontou que, caso haja uma reorganização espacial, é possível aumentar a capacidade do Entreposto e, desta forma, aumentar também a eficácia na execução das suas atividades.

No caso dos clientes, o principal interesse está no aumento do nível de serviço e redução do tempo de permanência no Entreposto para a realização da compra das mercadorias. 
Como é possível observar, a melhor alternativa varia, acompanhando os interesses particulares de cada um dos grupos e caracterizando uma situação de conflito de interesses. Esta situação ilustra o fato que cada ator possui visões e objetivos não necessariamente comuns.

A diferença em relação aos objetivos de cada um dos grupos de atores reflete os interesses particulares desses grupos. Para o grupo de cliente, por exemplo, os principais objetivos envolvem qualidade e disponibilidade adequadas e preço justo. Os permissionários possuem como principal exigência a garantia de instalações e infra-estrutura adequadas. E a administração do Entreposto se preocupa em garantir o abastecimento, regular os preços dos produtos e prover recursos para realização de investimentos nas instalações.

\subsection{Conclusões}

Assim sendo, o presente trabalho contribui para um melhor entendimento da problemática de localização através das seguintes ações:

- Primeiramente, delineou o conceito de plataformas logísticas e mostrou sua aplicabilidade dentro da realidade brasileira;

- Depois da pesquisa dos métodos multicritério na literatura, selecionou o AHP (Analytic Hierarchy Process) como método adequado para a resolução de problemas de localização de plataformas logísticas;

- Definiu os critérios relevantes a serem levados em consideração em problemas similares;

- Mostrou a importância de caracterizar de maneira adequada os stakeholders, de forma a obter as preferências reais dos tomadores de decisão;

- $\quad$ Estabeleceu uma metodologia de estruturação da hierarquia;

- Avaliou os impactos dos critérios, através da metodologia adotada, no objetivo geral do problema.

- Validou, através de um caso piloto, o método AHP para a seleção de locais para a instalação de plataformas logísticas; 
- Ilustrou que caso escolhido para aplicação da metodologia pode ser utilizado como modelo para casos de localização de plataformas logísticas.

Ao longo do trabalho foram identificadas algumas dificuldades na utilização do AHP para o problema em questão como, por exemplo, quantidade excessiva de critérios para a avaliação e ponderação e existência de grupos de interesse conflitantes.

É importante ressaltar que a ferramenta utilizada mostrou-se adequada no tratamento de questões complexas, porém ela pode apresentar inconsistências significativas em casos onde os respondestes assumam uma posição pré-definida, com viés no preenchimento dos questionários.

\subsection{Recomentações}

Com base nos resultados do presente estudo, sugere-se o desenvolvimento dos seguintes tópicos em trabalhos futuros:

- Ampliação do trabalho aqui desenvolvido, através da obtenção da composição de julgamentos de outros setores que podem ser considerados também representativos para o problema, tais como representantes do governo, da Companhia de Engenharia de Tráfego (CET), da comunidade local, etc.;

- $\quad$ Estudo de modernização e adequação da estrutura do ETSP da CEAGESP para atender a seus diversos clientes;

- Utilização de outras ferramentas computacionais para a implementação do AHP;

- Comparação dos resultados obtidos através do AHP com aqueles obtidos por outros métodos multicritério de auxílio à tomada de decisão. 


\section{ANEXOS}




\section{Anexo A - Formas de Cálculo da MCP}

As diferentes maneiras de cálculo, apresentadas a seguir, buscam a redução do efeito da reversão.

As formas de cálculo, segundo Saaty (1991), são três:

1. Modo distributivo

Esta é a forma original do cálculo do AHP. Neste modo, os pesos totalizam o valor unitário. Este é utilizado quando se pretende obter uma ordenação cardinal entre as alternativas. As alternativas podem ser consideradas como uma lista de atividades organizadas em seqüência para serem executadas.

Neste caso, o cálculo acontece da seguinte maneira, seja $\mathrm{a}_{\mathrm{ijk}} \mathrm{o}$ julgamento comparativo entre a i-ésima alternativa e a j-ésima alternativa com respeito ao késimo critério. E seja $c_{k}$ o peso do k-ésimo critério, o peso $\mathrm{w}_{\mathrm{i}}$ da i-ésima alternativa é dado pelo modo distributivo de cálculo por:

$$
\mathrm{W}_{\mathrm{i}}=\sum_{\mathrm{k}=1}^{\mathrm{m}} \mathrm{W}_{\mathrm{ik}} \boldsymbol{C}_{k}=\sum_{k=1}^{m} \boldsymbol{C}_{k} \frac{1}{n} \sum_{j=1}^{n} \frac{\boldsymbol{a}_{i j \mathrm{k}}}{\sum_{i=1}^{n} \boldsymbol{a}_{i j k}}
$$

Onde i e j são os mesmos índices da MPC de ordem n.

\section{Modo Ideal}

O modo ideal apresentado por Belton e Gear (1982), é utilizado para obter uma única e melhor alternativa. É atribuído o valor unitário para o peso da alternativa de maior prioridade. Posteriormente o vetor dos pesos resultantes é normalizado.

No modo ideal, a introdução de novas alternativas de pouco peso, irrelevantes, não modifica a posição da melhor alternativa. No modo distributivo, quando alguma alternativa irrelevante é adicionada, esta pode influenciar a melhor alternativa, pois as novas comparações fornecem referências adicionais. 
O modo ideal de cálculo gera um vetor de prioridade normalizado $\mathrm{w}_{\mathrm{i}}$ dado por:

$W_{i}=\frac{V_{i}}{\sum_{i=1}^{n} V_{i}}$

onde $V_{i}=\sum_{k=1}^{m} \frac{W_{i k} C_{k}}{\operatorname{maX} W_{i k}}$,

e onde $\boldsymbol{W}_{i k}=\frac{1}{n} \sum_{j=1}^{n} \frac{\boldsymbol{a}_{i j k}}{\sum_{i=1}^{n} \boldsymbol{a}_{i j k}}$

3. Modo Absoluto

O modo absoluto de determinação de ordem é a forma mais direta de seqüenciação cardinal.

Este modo é recomendado quando o número de alternativas é alto, acima de 9. Seja $\mathrm{W}_{\mathrm{i}}$ o peso resultante da i-ésima alternativa, do total de $\mathrm{n}$. Seja $\mathrm{c}_{\mathrm{k}} \mathrm{O}$ peso do k-ésimo critério normalizado. E seja $\mathrm{W}_{\mathrm{ik}}$ a avaliação da i-ésima alternativa para o critério $\mathrm{k}$ (do total de m), o modo absoluto de cálculo é dado por:

$$
\mathbf{W}_{\mathrm{i}}=\sum_{\mathrm{k}=1}^{\mathrm{m}} \mathbf{W}_{\mathrm{ik}} \boldsymbol{C}_{k}
$$

$\mathrm{O}$ peso $\mathrm{c}_{\mathrm{k}}$ reflete todos os pesos dos níveis acima das alternativas.

Foram divulgadas por (McLean, 1995), as seguintes regras para optar pelo modo de cálculo:

- Escolher o modo distributivo no caso de priorizar alternativas de planejamento, avaliar alternativas sob critérios que não se repetem e alocação de recursos escassos;

- Utilizar o modo ideal para o caso de busca de uma única e melhor alternativa de um conjunto, existência de alternativas muito semelhantes ou iguais entre si. 
Morita (1998) exemplifica a diferença entre os modos de cálculo ao dizer que no modo distributivo, a prioridade é a participação da “fatia de mercado", cuja entrada de participantes de pequenas fatias provoca a redução da fatia do líder e também reduz as distâncias entre os concorrentes. E ainda, conforme as forças intervenientes no processo, o líder pode perder sua posição. E no modo ideal existe uma disputa individual, ocorrendo maior ênfase em relação à seqüência que às medidas de classificação.

O modo ideal tem a sua utilidade em circunstâncias onde as alternativas não vão ser excluídas, mas apenas priorizadas. 


\section{Anexo B - Utilização do Autovetor}

O trecho abaixo foi extraído da dissertação de Morita (1998) e apresenta algumas explicações a respeito da utilização do autovetor.

O método utilizado para o AHP é o cálculo do autovetor. E o vetor de prioridades relativas é definido pela solução da equação:

$$
A \times P=\lambda_{\text {máx }} \times P
$$

Onde A é a matriz de comparações por pares (MCP) do tamanho $\mathrm{n} \times \mathrm{n}, \lambda$ máx é o maior autovalor de A, e P é o autovetor direito de A.

A validade do uso do autovetor como o vetor de prioridades da MCP será mostrado a seguir.

Se $A=($ aij) é consistente e se $\mathrm{P}=(\mathrm{pj})$, então aij pode ser escrito como uma relação entre os pesos do vetor $\mathrm{P}$.

$$
a_{i j}=\frac{p_{i}}{p_{j}}
$$

Se multiplicarmos a MCP pelo autovetor, teremos A x P. E desta forma:

$$
a_{i j} \times p_{j}=\left(\frac{p_{i}}{p_{j}}\right) \times p_{j}=n \times p_{j}
$$

Portanto tem-se:

$$
A \times P=n \times P
$$

Saaty (1994) demonstra que se A é uma matriz do tipo MCP (as condições para ser uma matriz deste tipo estão adiante), então $\lambda$ máx $\geq \mathrm{n}$, e também que A é uma MCP 
consistente se e somente se $\lambda$ máx $=n$. Portanto para o caso onde a matriz é consistente,

$$
A \times P=\lambda_{\text {máx }} \times P
$$

Se a matriz de comparações não estiver longe da inconsistência, então $\lambda$ máx também não estará longe de n, pois não existe descontinuidade.

Segundo Saaty (1980), o maior autovetor $\lambda$ máx é continuamente dependente dos elementos da MCP.

As condições para uma matriz ser MCP são as seguintes:

Uma matriz quadrada de ordem n é uma MCP se respeitar algumas condições.

Se $a_{i j}=\frac{p_{i}}{p_{j}}$, então $a_{i j}=\frac{1}{a_{j i}}$ e $a_{i i}=1$.

Dados que todos os $p_{j}>0$, então $a_{i j}>0$.

Portanto a matriz A do tipo MCP é quadrada, positiva e recíproca. 


\section{Anexo C - Cálculo Aproximado do Autovetor}

O trecho abaixo foi extraído da dissertação de Morita (1998) e apresenta algumas explicações a respeito do cálculo aproximado do autovetor.

O autovetor P direito é calculado de forma aproximada pela fórmula:

$$
p_{i}=\sum_{i=1}^{n} \frac{a_{i j}}{n} \cdot S_{j}
$$

onde $S_{j}=\frac{1}{\sum_{i=1}^{n} a_{i j}},(\mathrm{i}=1,2, \ldots ., \mathrm{n} \mathrm{e} \mathrm{j}=1,2, \ldots ., \mathrm{n})$.

Se S é o vetor de $s_{1}$ a $s_{n}$, podemos escrever, partindo da equação acima que:

$$
P=A \cdot \frac{S}{n}=\frac{(A \cdot S)}{n}
$$

Desenvolvendo algebricamente $A \cdot(A \cdot S)$ e simplificando o resultado, considerando as condições de consistência, o resultado é:

$$
A \cdot(A \cdot S)=n \cdot A \cdot S
$$

Utilizando as equações acima descritas chega-se a conclusão que: $A \cdot P=A \cdot S$ e $\lambda_{\text {máx }} \cdot P=A \cdot S$. Portanto pode-se afirmar que:

$$
A \cdot P=\lambda_{\text {máx }} \cdot P
$$

Através desta demonstração, pode-se concluir que o método de aproximação, no caso da MCP ser consistente, está aprovado. E se não existe descontinuidade nas vizinhanças de $\lambda_{\text {máx }}=n$, o autovetor $\mathrm{P}$ calculado desta forma também é válido. $\mathrm{Na}$ realidade, $\lambda_{\text {máx }} \geq n$ (Saaty, 1994 apud Morita, 1998) significa que só existe vizinhança de um lado, mas isso não invalida a conclusão, pois não existem descontinuidades entre os valores de $\mathrm{a}_{\mathrm{ij}}$ da MCP e o $\lambda_{\text {máx }}$.

Saaty (1980) apud Morita (1998) testou quatro métodos de aproximação. Ele concluiu que este método e o método das médias geométricas forneciam os melhores resultados. Os métodos exatos como de sucessivos cálculos é computacionalmente trabalhoso até atingir a precisão desejada. Além disso, já existem programas para o cálculo do autovetor. Para o propósito desejado, o método das médias para a 
aproximação é mais simples na implementação, mais adequado e suficiente para acompanhar os exemplos e conceitos deste trabalho. 


\section{Anexo D - Estudo de Caso Piloto}

A partir da hierarquia estruturada para o problema de plataformas logísticas e personalizada para um problema com as condições de contorno do ETSP da CEAGESP, que pode ser observada abaixo na Figura 1A, foi desenvolvido um piloto para a validação da metodologia proposta.

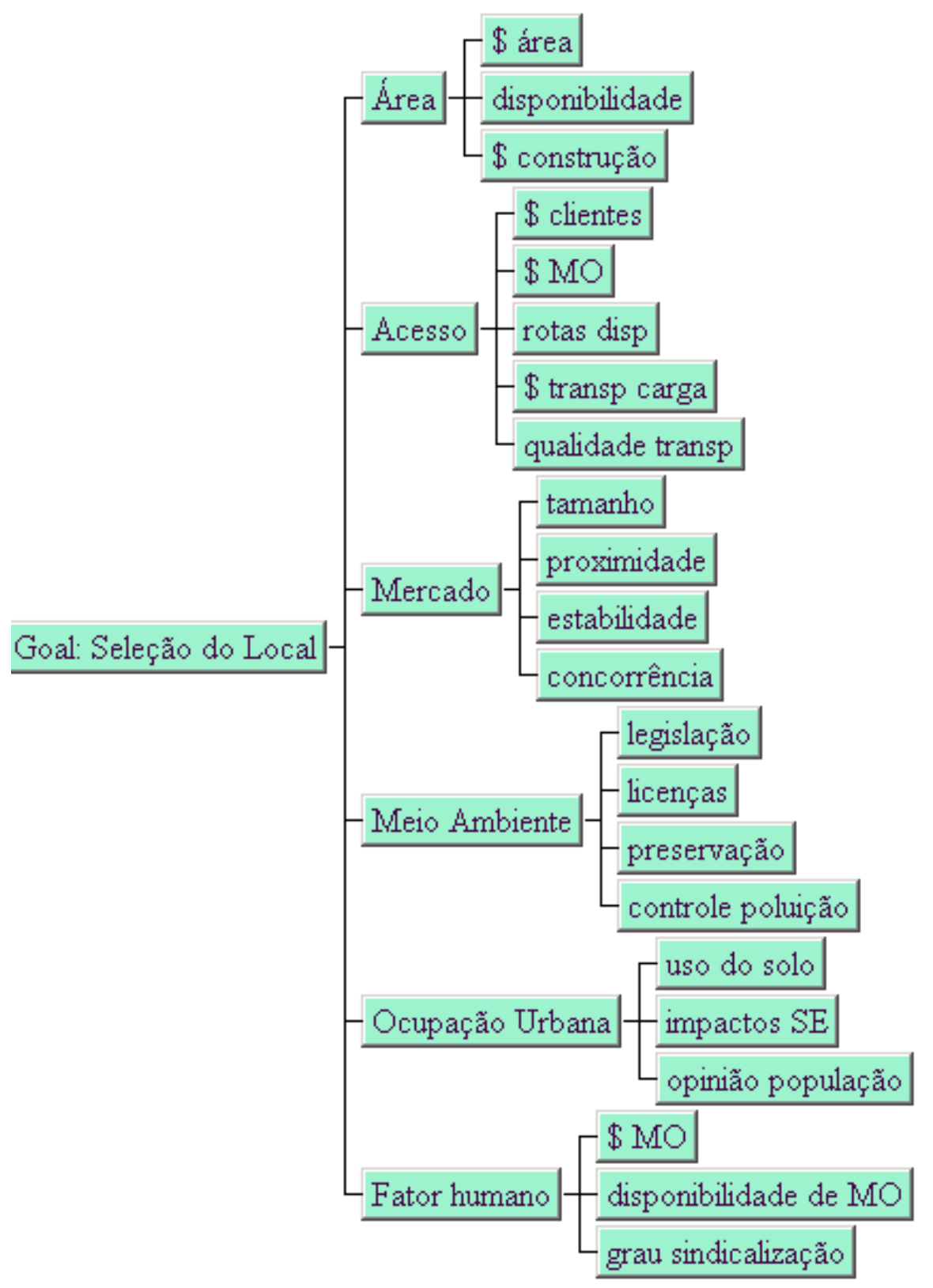

Figura 1A. Representação da Hierarquia do Problema do ETSP da CEAGESP. 
Primeiramente, é importante lembrar que todos os aspectos qualitativos foram avaliados sem a aplicação de um questionário. Nesta etapa inicial do estudo de caso, o julgamento de cada um dos critérios qualitativos encontra-se fundamentado na sensibilidade da própria autora. A seguir encontram-se as Tabelas de comparação paritária dos critérios e sub-critérios pertencentes à hierarquia do problema.

A Figura 2A mostra a ponderação dos pesos atribuída aos critérios em relação ao objetivo final.

\begin{tabular}{|c|c|c|c|c|c|c|}
\hline CRITÉRIOS & Área & Acesso & Mercado & Meio ambiente & Ocupação urbana & $\mathrm{RH}$ \\
\hline Área & 1 & $1 / 8$ & $1 / 7$ & $1 / 6$ & $1 / 5$ & $1 / 5$ \\
\hline Acesso & 8 & 1 & 5 & 6 & 7 & 7 \\
\hline Mercado & 7 & $1 / 5$ & 1 & 3 & 5 & 5 \\
\hline Meio ambiente & 6 & $1 / 6$ & $1 / 3$ & 1 & 3 & 3 \\
\hline Ocupação urbana & 5 & $1 / 7$ & $1 / 5$ & $1 / 3$ & 1 & $1 / 2$ \\
\hline $\mathrm{RH}$ & 5 & $1 / 7$ & $1 / 5$ & $1 / 3$ & 2 & 1 \\
\hline
\end{tabular}

Figura 2A. Comparação paritária dos critérios em relação ao objetivo final.

Em relação à área para a implantação da instalação, levando em consideração que alguns critérios referem-se a valores monetários, é necessário realizar uma pesquisa prévia dos valores de mercado para o custo da área, incluindo eventuais custos de desapropriação, custo da construção e impostos, como IPTU.

Na sua atual localização o ETSP da CEAGESP está localizado em um terreno de 700 mil m², com área construída total de $271 \mathrm{mil} \mathrm{m}^{2}$. Com relação aos custos de construção, utilizou-se o valor de $\mathrm{R} \$ 580,04 / \mathrm{m}^{2}$, valor médio, para o período de março de 2005, atribuído ao Estado de São Paulo, coletado no site do IBGE (Diretoria de Pesquisas, Coordenação de Índices de Preços, Sistema Nacional de Pesquisa de Custos e Índices da Construção Civil).

A ponderação dos pesos, em relação à área, foi realizada da seguinte maneira: a disponibilidade foi considerada muito mais importante que o custo da área (terreno) e o custo de construção foi considerado um pouco mais importante que o custo da área. A disponibilidade foi considerada um pouco mais importante que o custo da construção. A razão do custo de construção ser mais relevante que o custo do terreno se deve não apenas ao fato do seu valor monetário ser, comparativamente, mais alto, 
mas também ao tempo que é gasto na fase de construção de uma obra. A Figura 3A mostra a ponderação dos pesos atribuída aos critérios em relação à área.

\begin{tabular}{l|c|cc|}
\multicolumn{1}{c}{ ÁREA } & \$ área & disponibilidade & \$ construção \\
\hline $\begin{array}{l}\text { \$ área } \\
\text { disponibilidade } \\
\text { \$ construção }\end{array}$ & 1 & $1 / 5$ & $1 / 3$ \\
\hline 5 & 1 & 3 \\
\hline
\end{tabular}

Figura 3A. Comparação paritária dos critérios em relação à área.

Em relação ao acesso, serão avaliados os sub-critérios relevantes na acessibilidade do local que será escolhido. Os sub-critérios \$ cliente e \$ MO representam, respectivamente, os custos dos clientes (consumidores) e os custos dos funcionários para chegar ao local. O \$transporte carga é o custo de transporte dos produtos. Este custo pode ser a somatória dos custos de entrada e saída dos produtos comercializados no Entreposto.

Num primeiro instante, considerou-se também o sub-critério distância, que está relacionado às distâncias entre o local e os fornecedores e clientes. Porém, através de uma análise mais cuidadosa, percebeu-se que o fator distância estava sendo considerado em duplicidade. Isso porque os custos de acessibilidade de clientes, carga e mão-de-obra já estão inseridos nos custos de transporte, ou seja, as distâncias encontram-se, indiretamente, consideradas, em termos monetários.

Para cada localização ainda devem ser avaliadas as rotas disponíveis, ruas, avenidas e estradas que conectam o local aos centros fornecedores e consumidores. A qualidade do transporte oferecido para acessar o local também é uma característica que deve ser considerada, uma vez que conforto é um fator relevante.

A comparação paritária foi realizada com base nas seguintes considerações: como a análise está sendo realizada sob o ponto de vista da CEAGESP, o custo de locomoção da MO (a empresa é responsável pelo pagamento do transporte do trabalhador, ou pelo menos parte deste custo) é mais importante do que o custo de acesso do cliente. A existência de rotas disponíveis é absolutamente mais importante 
do que a $\$$ do acesso do cliente. O custo do transporte de carga é claramente mais importante que o $\$$ do acesso do cliente. $\mathrm{E}$ a qualidade do transporte é muito mais importante do que o $\$$ do acesso do cliente. Este último fator, no caso do negócio do CEAGESP é relevante devido ao tipo de carga que é comercializado no entreposto, que se caracteriza como perecível e com índices de perda altos. A Figura 4A mostra a ponderação dos pesos atribuída aos critérios em relação ao acesso.

\begin{tabular}{|c|c|c|c|c|c|}
\hline \multirow{6}{*}{$\begin{array}{l}\text { ACESSO } \\
\text { \$ clientes } \\
\text { \$ MO } \\
\text { rotas disponíveis } \\
\text { \$ transporte carga } \\
\text { qualidade transp. }\end{array}$} & $\$$ clientes & $\$ \mathrm{MO}$ & rotas disponíveis & $\$$ transporte carga & qualidade transp. \\
\hline & 1 & $1 / 3$ & $1 / 9$ & $1 / 7$ & $1 / 5$ \\
\hline & 3 & 1 & $1 / 7$ & $1 / 5$ & $1 / 3$ \\
\hline & 9 & 7 & $\frac{1}{3}$ & 6 & $1 / 7$ \\
\hline & 7 & 5 & $1 / 6$ & 1 & $1 / 3$ \\
\hline & 5 & 3 & $1 / 7$ & $1 / 3$ & 1 \\
\hline
\end{tabular}

Figura 4A. Comparação paritária dos critérios em relação ao acesso.

A comparação paritária dos critérios em relação ao mercado foi realizada da seguinte forma: quando foram considerados os sub-critérios em comparação àquele relacionado ao tamanho tem-se que a proximidade é fortemente mais importante que o tamanho, a estabilidade é um pouco mais importante que o tamanho, e a relação com a concorrência é muito mais importante que o tamanho. A proximidade também é fortemente mais importante que a estabilidade e muito mais importante que a concorrência. Esta última ponderação baseia-se no fato de que a proximidade confere vantagem competitiva, quando se pensa na redução dos custos de transporte, e conseqüentemente, redução do preço para o consumidor final (cliente). E a concorrência foi considerada um pouco mais importante que a estabilidade. A Figura 5A mostra a ponderação dos pesos atribuída aos critérios em relação ao mercado.

\begin{tabular}{|c|c|c|c|c|c|}
\hline \multirow{2}{*}{\multicolumn{2}{|c|}{ tamanho }} & tamanho & proximidade & estabilidade & concorrência \\
\hline & & 1 & $\begin{array}{r}1 / 7 \\
1 / 7\end{array}$ & $1 / 3$ & $1 / 5$ \\
\hline proximidade & & 7 & 1 & 7 & 5 \\
\hline estabilidade & & 3 & $1 / 7$ & 1 & $1 / 3$ \\
\hline concorrência & & 5 & $1 / 5$ & 3 & 1 \\
\hline
\end{tabular}

Figura 5A. Comparação paritária dos critérios em relação ao mercado.

Em relação ao critério meio ambiente, há uma questão importante a ser apontada. Os itens de conformidade com as legislações vigentes e obtenção de licenças são pré- 
requisitos para implementação da instalação em determinada área. Já os itens relacionados a políticas de controle da poluição e preservação do meio ambiente da região se aplicam à fase de operação da instalação (pós-implementação).

A partir da observação deste fato, entende-se a necessidade de uma análise mais cuidadosa na determinação de escala de prioridades para este critério. A legislação e a obtenção de licenças foram consideradas iguais em termos de importância. O controle da poluição possui importância absoluta em relação à legislação e à obtenção de licenças. A Figura 6A mostra a ponderação dos pesos atribuída aos critérios em relação ao meio ambiente.

\begin{tabular}{|c|c|c|c|c|}
\hline \multirow{5}{*}{$\begin{array}{l}\qquad \text { MEIO AMBIENTE } \\
\text { Legislação } \\
\text { licenças } \\
\text { preservação } \\
\text { controle da poluição }\end{array}$} & legislação & licenças & preservação & controle da poluição \\
\hline & 1 & 1 & $1 / 7$ & $1 / 9$ \\
\hline & 1 & 1 & $1 / 7$ & $1 / 9$ \\
\hline & 7 & 7 & 1 & $1 / 3$ \\
\hline & 9 & 9 & 3 & 1 \\
\hline
\end{tabular}

Figura 6A. Comparação paritária dos critérios em relação ao meio ambiente.

Os fatores ambientais são vistos em termos de sua contribuição. Os custos ambientais diferem dos benefícios ambientais, uma vez que representam algum mal sobre o ecossistema pelas várias alternativas.

Em relação à ocupação urbana tem-se que os impactos sócio-econômicos gerados pela implantação ou manutenção desta instalação são de grande importância. Na região do Rodoanel, avalia-se que a implantação deste tipo de plataforma logística fomentaria o desenvolvimento da região. Na região da Zona Leste, a implantação desta instalação traria como benefício o possível aproveitamento da mão-de-obra ociosa que habita a região.

Como os impactos sócio-econômicos influenciam diretamente a opinião da população, aquele fator foi classificado como absolutamente mais importante do que este. E ainda fortemente mais importante do que as condições de uso do solo. As condições de uso do solo são um pouco mais importantes que a opinião da 
população. A Figura 7A mostra a ponderação dos pesos atribuída aos critérios em relação à ocupação urbana.

\begin{tabular}{|c|c|c|c|}
\hline \multirow{4}{*}{$\begin{array}{l}\text { OCUPAÇÃO URBANA } \\
\text { uso do solo } \\
\text { impactos SE } \\
\text { opinião da população }\end{array}$} & uso do solo & impactos SE & opinião da população \\
\hline & 1 & $1 / 7$ & 3 \\
\hline & 7 & 1 & 9 \\
\hline & $1 / 3$ & $1 / 9$ & 1 \\
\hline
\end{tabular}

Figura 7A. Comparação paritária dos critérios em relação à ocupação urbana.

Os benefícios sociais do projeto representam os benefícios que a sociedade, de um modo geral, usufruirá a partir da implantação do projeto. Os custos sociais representam os custos para a sociedade. O custo final é o efeito sobre a sociedade do deslocamento de pessoas de suas casas de acordo com as alternativas escolhidas.

Em relação ao fator humano, no caso de mudança da localização do Entreposto, surge uma preocupação com possíveis manifestações e organização dos atuais carregadores que trabalham no ETSP. Partindo do pressuposto que o salário da mãode-obra não sofra grande variação, para a Região Metropolitana de São Paulo, a disponibilidade da mão-de-obra é claramente mais importante que o custo da mãode-obra, e o grau de sindicalização é um pouco mais importante que os salários. A disponibilidade da mão-de-obra é muito mais importante que o grau de sindicalização. A Figura 8A mostra a ponderação dos pesos atribuída aos critérios em relação ao fator humano.

FATOR HUMANO \$ MO (salários) disponibilidade MO grau de sindicalização \$MO (salários)
disponibilidade MO
grau de sindicalização

\begin{tabular}{|c|r|r|r|}
\hline 1 & $1 / 7$ & \\
7 & 1 & $1 / 3$ \\
\hline 3 & $1 / 5$ & 5 & 1 \\
\hline
\end{tabular}

Figura 8A. Comparação paritária dos critérios em relação ao fator humano.

A fim de detalhar o processo de julgamento dos pesos atribuídos a cada uma das alternativas, apresenta-se a comparação paritária das alternativas para cada um dos sub-critérios. As justificativas para as hipóteses adotadas na ponderação dos pesos das alternativas em cada um dos sub-critérios também são descritas abaixo. As alternativas estão relacionadas da seguinte forma com as letras: 
- $\quad$ A = Vila Leopoldina;

- $\quad$ B = Rodoanel;

- $\quad$ C = Descentralização.

1. Critério: Área

a. \$ área

Assumiu-se que o custo na área do Rodoanel é o mais alto, em comparação com as alternativas, portanto essa alternativa foi considerada a "menos preferível”. O custo da área, no caso de manutenção do Entreposto na Vila Leopoldina, é nulo e, portanto apresenta uma vantagem.

\begin{tabular}{l|llll} 
& $\mathrm{A}$ & $\mathrm{B}$ & $\mathrm{C}$ & \\
\hline $\mathrm{A}$ & & 9,0 & 6,0 & \\
$\mathrm{~B}$ & & & $1 / 3$ &
\end{tabular}

b. Disponibilidade

A disponibilidade, no caso do Rodoanel, é maior do que no caso de ocorrer descentralização. Esta afirmação apóia-se na hipótese de haver bastantes áreas desocupadas na região do Rodoanel. No caso da descentralização, como a alternativa é implantar uma nova unidade do Entreposto na zona Leste do município de São Paulo, a disponibilidade de áreas é menor, já que esta é uma região que possui um elevado nível de ocupação.

\begin{tabular}{l|llll} 
& $\mathrm{A}$ & $\mathrm{B}$ & $\mathrm{C}$ & \\
\hline A & & 9,0 & 8,0 & \\
B & & & 2,0 &
\end{tabular}

c. \$ construção

A alternativa de transferir o Entreposto para o Rodoanel apresenta o custo de construção mais elevado, seguido pelo custo associado à descentralização. 


\begin{tabular}{l|llll} 
& $\mathrm{A}$ & $\mathrm{B}$ & $\mathrm{C}$ & \\
\hline $\mathrm{A}$ & & 9,0 & 5,0 & \\
$\mathrm{~B}$ & & & $1 / 3$ &
\end{tabular}

\section{Acesso}

a. \$ clientes

A descentralização apresenta a melhor alternativa para reduzir o custo do cliente acessar o local. Já o Rodoanel aumenta as distâncias para acessar o local e, portanto, neste critério, apresenta o custo mais alto para o cliente.

\begin{tabular}{l|llll} 
& $\mathrm{A}$ & $\mathrm{B}$ & $\mathrm{C}$ & \\
\hline $\mathrm{A}$ & & 7,0 & $1 / 3$ & \\
$\mathrm{~B}$ & & & $1 / 9$ & \\
$\mathrm{C}$ & & & &
\end{tabular}

b. \$MO

A explicação dos julgamentos, em relação a esse critério, é similar a anterior.

\begin{tabular}{l|llll} 
& $\mathrm{A}$ & $\mathrm{B}$ & $\mathrm{C}$ & \\
\hline $\mathrm{A}$ & & 7,0 & $1 / 3$ & \\
$\mathrm{~B}$ & & & $1 / 9$ &
\end{tabular}

c. Rotas disponíveis

Como todos os candidatos situam-se na Região Metropolitana de São Paulo, é possível assumir que, para todos os cenários, há rotas disponíveis em uma mesma dimensão. Apenas em relação à descentralização, surge uma pequena diferença, pois nesta situação, multiplicam-se as rotas disponíveis na medida em que se multiplicam também as unidades do Entreposto.

\begin{tabular}{l|llll} 
& $\mathrm{A}$ & $\mathrm{B}$ & $\mathrm{C}$ & \\
\hline $\mathrm{A}$ & & 1,0 & $1 / 2$ & \\
$\mathrm{~B}$ & & & $1 / 2$ & \\
$\mathrm{C}$ & & & &
\end{tabular}


d. \$ transporte de carga

A descentralização é o caso menos favorável em relação ao custo do transporte da carga. Isso porque neste caso, ocorre o aumento no número de viagens realizadas pelos fornecedores, que deverão realizar a entrega dos produtos nos diversos pontos de vendas existentes.

\begin{tabular}{l|llll} 
& $\mathrm{A}$ & $\mathrm{B}$ & $\mathrm{C}$ & \\
\hline $\mathrm{A}$ & & $1 / 2$ & 8,0 & \\
B & & & 9,0 &
\end{tabular}

e. Qualidade de transporte

Em relação à qualidade do transporte de carga, é possível assumir que a descentralização acarreta uma sensível perda. Isso porque, para atender os diversos pontos de venda, o fornecedor talvez seja obrigado a fracionar a carga e transferi-la para veículos menores.

\begin{tabular}{l|llll} 
& $\mathrm{A}$ & $\mathrm{B}$ & $\mathrm{C}$ & \\
\hline $\mathrm{A}$ & & 1,0 & 2,0 & \\
$\mathrm{~B}$ & & & 2,0 &
\end{tabular}

\section{Mercado}

a. Tamanho

A descentralização permite a expansão da área atendida e, conseqüentemente, causa um incremento no tamanho do mercado. O cenário de implantação do Entreposto no Rodoanel, pode causar uma redução do mercado atendido, pois aumenta as distâncias até os centro consumidores.

\begin{tabular}{l|llll} 
& $\mathrm{A}$ & $\mathrm{B}$ & $\mathrm{C}$ & \\
\hline $\mathrm{A}$ & & 4,0 & $1 / 2$ & \\
$\mathrm{~B}$ & & & $1 / 6$ & \\
$\mathrm{C}$ & & & &
\end{tabular}

b. Proximidade 
Este sub-critério pode ser analisado de forma similar àquele referente ao tamanho do mercado. A descentralização diminui as distâncias aos centros consumidores, tornando o mercado mais próximo.

\begin{tabular}{l|llll} 
& $\mathrm{A}$ & $\mathrm{B}$ & $\mathrm{C}$ & \\
\hline $\mathrm{A}$ & & 4,0 & $1 / 2$ & \\
$\mathrm{~B}$ & & & $1 / 7$ & \\
$\mathrm{C}$ & & & &
\end{tabular}

\section{c. Estabilidade}

A condição de estabilidade tende a ser mais forte no caso de manutenção da atual localização do ETSP. A tendência do mercado, no caso do Rodoanel, é de redução, enquanto no caso da descentralização é de aumento.

\begin{tabular}{l|llll} 
& $\mathrm{A}$ & $\mathrm{B}$ & $\mathrm{C}$ & \\
\hline $\mathrm{A}$ & & 6,0 & 7,0 & \\
$\mathrm{~B}$ & & & 2,0 &
\end{tabular}

\section{d. Concorrência}

A presença da concorrência apresenta-se com muito mais força no caso da descentralização. Isso acontece porque a descentralização pulveriza as atividades do Entreposto e habilita unidades comerciais de menor escala a tornarem-se concorrentes.

\begin{tabular}{l|llll} 
& A & B & C & \\
\hline A & & 1,0 & 4,0 & \\
B & & & 4,0 &
\end{tabular}

4. Meio ambiente

a. Legislação

Em termos de legislação ambiental, a Vila Leopoldina é preferível em relação à conformidade com a legislação, já que o Entreposto encontra-se devidamente localizado e em funcionamento. O Rodoanel é a alternativa que apresenta maior impedância para instalação da plataforma, pelo fato de constituir uma região menos explorada. 


\begin{tabular}{l|llll} 
& $\mathrm{A}$ & $\mathrm{B}$ & $\mathrm{C}$ & \\
\hline $\mathrm{A}$ & & 5,0 & 4,0 & \\
$\mathrm{~B}$ & & & $1 / 2$ &
\end{tabular}

b. Licenças

Este sub-critério pode ser analisado de forma similar àquele referente à legislação ambiental.

\begin{tabular}{l|llll} 
& $\mathrm{A}$ & $\mathrm{B}$ & $\mathrm{C}$ & \\
\hline A & & 5,0 & 4,0 & \\
B & & & $1 / 2$ & \\
C & & & &
\end{tabular}

\section{c. Preservação}

O cenário que apresenta como localização a região do Rodoanel é aquele que mais prejudica a preservação do meio ambiente no entorno. O cenário de descentralização, num primeiro instante, não causa grandes problemas relacionados com a preservação, uma vez que serão utilizadas áreas em regiões previamente ocupadas. Ao longo do tempo, o aumento do fluxo de veículos na região pode acarretar a degradação do local.

\begin{tabular}{l|llll} 
& A & B & C & \\
\hline A & & 7,0 & 5,0 & \\
B & & & $1 / 2$ &
\end{tabular}

d. Controle da poluição

A descentralização apresenta o cenário que mais contribui no controle da poluição. No caso de mudança de local do Entreposto para a região do Rodoanel, o que acontece é apenas a transferência de incidência do problema.

\begin{tabular}{l|llll} 
& $\mathrm{A}$ & $\mathrm{B}$ & $\mathrm{C}$ & \\
\hline $\mathrm{A}$ & & 1,0 & $1 / 6$ & \\
$\mathrm{~B}$ & & & $1 / 6$ & \\
$\mathrm{C}$ & & & &
\end{tabular}

\section{Ocupação urbana}
a. Uso do solo 
A alternativa que apresenta a maior probabilidade de encontrar barreiras ou restrições para a implantação de um entreposto é o Rodoanel.

\begin{tabular}{l|llll} 
& A & B & C & \\
\hline A & & 9,0 & 3,0 & \\
B & & & $1 / 5$ & \\
C & & & &
\end{tabular}

b. Impactos sócio-econômicos

O Rodoanel, como cenário, apresenta como principal impacto sócio-econômico o desenvolvimento da região, promovendo, inclusive, a geração de empregos. Com a descentralização ocorre a grande oportunidade de aproveitamento da mão-de-obra ociosa que habita a região.

Ainda é necessário levar em consideração que qualquer alteração da localização atual pode acarretar problemas na região da Vila Leopoldina.

\begin{tabular}{l|llll} 
& $\mathrm{A}$ & $\mathrm{B}$ & $\mathrm{C}$ & \\
\hline $\mathrm{A}$ & & $1 / 3$ & $1 / 2$ & \\
$\mathrm{~B}$ & & & 2,0 &
\end{tabular}

\section{c. Opinião da população}

A opinião da população é um critério que apresenta relevância maior no cenário da Vila Leopoldina em relação aos outros aqui estudados. Além dos moradores da região já estarem habituados com as atividades do Entreposto, há sindicatos dos empregados atuando na região. Na região do Rodoanel, a opinião da população também afetará a implantação, porém seus impactos afetarão o projeto em uma escala menor. Isso porque o Entreposto traz consigo tanto benefícios, como a geração de empregos, quanto desvantagens, como o aumento do tráfego de veículos na região e sua conseqüente degradação.

\begin{tabular}{l|llll} 
& A & B & C & \\
\hline A & & 5,0 & 3,0 & \\
$B$ & & & $1 / 2$ &
\end{tabular}

6. Fator humano

a. \$MO 
Neste caso a ponderação foi realizada da seguinte forma: quanto maior o custo menor a importância da alternativa analisada. Considerou-se também que os maiores salários seriam pagos na Vila Leopoldina, já que os empregados encontram-se organizados e o grau de sindicalização é maior. Os salários na região do Rodoanel e no caso da descentralização são bastante similares, no entanto assumiu-se que eles são levemente menores na região do Rodoanel.

\begin{tabular}{l|llll} 
& $\mathrm{A}$ & $\mathrm{B}$ & $\mathrm{C}$ & \\
\hline $\mathrm{A}$ & & $1 / 3$ & $1 / 2$ & \\
$\mathrm{~B}$ & & & 1,0 &
\end{tabular}

b. Disponibilidade de MO

Com a descentralização será possível o aproveitamento da mão-de-obra ociosa e disponível existente na região onde for instalada a nova unidade do Entreposto. O Rodoanel é a região que apresenta a menor quantidade de mão-de-obra disponível, devido às maiores distâncias às concentrações populacionais.

\begin{tabular}{l|llll} 
& $\mathrm{A}$ & $\mathrm{B}$ & $\mathrm{C}$ & \\
\hline $\mathrm{A}$ & & 5,0 & $1 / 2$ & \\
$\mathrm{~B}$ & & & $1 / 9$ &
\end{tabular}

c. Grau de sindicalização

Num primeiro instante, o grau de sindicalização é um fator que possui relevância apenas no cenário da Vila Leopoldina, pois neste caso os empregados já se encontram organizados.

\begin{tabular}{l|llll} 
& A & B & C & \\
\hline A & & $1 / 9$ & $1 / 9$ & \\
B & & & 1,0 &
\end{tabular}

Num primeiro instante o custo de vida foi selecionado como um fator relevante para a localização do ETSP da CEAGESP, mas surgiu a questão se este custo possui alguma relevância no tratamento do problema. Principalmente sob o ponto de vista da Companhia, este fator parece não merecer relevância. O custo de transporte, ou locomoção, considerado neste item já apareceu anteriormente, inserido no subcritério de acessibilidade. 
Inicialmente, todas as variáveis que tem algum efeito no julgamento a ser feito, sugeridas pelo decisor ou grupo de decisores, são aceitas. Ao longo do procedimento, algumas poderão ser ignoradas, por sua baixa prioridade, ou por apresentar duplicidade em relação à outra variável.

Abaixo, nas Figuras 9A a 14A, apresentam-se alguns resultados extraídos do software Expert Choice, na aplicação ao caso piloto do ETSP da CEAGESP.

A Figura 9A representa o resultado final obtido na avaliação das alternativas. Entre as alternativas avaliadas e considerando o procedimento adotado no preenchimento das matrizes de comparação paritária, o cenário de descentralização do ETSP da CEAGESP constitui a melhor alternativa e a mudança do local do Entreposto para a região do Rodoanel apresenta a pior opção.

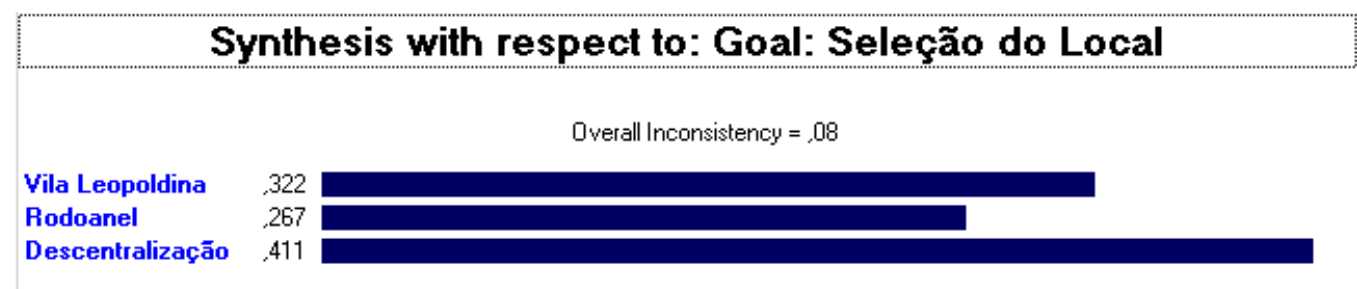

Figura 9A. Resultado da Avaliação das alternativas.

A Figura 10A mostra o desempenho de todos os critérios em cada um dos cenários avaliados. Este gráfico facilita a visualização dos pontos fortes e fracos de cada uma das alternativas. 


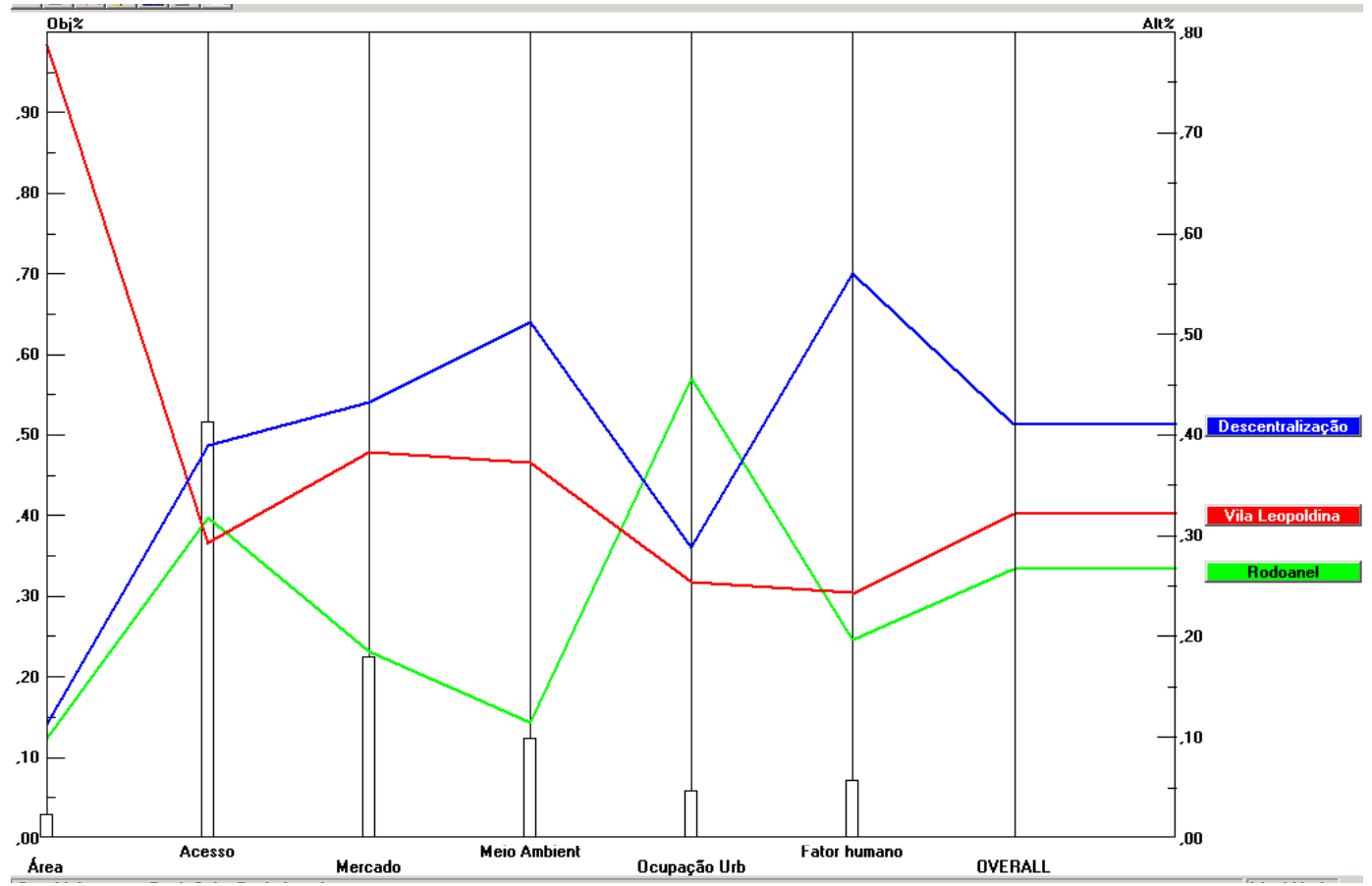

Figura 10A. Gráfico de desempenho dos critérios, para cada uma das alternativas.

A Figura 11A apresenta o gráfico de sensibilidade dos critérios e alternativas. Os resultados da avaliação das alternativas foram apresentados anteriormente na Figura 9A. Em relação à avaliação dos critérios, através deste gráfico, é possível verificar os pesos de contribuição de cada um dos critérios no objetivo final do problema apresentado.

No estudo do caso piloto do ETSP da CEAGESP, o peso atribuído à acessibilidade do local torna este critério bastante relevante no processo de tomada de decisão. Outro critério importante está voltado às condições oferecidas ao mercado consumidor e, por outro lado, como o mercado consumidor pode influenciar na localização da instalação.

As Figuras 12A, 13A e 14A apresentam a comparação dos pesos dos critérios entre as alternativas, duas a duas. Nestes gráficos comparativos, é possível notar que a opção de descentralização é, realmente, a melhor alternativa. E a comparação entre o cenário da Vila Leopoldina e o Rodoanel mostra o resultado favorável para a manutenção do Entreposto na sua localização atual. 


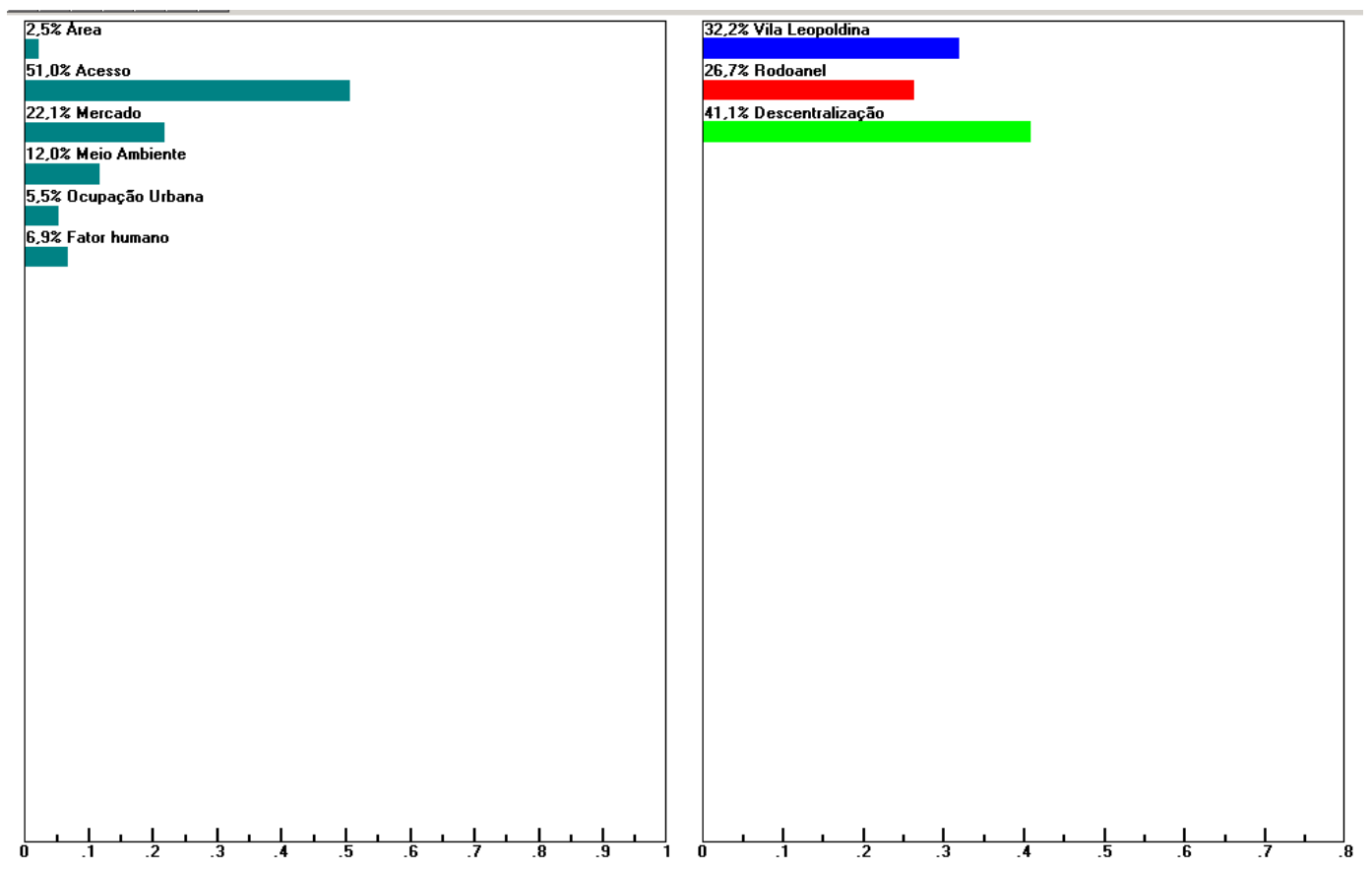

Figura 11A. Gráfico de sensibilidade dos critérios e alternativas.

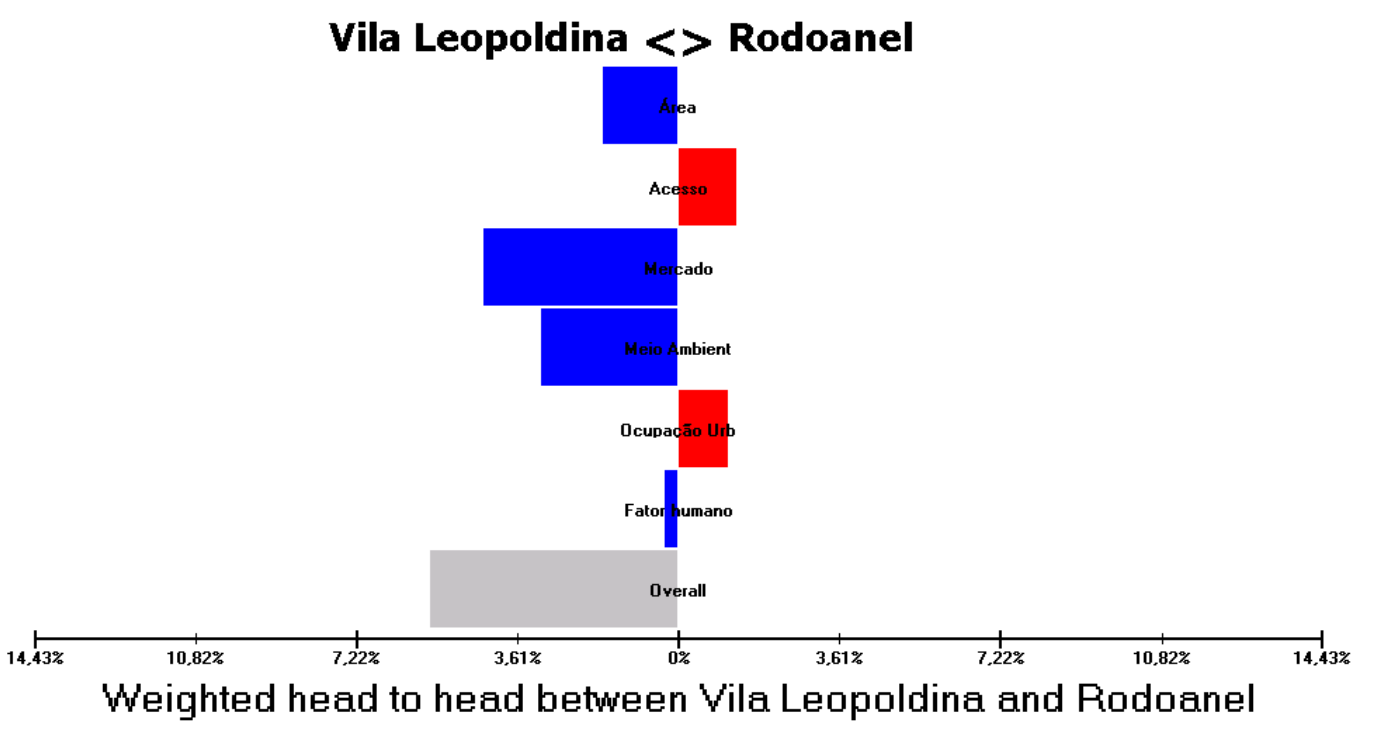

Figura 12A. Comparação dos pesos entre as alternativas: Vila Leopoldina $\mathrm{x}$ Rodoanel. 


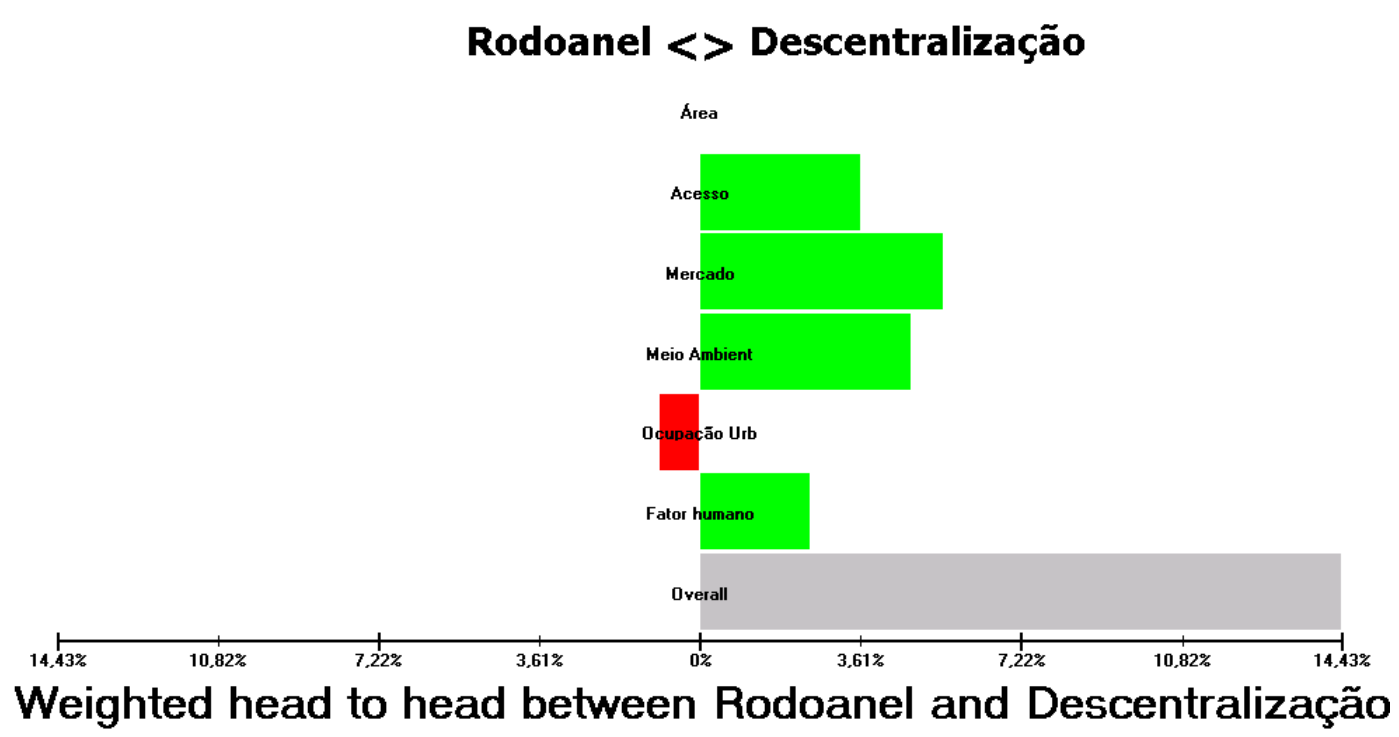

Figura 13A. Comparação dos pesos entre as alternativas: Rodoanel $\mathrm{x}$ Descentralização.

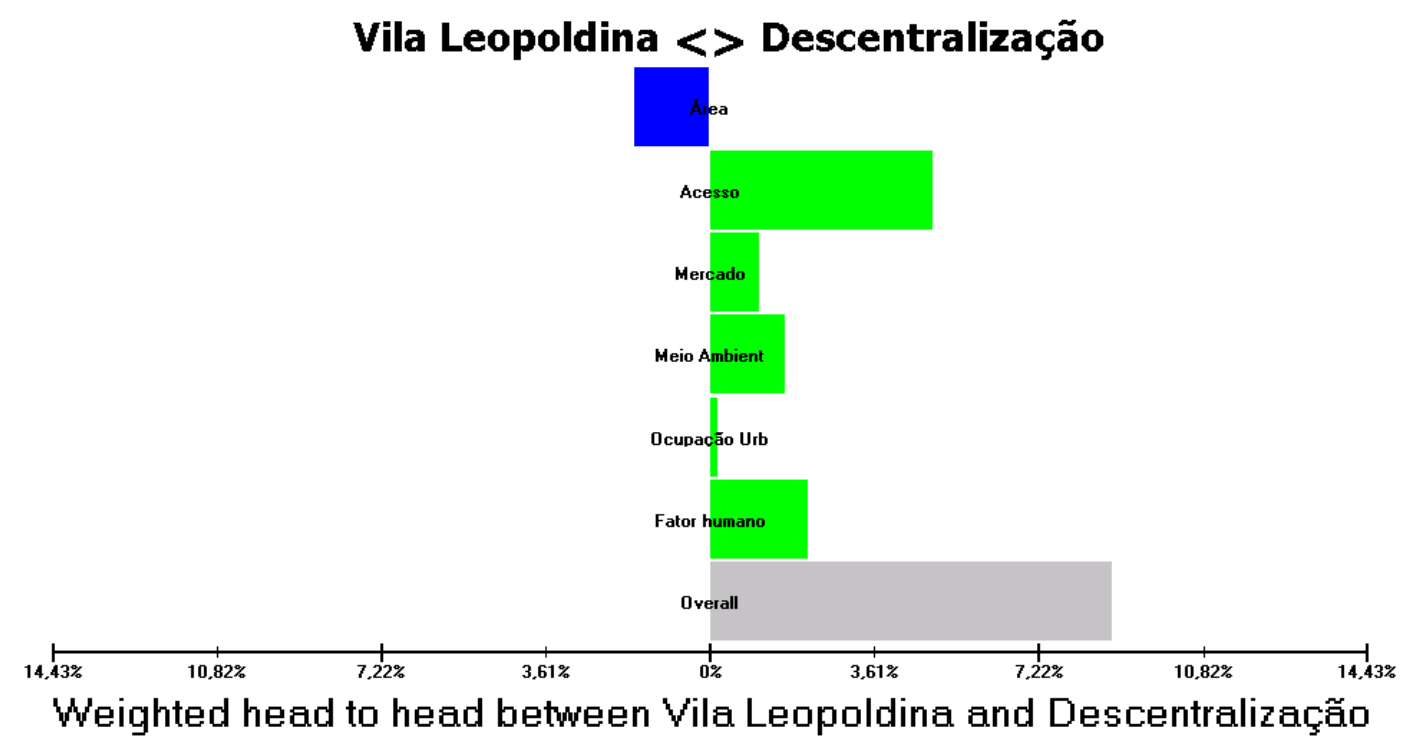

Figura 14A. Comparação dos pesos entre as alternativas: Vila Leopoldina $\mathrm{x}$ Descentralização. 


\section{Anexo E - Questionários}

A solução adotada foi a de desenvolver discussões para a elaboração dos questionários. Como os agentes deliberantes tinham pouca familiaridade com o AHP, a escolha dos questionários foi baseada em sua forma objetiva de organizar a análise da estrutura e resposta das questões.

O questionário consiste de um conjunto de questões de múltipla escolha elaboradas para que os agentes deliberantes comparem todos os elementos de cada nível da estrutura hierárquica sob um determinado ponto de vista.

Portanto em cada questão os deliberantes encontrarão o ponto de vista a ser considerado nas comparações paritárias e uma Tabela contendo todos os elementos do nível analisado.

Abaixo segue a estrutura utilizada no questionário aplicado ao problema do ETSP da CEAGESP.

\section{1) Perguntas Gerais:}

Nome:

Grupo que faz parte:

( ) Administração do Entreposto;

( ) Permissionários;

( ) Clientes;

( ) Equipe de projeto LPT/EPUSP.

( ) Outro:

\section{2) Análise dos Critérios Relevantes para a localização do ETSP da CEAGESP:}

Esta parte do questionário busca obter a classificação das alternativas, através da comparação relativa dos diversos elementos de cada nível da estrutura hierárquica sob um determinado ponto de vista. 
As questões estão organizadas da seguinte forma: cada linha contém apenas dois elementos que devem ser comparados sob o ponto de vista em questão. Entre esses elementos está expressa uma seqüência numérica, que representa a escala de julgamentos, proposta por Saaty (1991), e melhor explicada na Tabela de escala de razão.

E o procedimento de preenchimento dos questionários segue as instruções: os respondentes deverão fazer uma marca na escala de julgamentos, de cada linha, que em sua opinião apresenta melhor o grau de importância de um critério sobre o outro, segundo o ponto de vista em questão. Portanto, de maneira análoga a uma balança, deverá ser identificado o critério de maior peso e sua intensidade.

\begin{tabular}{|c|c|c|}
\hline $\begin{array}{l}\text { Intensidade de } \\
\text { Importância }\end{array}$ & Definição & Explicação \\
\hline 1 & mesma importância & $\begin{array}{l}\text { indiferente, peso de cada uma das atividades } \\
\text { é similar }\end{array}$ \\
\hline 3 & importância pequena de uma sobre a outra & $\begin{array}{l}\text { uma alternativa é levemente mais importante } \\
\text { que a outra }\end{array}$ \\
\hline 5 & importância grande ou essencial & $\begin{array}{l}\text { uma alternativa é fortemente mais importante } \\
\text { que a outra }\end{array}$ \\
\hline 7 & importância grande ou demonstrada & $\begin{array}{l}\text { uma alternativa é muito fortemente mais } \\
\text { importante que a outra e é possível } \\
\text { demonstrar sua importância na prática. }\end{array}$ \\
\hline 9 & importância absoluta & $\begin{array}{l}\text { Não há dúvida que uma alternativa é } \\
\text { absolutamente mais importante que a outra }\end{array}$ \\
\hline $2,4,6,8$ & valores intermediários entre os valores adjacentes & $\begin{array}{l}\text { quando se procura uma condição de } \\
\text { compromisso intermediária entre duas } \\
\text { definições. }\end{array}$ \\
\hline
\end{tabular}

Fonte: Adaptado de Saaty (1991).

Primeiramente, para cada um dos sub-critérios devem ser comparadas as alternativas de locais para a instalação do ETSP da CEAGESP. A alternativa "Vila Leopoldina” consiste na manutenção da localização atual do Entreposto e a conseqüente readequação das suas instalações. A alternativa "Rodoanel” consiste na transferência da instalação, na sua totalidade, para a região do tramo oeste do Rodoanel. A alternativa de "Descentralização" implica a instalação de novas unidades da CEAGESP dentro da RMSP sem a desativação do Entreposto da Vila Leopoldina. Para efeito de análise, a descentralização considerada consiste na ativação de uma nova unidade na Zona Leste do município de São Paulo. 
Em relação à disponibilidade de área, compare relativamente as seguintes alternativas:

\begin{tabular}{llllllllllllllllllll|}
\hline Vila Leopoldina & 9 & 8 & 7 & 6 & 5 & 4 & 3 & 2 & 1 & 2 & 3 & 4 & 5 & 6 & 7 & 8 & 9 & Rodoanel \\
\hline Vila Leopoldina & 9 & 8 & 7 & 6 & 5 & 4 & 3 & 2 & 1 & 2 & 3 & 4 & 5 & 6 & 7 & 8 & 9 & Descentralização \\
\hline Rodoanel & 9 & 8 & 7 & 6 & 5 & 4 & 3 & 2 & 1 & 2 & 3 & 4 & 5 & 6 & 7 & 8 & 9 & Descentralização \\
\hline
\end{tabular}

Em relação ao investimento necessário para a remodelação do ETSP ou implantação de novos entrepostos, compare relativamente as seguintes alternativas:

\begin{tabular}{|lcccccccccccccccccc|}
\hline Vila Leopoldina & 9 & 8 & 7 & 6 & 5 & 4 & 3 & 2 & 1 & 2 & 3 & 4 & 5 & 6 & 7 & 8 & 9 & Rodoanel \\
\hline Vila Leopoldina & 9 & 8 & 7 & 6 & 5 & 4 & 3 & 2 & 1 & 2 & 3 & 4 & 5 & 6 & 7 & 8 & 9 & Descentralização \\
\hline Rodoanel & 9 & 8 & 7 & 6 & 5 & 4 & 3 & 2 & 1 & 2 & 3 & 4 & 5 & 6 & 7 & 8 & 9 & Descentralização \\
\hline
\end{tabular}

Em relação ao custo de acesso para os clientes, compare relativamente as seguintes alternativas:

\begin{tabular}{|lcccccccccccccccccc|}
\hline Vila Leopoldina & 9 & 8 & 7 & 6 & 5 & 4 & 3 & 2 & 1 & 2 & 3 & 4 & 5 & 6 & 7 & 8 & 9 & Rodoanel \\
\hline Vila Leopoldina & 9 & 8 & 7 & 6 & 5 & 4 & 3 & 2 & 1 & 2 & 3 & 4 & 5 & 6 & 7 & 8 & 9 & Descentralização \\
\hline Rodoanel & 9 & 8 & 7 & 6 & 5 & 4 & 3 & 2 & 1 & 2 & 3 & 4 & 5 & 6 & 7 & 8 & 9 & Descentralização \\
\hline
\end{tabular}

Em relação ao custo de acesso para os empregados, compare relativamente as seguintes alternativas:

\begin{tabular}{|lcccccccccccccccccc|}
\hline Vila Leopoldina & 9 & 8 & 7 & 6 & 5 & 4 & 3 & 2 & 1 & 2 & 3 & 4 & 5 & 6 & 7 & 8 & 9 & Rodoanel \\
\hline Vila Leopoldina & 9 & 8 & 7 & 6 & 5 & 4 & 3 & 2 & 1 & 2 & 3 & 4 & 5 & 6 & 7 & 8 & 9 & Descentralização \\
\hline Rodoanel & 9 & 8 & 7 & 6 & 5 & 4 & 3 & 2 & 1 & 2 & 3 & 4 & 5 & 6 & 7 & 8 & 9 & Descentralização \\
\hline
\end{tabular}

Em relação ao custo de abastecimento de mercadorias, compare relativamente as seguintes alternativas:

\begin{tabular}{|lcccccccccccccccccc|}
\hline Vila Leopoldina & 9 & 8 & 7 & 6 & 5 & 4 & 3 & 2 & 1 & 2 & 3 & 4 & 5 & 6 & 7 & 8 & 9 & Rodoanel \\
\hline Vila Leopoldina & 9 & 8 & 7 & 6 & 5 & 4 & 3 & 2 & 1 & 2 & 3 & 4 & 5 & 6 & 7 & 8 & 9 & Descentralização \\
\hline Rodoanel & 9 & 8 & 7 & 6 & 5 & 4 & 3 & 2 & 1 & 2 & 3 & 4 & 5 & 6 & 7 & 8 & 9 & Descentralização \\
\hline
\end{tabular}

Em relação ao custo de distribuição das mercadorias, compare relativamente as seguintes alternativas:

\begin{tabular}{|lcccccccccccccccccc|}
\hline Vila Leopoldina & 9 & 8 & 7 & 6 & 5 & 4 & 3 & 2 & 1 & 2 & 3 & 4 & 5 & 6 & 7 & 8 & 9 & Rodoanel \\
\hline Vila Leopoldina & 9 & 8 & 7 & 6 & 5 & 4 & 3 & 2 & 1 & 2 & 3 & 4 & 5 & 6 & 7 & 8 & 9 & Descentralização \\
\hline Rodoanel & 9 & 8 & 7 & 6 & 5 & 4 & 3 & 2 & 1 & 2 & 3 & 4 & 5 & 6 & 7 & 8 & 9 & Descentralização \\
\hline
\end{tabular}


Em relação à facilidade de acesso para os clientes, compare relativamente as seguintes alternativas:

\begin{tabular}{|lcccccccccccccccccc|}
\hline Vila Leopoldina & 9 & 8 & 7 & 6 & 5 & 4 & 3 & 2 & 1 & 2 & 3 & 4 & 5 & 6 & 7 & 8 & 9 & Rodoanel \\
\hline Vila Leopoldina & 9 & 8 & 7 & 6 & 5 & 4 & 3 & 2 & 1 & 2 & 3 & 4 & 5 & 6 & 7 & 8 & 9 & Descentralização \\
\hline Rodoanel & 9 & 8 & 7 & 6 & 5 & 4 & 3 & 2 & 1 & 2 & 3 & 4 & 5 & 6 & 7 & 8 & 9 & Descentralização \\
\hline
\end{tabular}

Em relação à facilidade de acesso para os empregados, compare relativamente as seguintes alternativas:

\begin{tabular}{|lcccccccccccccccccc|}
\hline Vila Leopoldina & 9 & 8 & 7 & 6 & 5 & 4 & 3 & 2 & 1 & 2 & 3 & 4 & 5 & 6 & 7 & 8 & 9 & Rodoanel \\
\hline Vila Leopoldina & 9 & 8 & 7 & 6 & 5 & 4 & 3 & 2 & 1 & 2 & 3 & 4 & 5 & 6 & 7 & 8 & 9 & Descentralização \\
\hline Rodoanel & 9 & 8 & 7 & 6 & 5 & 4 & 3 & 2 & 1 & 2 & 3 & 4 & 5 & 6 & 7 & 8 & 9 & Descentralização \\
\hline
\end{tabular}

Em relação à facilidade de acesso para fornecimento dos produtos, compare relativamente as seguintes alternativas:

\begin{tabular}{|lcccccccccccccccccc|}
\hline Vila Leopoldina & 9 & 8 & 7 & 6 & 5 & 4 & 3 & 2 & 1 & 2 & 3 & 4 & 5 & 6 & 7 & 8 & 9 & Rodoanel \\
\hline Vila Leopoldina & 9 & 8 & 7 & 6 & 5 & 4 & 3 & 2 & 1 & 2 & 3 & 4 & 5 & 6 & 7 & 8 & 9 & Descentralização \\
\hline Rodoanel & 9 & 8 & 7 & 6 & 5 & 4 & 3 & 2 & 1 & 2 & 3 & 4 & 5 & 6 & 7 & 8 & 9 & Descentralização \\
\hline
\end{tabular}

Em relação à facilidade de acesso para distribuição dos produtos, compare relativamente as seguintes alternativas:

\begin{tabular}{|lcccccccccccccccccc|}
\hline Vila Leopoldina & 9 & 8 & 7 & 6 & 5 & 4 & 3 & 2 & 1 & 2 & 3 & 4 & 5 & 6 & 7 & 8 & 9 & Rodoanel \\
\hline Vila Leopoldina & 9 & 8 & 7 & 6 & 5 & 4 & 3 & 2 & 1 & 2 & 3 & 4 & 5 & 6 & 7 & 8 & 9 & Descentralização \\
\hline Rodoanel & 9 & 8 & 7 & 6 & 5 & 4 & 3 & 2 & 1 & 2 & 3 & 4 & 5 & 6 & 7 & 8 & 9 & Descentralização \\
\hline
\end{tabular}

Em relação à possibilidade de incremento do mercado consumidor, compare relativamente as seguintes alternativas:

\begin{tabular}{|lcccccccccccccccccc|}
\hline Vila Leopoldina & 9 & 8 & 7 & 6 & 5 & 4 & 3 & 2 & 1 & 2 & 3 & 4 & 5 & 6 & 7 & 8 & 9 & Rodoanel \\
\hline Vila Leopoldina & 9 & 8 & 7 & 6 & 5 & 4 & 3 & 2 & 1 & 2 & 3 & 4 & 5 & 6 & 7 & 8 & 9 & Descentralização \\
\hline Rodoanel & 9 & 8 & 7 & 6 & 5 & 4 & 3 & 2 & 1 & 2 & 3 & 4 & 5 & 6 & 7 & 8 & 9 & Descentralização \\
\hline
\end{tabular}

Em relação à competitividade do Entreposto face à concorrência, compare relativamente as seguintes alternativas:

\begin{tabular}{|lcccccccccccccccccc|}
\hline Vila Leopoldina & 9 & 8 & 7 & 6 & 5 & 4 & 3 & 2 & 1 & 2 & 3 & 4 & 5 & 6 & 7 & 8 & 9 & Rodoanel \\
\hline Vila Leopoldina & 9 & 8 & 7 & 6 & 5 & 4 & 3 & 2 & 1 & 2 & 3 & 4 & 5 & 6 & 7 & 8 & 9 & Descentralização \\
\hline Rodoanel & 9 & 8 & 7 & 6 & 5 & 4 & 3 & 2 & 1 & 2 & 3 & 4 & 5 & 6 & 7 & 8 & 9 & Descentralização \\
\hline
\end{tabular}


Em relação ao controle da poluição, mais especificamente geração de poluição veicular e conseqüentes prejuízos à qualidade do ar, compare relativamente as seguintes alternativas:

\begin{tabular}{|lcccccccccccccccccc|}
\hline Vila Leopoldina & 9 & 8 & 7 & 6 & 5 & 4 & 3 & 2 & 1 & 2 & 3 & 4 & 5 & 6 & 7 & 8 & 9 & Rodoanel \\
\hline Vila Leopoldina & 9 & 8 & 7 & 6 & 5 & 4 & 3 & 2 & 1 & 2 & 3 & 4 & 5 & 6 & 7 & 8 & 9 & Descentralização \\
\hline Rodoanel & 9 & 8 & 7 & 6 & 5 & 4 & 3 & 2 & 1 & 2 & 3 & 4 & 5 & 6 & 7 & 8 & 9 & Descentralização \\
\hline
\end{tabular}

Em relação à obediência à legislação ambiental, compare relativamente as seguintes alternativas:

\begin{tabular}{|lcccccccccccccccccc|}
\hline Vila Leopoldina & 9 & 8 & 7 & 6 & 5 & 4 & 3 & 2 & 1 & 2 & 3 & 4 & 5 & 6 & 7 & 8 & 9 & Rodoanel \\
\hline Vila Leopoldina & 9 & 8 & 7 & 6 & 5 & 4 & 3 & 2 & 1 & 2 & 3 & 4 & 5 & 6 & 7 & 8 & 9 & Descentralização \\
\hline Rodoanel & 9 & 8 & 7 & 6 & 5 & 4 & 3 & 2 & 1 & 2 & 3 & 4 & 5 & 6 & 7 & 8 & 9 & Descentralização \\
\hline
\end{tabular}

Em relação à preservação do local, ou seja, às interferências ou impactos negativos provocados pela instalação, compare relativamente as seguintes alternativas:

\begin{tabular}{|lcccccccccccccccccc|}
\hline Vila Leopoldina & 9 & 8 & 7 & 6 & 5 & 4 & 3 & 2 & 1 & 2 & 3 & 4 & 5 & 6 & 7 & 8 & 9 & Rodoanel \\
\hline Vila Leopoldina & 9 & 8 & 7 & 6 & 5 & 4 & 3 & 2 & 1 & 2 & 3 & 4 & 5 & 6 & 7 & 8 & 9 & Descentralização \\
\hline Rodoanel & 9 & 8 & 7 & 6 & 5 & 4 & 3 & 2 & 1 & 2 & 3 & 4 & 5 & 6 & 7 & 8 & 9 & Descentralização \\
\hline
\end{tabular}

Em relação ao uso do solo, a respeito de barreiras ou restrições físicas ou de legislação que dificultem ou impeçam a instalação ou operação do Entreposto, compare relativamente as seguintes alternativas:

\begin{tabular}{|lcccccccccccccccccc|}
\hline Vila Leopoldina & 9 & 8 & 7 & 6 & 5 & 4 & 3 & 2 & 1 & 2 & 3 & 4 & 5 & 6 & 7 & 8 & 9 & Rodoanel \\
\hline Vila Leopoldina & 9 & 8 & 7 & 6 & 5 & 4 & 3 & 2 & 1 & 2 & 3 & 4 & 5 & 6 & 7 & 8 & 9 & Descentralização \\
\hline Rodoanel & 9 & 8 & 7 & 6 & 5 & 4 & 3 & 2 & 1 & 2 & 3 & 4 & 5 & 6 & 7 & 8 & 9 & Descentralização \\
\hline
\end{tabular}

Em relação aos impactos sócio-ecônomicos positivos como, por exemplo, desenvolvimento da região, criação de postos de trabalho, compare relativamente as seguintes alternativas:

\begin{tabular}{llllllllllllllllllll|}
\hline Vila Leopoldina & 9 & 8 & 7 & 6 & 5 & 4 & 3 & 2 & 1 & 2 & 3 & 4 & 5 & 6 & 7 & 8 & 9 & Rodoanel \\
\hline Vila Leopoldina & 9 & 8 & 7 & 6 & 5 & 4 & 3 & 2 & 1 & 2 & 3 & 4 & 5 & 6 & 7 & 8 & 9 & Descentralização \\
\hline Rodoanel & 9 & 8 & 7 & 6 & 5 & 4 & 3 & 2 & 1 & 2 & 3 & 4 & 5 & 6 & 7 & 8 & 9 & Descentralização \\
\hline
\end{tabular}

Em relação à opinião favorável pela população, compare relativamente as seguintes alternativas: 


\begin{tabular}{|llllllllllllllllllll}
\hline Vila Leopoldina & 9 & 8 & 7 & 6 & 5 & 4 & 3 & 2 & 1 & 2 & 3 & 4 & 5 & 6 & 7 & 8 & 9 & Rodoanel \\
\hline
\end{tabular}

\begin{tabular}{|lllllllllllllllllll|}
\hline Vila Leopoldina & 9 & 8 & 7 & 6 & 5 & 4 & 3 & 2 & 1 & 2 & 3 & 4 & 5 & 6 & 7 & 8 & 9 & Descentralização \\
\hline
\end{tabular}

\begin{tabular}{|llllllllllllllllllll}
\hline Rodoanel & 9 & 8 & 7 & 6 & 5 & 4 & 3 & 2 & 1 & 2 & 3 & 4 & 5 & 6 & 7 & 8 & 9 & Descentralização \\
\hline
\end{tabular}

Em relação ao custo da mão-de-obra, compare relativamente as seguintes alternativas:

\begin{tabular}{|lcccccccccccccccccc|}
\hline Vila Leopoldina & 9 & 8 & 7 & 6 & 5 & 4 & 3 & 2 & 1 & 2 & 3 & 4 & 5 & 6 & 7 & 8 & 9 & Rodoanel \\
\hline Vila Leopoldina & 9 & 8 & 7 & 6 & 5 & 4 & 3 & 2 & 1 & 2 & 3 & 4 & 5 & 6 & 7 & 8 & 9 & Descentralização \\
\hline Rodoanel & 9 & 8 & 7 & 6 & 5 & 4 & 3 & 2 & 1 & 2 & 3 & 4 & 5 & 6 & 7 & 8 & 9 & Descentralização \\
\hline
\end{tabular}

Em relação à disponibilidade de mão-de-obra, compare relativamente as seguintes alternativas:

\begin{tabular}{lllllllllllllllllll|}
\hline Vila Leopoldina & 9 & 8 & 7 & 6 & 5 & 4 & 3 & 2 & 1 & 2 & 3 & 4 & 5 & 6 & 7 & 8 & 9 & Rodoanel \\
\hline Vila Leopoldina & 9 & 8 & 7 & 6 & 5 & 4 & 3 & 2 & 1 & 2 & 3 & 4 & 5 & 6 & 7 & 8 & 9 & Descentralização \\
\hline Rodoanel & 9 & 8 & 7 & 6 & 5 & 4 & 3 & 2 & 1 & 2 & 3 & 4 & 5 & 6 & 7 & 8 & 9 & Descentralização \\
\hline
\end{tabular}

Em relação ao grau de sindicalização, compare relativamente as seguintes alternativas:

\begin{tabular}{lllllllllllllllllll|}
\hline Vila Leopoldina & 9 & 8 & 7 & 6 & 5 & 4 & 3 & 2 & 1 & 2 & 3 & 4 & 5 & 6 & 7 & 8 & 9 & Rodoanel \\
\hline Vila Leopoldina & 9 & 8 & 7 & 6 & 5 & 4 & 3 & 2 & 1 & 2 & 3 & 4 & 5 & 6 & 7 & 8 & 9 & Descentralização \\
\hline Rodoanel & 9 & 8 & 7 & 6 & 5 & 4 & 3 & 2 & 1 & 2 & 3 & 4 & 5 & 6 & 7 & 8 & 9 & Descentralização \\
\hline
\end{tabular}

Agora os sub-critérios devem ser comparados sob o ponto de vista dos critérios relacionados:

a) Comparação paritária dos critérios em relação à área:

\begin{tabular}{|lllllllllllllllllll}
\hline Disponibilidade & 9 & 8 & 7 & 6 & 5 & 4 & 3 & 2 & 1 & 2 & 3 & 4 & 5 & 6 & 7 & 8 & 9 & Investimento
\end{tabular}

Legenda:

Investimento: custo da área para a instalação do entreposto e custo de construção de novas instalações.

Disponibilidade: existência de áreas (ou terrenos) disponíveis.

b) Comparação paritária dos critérios em relação ao custo de acesso: 


\begin{tabular}{|lcccccccccccccccccc|}
\hline \$ clientes & 9 & 8 & 7 & 6 & 5 & 4 & 3 & 2 & 1 & 2 & 3 & 4 & 5 & 6 & 7 & 8 & 9 & \$ MO \\
\hline \$ clientes & 9 & 8 & 7 & 6 & 5 & 4 & 3 & 2 & 1 & 2 & 3 & 4 & 5 & 6 & 7 & 8 & 9 & \$ abastecimento \\
\hline \$ clientes & 9 & 8 & 7 & 6 & 5 & 4 & 3 & 2 & 1 & 2 & 3 & 4 & 5 & 6 & 7 & 8 & 9 & \$ distribuição \\
\hline \$ MO & 9 & 8 & 7 & 6 & 5 & 4 & 3 & 2 & 1 & 2 & 3 & 4 & 5 & 6 & 7 & 8 & 9 & \$ abastecimento \\
\hline \$ MO & 9 & 8 & 7 & 6 & 5 & 4 & 3 & 2 & 1 & 2 & 3 & 4 & 5 & 6 & 7 & 8 & 9 & \$ distribuição \\
\hline \$ abastecimento & 9 & 8 & 7 & 6 & 5 & 4 & 3 & 2 & 1 & 2 & 3 & 4 & 5 & 6 & 7 & 8 & 9 & \$ distribuição \\
\hline
\end{tabular}

Legenda:

\$ clientes: custo de acesso para o cliente.

\$ MO: custo de acesso para aqueles que trabalham no Entreposto.

\$ abastecimento: custo de abastecimento de mercadorias.

\$ distribuição: custo de distribuição de mercadorias.

c) Comparação paritária dos critérios em relação à facilidade de acesso:

\begin{tabular}{|lcccccccccccccccccc|}
\hline Clientes & 9 & 8 & 7 & 6 & 5 & 4 & 3 & 2 & 1 & 2 & 3 & 4 & 5 & 6 & 7 & 8 & 9 & MO \\
\hline Clientes & 9 & 8 & 7 & 6 & 5 & 4 & 3 & 2 & 1 & 2 & 3 & 4 & 5 & 6 & 7 & 8 & 9 & Abastecimento \\
\hline Clientes & 9 & 8 & 7 & 6 & 5 & 4 & 3 & 2 & 1 & 2 & 3 & 4 & 5 & 6 & 7 & 8 & 9 & Distribuição \\
\hline MO & 9 & 8 & 7 & 6 & 5 & 4 & 3 & 2 & 1 & 2 & 3 & 4 & 5 & 6 & 7 & 8 & 9 & Abastecimento \\
\hline MO & 9 & 8 & 7 & 6 & 5 & 4 & 3 & 2 & 1 & 2 & 3 & 4 & 5 & 6 & 7 & 8 & 9 & Distribuição \\
\hline Abastecimento & 9 & 8 & 7 & 6 & 5 & 4 & 3 & 2 & 1 & 2 & 3 & 4 & 5 & 6 & 7 & 8 & 9 & Distribuição \\
\hline
\end{tabular}

Legenda:

Clientes: facilidade de acesso para o cliente.

MO: facilidade de acesso para aqueles que trabalham no Entreposto.

Abastecimento: facilidade de acesso no abastecimento das mercadorias.

Distribuição: facilidade de acesso na distribuição das mercadorias.

d) Comparação paritária dos critérios em relação ao mercado:

\begin{tabular}{|lllllllllllllllllll}
\hline Tamanho & 9 & 8 & 7 & 6 & 5 & 4 & 3 & 2 & 1 & 2 & 3 & 4 & 5 & 6 & 7 & 8 & 9 & Concorrência
\end{tabular}

Legenda:

Tamanho: incremento mercado consumidor (aumento da demanda).

Concorrência: presença e influência da concorrência.

e) Comparação paritária dos critérios em relação ao meio ambiente: 


\begin{tabular}{|lllllllllllllllllll|}
\hline Legislação & 9 & 8 & 7 & 6 & 5 & 4 & 3 & 2 & 1 & 2 & 3 & 4 & 5 & 6 & 7 & 8 & 9 & Preservação \\
\hline Legislação & 9 & 8 & 7 & 6 & 5 & 4 & 3 & 2 & 1 & 2 & 3 & 4 & 5 & 6 & 7 & 8 & 9 & Controle Polu \\
\hline Preservaçãa & 9 & 8 & 7 & 6 & 5 & 4 & 3 & 2 & 1 & 2 & 3 & 4 & 5 & 6 & 7 & 8 & 9 & Controle Polu \\
\hline
\end{tabular}

Legenda:

Legislação: legislação ambiental, respeito e adequação às leis vigentes.

Controle polu: melhora, estabilidade ou piora nos níveis de poluição ambiental, principalmente em relação à poluição veicular e qualidade do ar.

Preservação: preservação do meio ambiente no entorno, considerando possível degradação do local.

f) Comparação paritária dos critérios em relação à ocupação urbana:

\begin{tabular}{|lcccccccccccccccccc|}
\hline Uso do solo & 9 & 8 & 7 & 6 & 5 & 4 & 3 & 2 & 1 & 2 & 3 & 4 & 5 & 6 & 7 & 8 & 9 & Impactos SE \\
\hline Uso do solo & 9 & 8 & 7 & 6 & 5 & 4 & 3 & 2 & 1 & 2 & 3 & 4 & 5 & 6 & 7 & 8 & 9 & Opinião Popul \\
\hline Impactos SE & 9 & 8 & 7 & 6 & 5 & 4 & 3 & 2 & 1 & 2 & 3 & 4 & 5 & 6 & 7 & 8 & 9 & Opinião Popul \\
\hline
\end{tabular}

Legenda:

Uso do solo: existência de possíveis barreiras ou restrições físicas para a implantação do Entreposto.

Impactos SE: impactos sócio-econômicos positivos, considerando o desenvolvimento da região.

Opinião popul: opinião da população da região em relação às atividades do Entreposto, considerando as vantagens e desvantagens criadas por uma instalação deste porte.

g) Comparação paritária dos critérios em relação ao fator humano:

\begin{tabular}{|lllllllllllllllllll|}
\hline \$ MO & 9 & 8 & 7 & 6 & 5 & 4 & 3 & 2 & 1 & 2 & 3 & 4 & 5 & 6 & 7 & 8 & 9 & Disp MO \\
\hline \$ MO & 9 & 8 & 7 & 6 & 5 & 4 & 3 & 2 & 1 & 2 & 3 & 4 & 5 & 6 & 7 & 8 & 9 & Grau Sindical \\
\hline Disp MO & 9 & 8 & 7 & 6 & 5 & 4 & 3 & 2 & 1 & 2 & 3 & 4 & 5 & 6 & 7 & 8 & 9 & Grau Sindical \\
\hline
\end{tabular}

Legenda:

\$ MO: custo da mão-de-obra (diferenças salariais).

Disp MO: quantidade e qualidade da mão-de-obra disponível na região.

Grau Sindical: grau de sindicalização (organizações de funcionários). 
Para finalizar o questionário, devem-se comparar os critérios, dois a dois, em Relação ao Objetivo final:

\begin{tabular}{|lcccccccccccccccccc|}
\hline Area & 9 & 8 & 7 & 6 & 5 & 4 & 3 & 2 & 1 & 2 & 3 & 4 & 5 & 6 & 7 & 8 & 9 & \$ Acesso \\
\hline Area & 9 & 8 & 7 & 6 & 5 & 4 & 3 & 2 & 1 & 2 & 3 & 4 & 5 & 6 & 7 & 8 & 9 & Facilidade Acesso \\
\hline \hline Area & 9 & 8 & 7 & 6 & 5 & 4 & 3 & 2 & 1 & 2 & 3 & 4 & 5 & 6 & 7 & 8 & 9 & Mercado \\
\hline \hline Area & 9 & 8 & 7 & 6 & 5 & 4 & 3 & 2 & 1 & 2 & 3 & 4 & 5 & 6 & 7 & 8 & 9 & Meio Ambiente \\
\hline Area & 9 & 8 & 7 & 6 & 5 & 4 & 3 & 2 & 1 & 2 & 3 & 4 & 5 & 6 & 7 & 8 & 9 & Ocupação Urbana \\
\hline \hline Area & 9 & 8 & 7 & 6 & 5 & 4 & 3 & 2 & 1 & 2 & 3 & 4 & 5 & 6 & 7 & 8 & 9 & RH \\
\hline \$Acesso & 9 & 8 & 7 & 6 & 5 & 4 & 3 & 2 & 1 & 2 & 3 & 4 & 5 & 6 & 7 & 8 & 9 & Facilidade Acesso \\
\hline \$ Acesso & 9 & 8 & 7 & 6 & 5 & 4 & 3 & 2 & 1 & 2 & 3 & 4 & 5 & 6 & 7 & 8 & 9 & Mercado \\
\hline \$ Acesso & 9 & 8 & 7 & 6 & 5 & 4 & 3 & 2 & 1 & 2 & 3 & 4 & 5 & 6 & 7 & 8 & 9 & Meio Ambiente \\
\hline \$Acesso & 9 & 8 & 7 & 6 & 5 & 4 & 3 & 2 & 1 & 2 & 3 & 4 & 5 & 6 & 7 & 8 & 9 & Ocupação Urbana \\
\hline \$ Acesso & 9 & 8 & 7 & 6 & 5 & 4 & 3 & 2 & 1 & 2 & 3 & 4 & 5 & 6 & 7 & 8 & 9 & RH \\
\hline Facilidade Acesso & 9 & 8 & 7 & 6 & 5 & 4 & 3 & 2 & 1 & 2 & 3 & 4 & 5 & 6 & 7 & 8 & 9 & Mercado \\
\hline Facilidade Acesso & 9 & 8 & 7 & 6 & 5 & 4 & 3 & 2 & 1 & 2 & 3 & 4 & 5 & 6 & 7 & 8 & 9 & Meio Ambiente \\
\hline Facilidade Acesso & 9 & 8 & 7 & 6 & 5 & 4 & 3 & 2 & 1 & 2 & 3 & 4 & 5 & 6 & 7 & 8 & 9 & Ocupação Urbana \\
\hline Facilidade Acesso & 9 & 8 & 7 & 6 & 5 & 4 & 3 & 2 & 1 & 2 & 3 & 4 & 5 & 6 & 7 & 8 & 9 & RH \\
\hline Mercado & 9 & 8 & 7 & 6 & 5 & 4 & 3 & 2 & 1 & 2 & 3 & 4 & 5 & 6 & 7 & 8 & 9 & Meio Ambiente \\
\hline Mercado & 9 & 8 & 7 & 6 & 5 & 4 & 3 & 2 & 1 & 2 & 3 & 4 & 5 & 6 & 7 & 8 & 9 & Ocupação Urbana \\
\hline Mercado & 9 & 8 & 7 & 6 & 5 & 4 & 3 & 2 & 1 & 2 & 3 & 4 & 5 & 6 & 7 & 8 & 9 & RH \\
\hline Meio Ambiente & 9 & 8 & 7 & 6 & 5 & 4 & 3 & 2 & 1 & 2 & 3 & 4 & 5 & 6 & 7 & 8 & 9 & Ocupação Urbana \\
\hline Meio Ambiente & 9 & 8 & 7 & 6 & 5 & 4 & 3 & 2 & 1 & 2 & 3 & 4 & 5 & 6 & 7 & 8 & 9 & RH \\
\hline Ocupação Urbana & 9 & 8 & 7 & 6 & 5 & 4 & 3 & 2 & 1 & 2 & 3 & 4 & 5 & 6 & 7 & 8 & 9 & RH \\
\hline
\end{tabular}

Legenda:

Área: área para a implantação da instalação.

\$ Acesso: custo para acessar o local.

Facilidade Acesso: acessibilidade do local.

Mercado: Mercado consumidor (demanda e atendimento).

Meio ambiente: meio ambiente (leis e preservação).

Ocupação urbana: possibilidade de instalação do Entreposto e impactos gerados pela mesma.

RH: questões relacionadas com o fator humano. 


\section{8 . REFERÊNCIAS BIBLIOGRÁFICAS}

ADLER, H. A. Avaliação Econômica dos Projetos de Transporte. 1978.

ALDIN, N.; STAHRE, F. Electronic commerce, marketing channels and logistic platforms: a wholesaler perspective. European journal of operational research, v.144, pg. 270-279, 2003.

ANDRADE, L. E. C. Um Estudo sobre Terminais Intermodais para Granéis Sólidos. 2003. 246p. Dissertação (Mestrado) - Escola Politécnica, Universidade de São Paulo. São Paulo, 2003.

ARMACOST, R. L.; HOSSEINI, J. C.; JALVAGI, R. Using the Analytic Hierarchy Process for small business decision making. Akron Business and Economic Review, v. 21, n. 1, 1990.

BALLOU, R. H. Gerenciamento da cadeia de suprimentos: planejamento, organização e logística empresarial. - 4 ed. - Bookman, 2001.

BELCORSO, F. Modelo para localização geográfica de indústrias baseado em regras difusas. 2001. 174p. Dissertação (Mestrado) - Escola Politécnica, Universidade de São Paulo. São Paulo, 2001.

BELTON, V.; STEWART, T. J. Multiple Criteria Decision Analysis: An integrated approach. Academic Publishers, 2002.

BHATNAGAR, R.; JAYARAM, J.; PHUA, Y. C. Relative importance of plant location factors: a cross national comparison between Singapore and Malaysia. Journal of Business Logistics, v. 24, n. 1, 2003. 
BOGARDI, J. J., NACHTNEBEL, H. (Ed.) Multicriteria decision analysis in water resources management. UNESCO, Paris, 1994.

BOWERSOX, D. J.; CLOSS, D. J. Logística Empresarial: o processo de integração da cadeia de suprimento. Editora Atlas, São Paulo. 2001.

BOZÓKI, S.; LEWIS, R. H. Solving the least squares method problem in the AHP for $3 \times 3$ and $4 \times 4$ matrices. In: International Symposium on the Analytic Hierarchy Process, Bali. 2003.

BRIMBERG, J.; REVELLE, C. A bi-objective problem: cost vs. demand served. Location Science, v. 6, pg.121-135, 1998.

BRONDINO, N. C. M. Estudo da influência da acessibilidade no valor de lotes urbanos através do uso de redes neurais. 1999. 158p. Tese (Doutorado) - Escola de Engenharia de São Carlos, Universidade de São Paulo. São Carlos, 1999.

CAIXETA-FILHO, J. V.; MARTINS, R. S. Gestão e logística no transporte de cargas. Editora Atlas, São Paulo. 2001.

CEAGESP. São Paulo. Apresenta informações sobre a Companhia de Armazéns Gerais do Estado de São Paulo. Disponível em: <http://www.ceagesp.com.br>. Acesso entre: 10 de novembro de 2004 e 14 de março de 2005.

CHAN, Y. Location Theory and decision analysis. South-western college publishing, 2001.

$\mathrm{CHO}, \mathrm{K} . ; \mathrm{CHO}, \mathrm{Y}$. A loss function approach to group preference aggregation in the AHP. In: International Symposium on the Analytic Hierarchy Process, Bali. 2003. 
CHUANG, P. T. Combining the Analytic Hierarchy Process and Quality Function Deployment for location decision from a requirement perspective. The International Journal of Advanced Manufacturing Tecnology, v. 18, pg.842-849, 2001.

CHURCHMAN, C. W. Introdução à teoria dos sistemas. Vozes, Petrópolis, 1971.

CUNHA, R. F. F. Pólo Gerador de Tráfego - Análise sistemática de avaliação. 2001. Monografia do curso de especialização (Mestrado executivo em transporte) COPPE / Universidade Federal do Rio de Janeiro. Rio de Janeiro, 2001.

DASKIN, M. S. Network and discrete location - models, algorithms and aplications. John Wiley \& Sons, New York. 1995.

DE BOER, L.; LABRO, E.; MORLACCHI, P. A review of methods supporting supplier selection. European Journal of Purchaising \& Supply Management, n.7, p.75-89, 2001.

DUARTE, P. C. Modelo para o desenvolvimento de plataforma logística em um terminal - Estudo de caso na Estação Aduaneira do Interior - Itajaí/SC. 1999. Dissertação (Mestrado) -Universidade Federal de Santa Catarina. Florianópolis, 1999.

DUCKSTEIN, L.; PARENT, E. Engineering risk in natural resources management : with special references to hydrosystems under changes of physical or climatic environment. Kluwer Academic. 1994.

ENSSLIN, L. Apoio à decisão - Metodologia para a estruturação de problemas e avaliação multicritério de alternativas. Insular, Florianópolis. 2001.

EXPERT CHOICE Inc. Software Expert Choice Educational Version 11. Disponível em: < http://www.expertchoice.com/software/ > . Acesso em: 20 de março de 2005. 
FUNDAÇÃO VANZOLINI. São Paulo. Apresenta recursos e atividades desenvolvidas. Disponível em $<$ http://www.vanzolini.org.br $>$. Acesso em: Acesso em 08 de abril de 2005.

GAlvão JR., F. A.; GUALDA, N. D. F.; CUnHA, C. B. An Application of the Analytic Hierarchy Process (AHP) for Locating a Distribution Center. In: International Symposium on the Analytic Hierarchy Process, Bali. 2003.

GAVIRA, M. O. Simulação computacional como uma ferramenta de aquisição de conhecimento. 2003. 162p. Dissertação (Mestrado) - Escola de Engenharia de São Carlos, Universidade de São Paulo. São Carlos, 2003.

GOLDENBERG, M. A arte de pesquisar - como fazer pesquisa qualitativa em ciências sociais. Editora Record, Rio de Janeiro. 1997.

GOLDSCHMIDT, A. Análise SWOT na captação de recursos - avaliação de oportunidades, ameaças, pontos fortes e pontos fracos. Revista IntegrAção, São Paulo, ano 6, n.27, junho de 2003. Disponível em: < http://integracao.fgvsp.br/ano6/06/index.htm>. Acesso em: 30 de março de 2005.

GOMES, L.F.A.M.; GOMES, C.F.S.; ALMEIDA, A.T. Tomada de Decisão Gerencial - Enfoque Multicritério. Editora Atlas, São Paulo. 2002.

GONÇALVES, P. G. Contribuição ao estudo de conflitos na implantação do Ferroanel na Região Metropolitana de São Paulo. 2005. 165p. Dissertação (Mestrado) - Escola Politécnica, Universidade de São Paulo. São Paulo, 2005.

GUALDA, N. D. F. Estudo da USP confirma: ETSP está muito bem localizado. Entrevista a Paulo Fernando Costa. Jornal Entreposto, São Paulo, ano 5, n. 53, pg. 4, outubro 2004. 
GUALDA, N. D. F. Terminais de Transporte: contribuição ao planejamento e dimensionamento operacional. 1995. 277p + anexos. Tese (Livre-docência) Escola Politécnica, Universidade de São Paulo. São Paulo, 1995.

HARTMAN, D. H.; GOLTZ, M. N. (Ed.) Application of the Analytic Hierarchy Process to select characterization and risk-based decision making and management methods for hazardous waste sites. Environ Eng Policy, v. 3, pg. 1-7, 2002.

HAYASHI, Y.; ROY, J. Transport, land-use and the environment. Kluwer Academic Publishers, 1996.

HOLLAENDER, M. P. Localização de centros de distribuição. 1978. 149p. Dissertação (Mestrado) - Escola Politécnica, Universidade de São Paulo. São Paulo, 1978.

IAÑEZ, M. M. Uma contribuição ao processo decisório de terceirização de atividades logísticas. 2002. 230p. Dissertação (Mestrado) - Escola Politécnica, Universidade de São Paulo. São Paulo, 2002.

IBGE. Apresenta dados e indicadores de relacionados à construção civil (SINAPI). Disponível em: < http://www.ibge.gov.br >. Acesso em 08 de abril de 2005.

JORNAL ENTREPOSTO. São Paulo. Apresenta artigos e pesquisas sobre a CEAGESP. Disponível em: < http://www.jornalentreposto.com.br >. Acesso em: 14 de março de 2005.

KABIR, A. B. M. Z.; SHIHAN, S. M. A. Selection of renewable energy sources using Analytic Hierarchy Process. In: International Symposium on the Analytic Hierarchy Process, Bali. 2003.

KORPELLA, J; TUOMINEN, M. A decision aid in warehouse site selection. International Journal of production economics, v.45, pg. 169-180, 1996. 
LIEBOWITZ, J. (ed.). Expert systems for business and management. PrenticeHall, 1990.

LISBOA, M. V. Contribuição da Tomada de Decisão na Classificação e Seleção de Alternativas de Traçado para Rodovias em Trechos Urbanizados. 2002. 206p. Dissertação (Mestrado) - Escola Politécnica, Universidade de São Paulo. São Paulo, 2002.

LOPEZ, R. A.; HENDERSON, N. R. The determinants of location choices for food processing plants. Agribusiness, v. 5, n. 6, pg. 619-632, 1989.

LOVE, R. F. Facilities Location - models and methods. North-Holland, 1988.

MAIA, N B.; MARTOS, H. L. (Cood.) Indicadores Ambientais. Sorocaba, 1997.

MALCZEWSKI, J. GIS and Multicriteria Decision Analysis. John Wiley \& Sons, New York. 1999.

MIN, H. Location planning of airport facilities using the Analytic Hierarchy Process. Logistics and Transportation Review, v.30, n. 1, pg. 79-94, 1994.

MIN, H. Location Analysis of international consolidation terminals using the Analytic Hierarchy Process. Journal of Business Logistics, v.15, n. 2, pg. 25-44, 1994.

MINTZBERG, H.; QUINN, J. B. The strategy Process: concepts, contexts and cases. Prentice-Hall, 1996.

MORITA, H. Revisão do Método da Análise Hierárquica - MAH (AHP Analytic Hierarchy Process). 1998. 129p. Dissertação (Mestrado) - Escola Politécnica, Universidade de São Paulo. São Paulo, 1998. 
MORITA, H. Contribuição à análise do processo de decisão em problemas nãoestruturados. 2003. 154p. Tese (Doutorado) - Escola Politécnica, Universidade de São Paulo. São Paulo, 2003.

MURAKAMI, M. Decisão estratégica em TI. 2003. 167p. Dissertação (Mestrado) Faculdade de Economia, Administração e Contabilidade, Universidade de São Paulo. São Paulo, 2003.

NOGUEIRA, C. W. A Metodologia multicritério de apóio à decisão Analytic Hierarchy Process (AHP): um estudo de caso na priorização de traçado de pavimentação de uma estrada. 2002. 194p. Dissertação (Mestrado) - Universidade Federal de Santa Catarina. Florianópolis, 2002.

NOVAES, A. G. Logística e Gerenciamento da cadeia de distribuição: Estratégia, Operação e Avaliação. Editora Campus, Rio de Janeiro. 2001.

OZQEMIR, M. S. Beyond Inconsistency in the AHP/ANP. In: International Symposium on the Analytic Hierarchy Process, Bali. 2003.

PAIVA JUNIOR, H. Avaliação de desempenho de ferrovias utilizando a abordagem integrada DEA/AHP. 2000. 178p. Dissertação (Mestrado) Universidade Estadual de Campinas. Campinas, 2000.

PEGDEN, C. D. et al. Introduction to simulation using SIMAN. McGrall-Hill, New York. 1995.

PORTUGAL, L. S; GOLDNER, L G. Estudo de Pólos Geradores de Tráfego e seus impactos nos sistemas viários e de transportes. Editora Edgard Blücher LTDA, São Paulo, 2003. 
RANDHAWA, S. U.; WEST, T. M. An Integrated Approach to Facility Location Problems. Computers and Engeneering, v.29, n. 1, pg. 261-265, 1995.

ROSA, D. P. Plataforma Logístico-Cooperativa: Integração Horizontal das Cadeias de Abastecimento. In: Anais ANPET, 18, Florianópolis, 2004.

SAATY, T. L. Método de Análise Hierárquica. Editora Makron, São Paulo. 1991.

SCHMENNER, R. W. Making business location decisions. Prentice-Hall, 1982.

SECRETARIA DE PLANEJAMENTO E DESENVOLVIMENTO DE GOIÁS. Apresenta estudo sobre a Plataforma Mutimodal de Goiás. Disponível em: $<$ http://www.plataformalogistica.go.gov.br/experiencias/1.htm>. Acesso em: 14 de dezembro de 2004.

SOARES, M. G. Classificação de operadores terceirizados, visando o estabelecimento de parcerias de negócio no contexto logístico empresarial. 2002. 165p. Dissertação (Mestrado) - Escola Politécnica, Universidade de São Paulo. São Paulo, 2002.

TONDO, C. M. Um modelo matemático para a localização estratégica de terminais de contêineres no interior: aplicação ao Estado de São Paulo. 1992. 115p. Tese (Doutorado) - Escola Politécnica, Universidade de São Paulo. São Paulo, 1992.

VALLIM FILHO, A. R. A. Localização de centros de distribuição e carga contribuições à modelagem matemática. 2004. 286p (edição revisada). Tese (Doutorado) - Escola Politécnica, Universidade de São Paulo. São Paulo, 2004.

VINCKE, P. Multicriteria decision-aid. John Wiley \& Sons, 1992. 
WANKE, P. Aspectos fundamentais do problema de localização de instalações em redes logísticas. Artigos CEL (Centro de Estudos em Logística - COPPEAD/UFRJ), 2003. Disponível em: < http://www.cel.coppead.ufrj.br >. Acesso em: 22/03/05.

WANKE, P. Posicionamento logístico e a definição da política de atendimento aos clientes. Artigos CEL (Centro de Estudos em Logística - COPPEAD/UFRJ), 2000. Disponível em: < http://www.cel.coppead.ufrj.br > . Acesso em: 22/03/05.

WIIG, K. M. Knowledge Management Methods: pratical approaches to managing knowledge. Schema Press, Arlington, Tex. 1995.

YANG, J.; LEE, H. A AHP decision model for facility location selection. Facilities, v. 15, iss. 9/10, pg.241, 1997.

YOSHIZAKI, H. T. Y. Projeto de redes de distribuição física considerando a influência do imposto de circulação de mercadorias e serviços. 2002. 144p . Tese (Livre-Docência) - Escola Politécnica, Universidade de São Paulo. São Paulo, 2002.

ZAMPROGNO, D. P. Sistema de suporte à decisão espacial para escolha de locais e dimensionamento de reservatórios. 2004. 182p (edição revisada). Tese (Doutorado) - Escola Politécnica, Universidade de São Paulo. São Paulo, 2004. 